RENAN BEZERRA LIRA

\title{
Microambiente imune no carcinoma papilífero de tireoide e sua relação com fatores prognósticos clínico-patológicos e sobrevida
}

Tese apresentada à Faculdade de Medicina da Universidade de São Paulo para obtenção do título de Doutor em Ciências

Programa de Oncologia

Orientador: Prof. Dr. Luiz Paulo Kowalski

São Paulo

2016 
Dados Internacionais de Catalogação na Publicação (CIP)

Preparada pela Biblioteca da

Faculdade de Medicina da Universidade de São Paulo

Creprodução autorizada pelo autor

\section{Lira, Renan Bezerra}

Microambiente imune no carcinoma papilífero de tireoide e sua relação com fatores prognósticos clínico-patológicos e sobrevida / Renan Bezerra Lira. -- São Paulo, 2016.

Tese(doutorado)--Faculdade de Medicina da Universidade de São Paulo.

Programa de Oncologia.

Orientador: Luiz Paulo Kowalski.

Descritores: 1.Neoplasias da glândula tireoide 2.Microambiente tumoral 3.Linfócitos $T$ 4.Macrófagos 5.Ativação de macrófagos 6.Linfócitos T CD8-positivos

USP/FM/DBD-322/16 


\section{Dedicatória}

Dedico este trabalho a minha família, especialmente, a minha esposa Jordana, que tem me apoiado de forma incondicional e altruísta neste e em todos os outros aspectos de minha vida, a meus pais, Erivaldo e Roneide, que propiciaram e guiaram-me para uma sólida educação e formação de caráter, sempre com muita sabedoria e carinho e também a meus irmãos que, apesar da distância, sempre mantiveram nossa unidade familiar íntegra. Sem estas pessoas, eu não seria quem sou e, certamente, não teria conseguido reunir condições de produzir este estudo. 


\section{Agradecimentos}

A todos aqueles que contribuíram para a realização deste estudo e, em especial,

Ao Prof. Dr. Luiz Paulo Kowalski, pela orientação, dedicação, disposição e oportunidade, além de todo estímulo e inspiração diária.

Ao Dr. Clóvis Antônio Lopes Pinto, pelas orientações específicas e toda ajuda e ensinamento na metodologia prática e teórica do projeto.

Aos patologistas Dr. Marcelo Balancin e Dr. Felipe D'Almeida, pela ajuda na confecção e leitura das lâminas.

À Dra. Ana Lúcia Francisco, pela disposição e por todo o auxílio imprescindível em todas as etapas da realização deste estudo.

A todos os colaboradores do Departamento de Anatomia Patológica do A. C. Camargo Cancer Center, por tantas providências tomadas.

Aos colegas do Departamento de Cirurgia de Cabeça e Pescoço e Otorrinolaringologia do A. C. Camargo Cancer Center, pelo convívio inspirador e empenho nas atividades de assistência e pesquisa, que possibilitaram o estudo.

Aos Drs. Sérgio Samir Arap, Gilberto Castro Júnior e Victor Piana de Andrade, pelas sugestões e orientações dispensadas em meu exame de qualificação.

Ao Prof. Dr. Roger Chammas, pelos ensinamentos em biologia e microambiente dos tumores.

À FAPESP pela confiança e auxílio financeiro que viabilizaram a realização do estudo (Processo 2013/22094-7). 
Esta tese está de acordo com as seguintes normas, em vigor no momento desta publicação:

Referências: adaptado de International Committee of Medical Journals Editors (Vancouver).

Universidade de São Paulo. Faculdade de Medicina. Divisão de Biblioteca e Documentação. Guia de apresentação de dissertações, teses e monografias. Elaborado por Anneliese Carneiro da Cunha, Maria Julia de A. L. Freddi, Maria F. Crestana, Marinalva de Souza Aragão, Suely Campos Cardoso, Valéria Vilhena. 3a ed. São Paulo: Divisão de Biblioteca e Documentação; 2011.

Abreviaturas dos títulos dos periódicos de acordo com List of Journals Indexed in Index Medicus. 


\section{Sumário}

Lista de abreviaturas, siglas e símbolos

Lista de tabelas

Lista de figuras

Resumo

Abstract

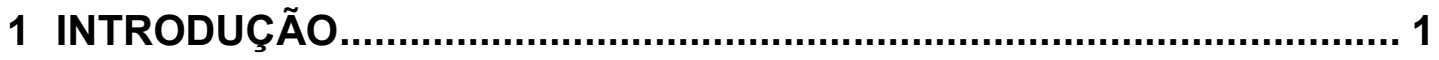

1.1 Câncer da glândula tireoide .............................................. 2

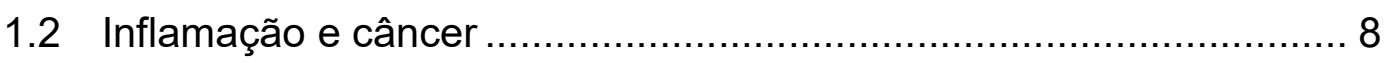

1.2.1 Tireoidite e câncer de tireoide ....................................... 9

1.3 Resposta imune e microambiente tumoral ............................... 10

1.3.1 O papel dos macrófagos ........................................... 11

1.3.2 O papel dos linfócitos................................................ 15

1.3.3 O papel de outras células inflamatórias ........................... 16

1.3.4 Microambiente imune do câncer de tireoide ..................... 17

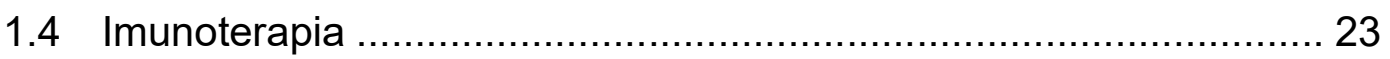

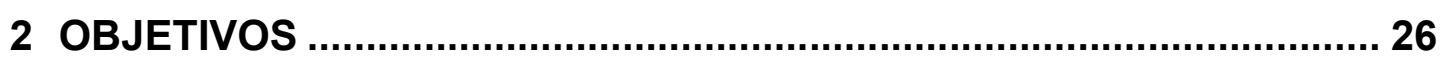



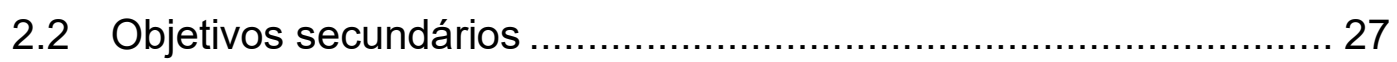

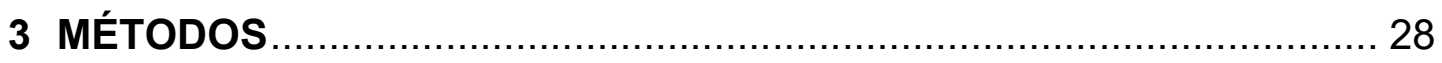

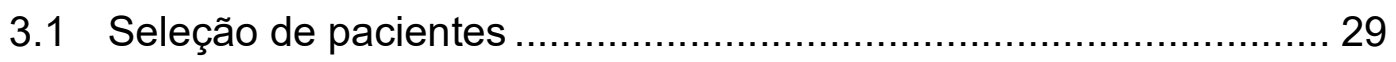

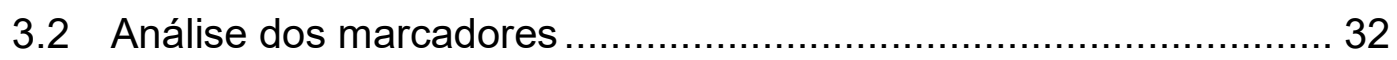

3.3 Análise estatística........................................................... 37

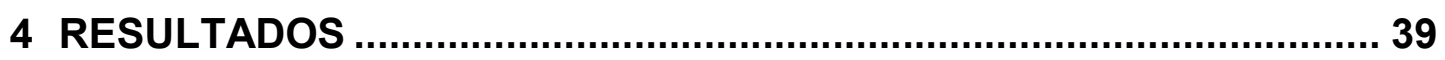

4.1 Resultados epidemiológicos e clínicos .................................... 40

4.2 Tratamento realizado.......................................................... 41

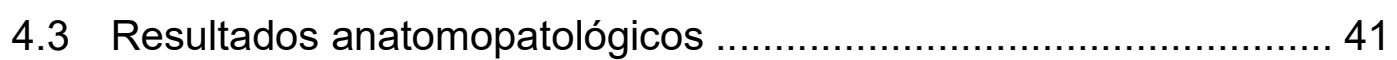

4.4 Comparação de amostra do estudo com o total de casos............... 42



4.6 Marcadores imuno-histoquímicos..................................... 49 
4.6.1 Caracterização do microambiente imune (leitura de

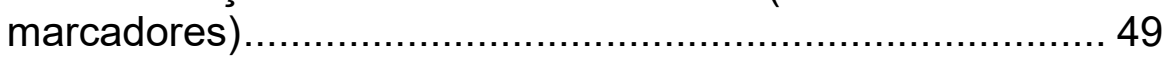

4.6.2 Relação entre marcadores e fatores clínico-patológicos ...... 55

4.6.2.1 Relação entre marcadores e faixa etária ............... 56

4.6.2.2 Relação entre marcadores e extensão extratireoidiana do carcinoma papilífero ................ 58

4.6.2.3 Relação entre marcadores e metástase linfonodal....................................................... 60

4.6.2.4 Outras análises de possível associação entre microambiente imune e fatores prognósticos......... 62

4.6.3 Relação entre marcadores e sobrevida ............................... 66

5 DISCUSSÃO

6 CONCLUSÕES

7 ANEXOS

7.1 Anexo 1 - Aprovação do Comitê de Ética em Pesquisa ................... 85

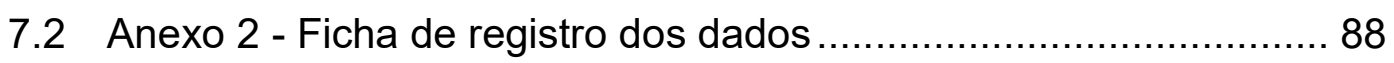

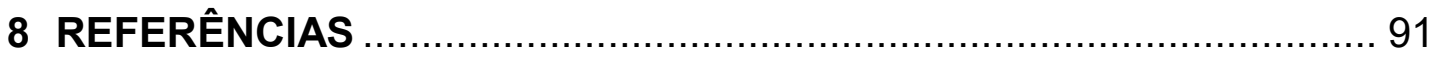




\section{Listas}

\section{ABREVIATURAS}

Dr. doutor

et al. e outros

Fig. figura

Prof. professor

Cont. continuação

\section{SÍMBOLOS}

$\begin{array}{ll}\mathrm{cm} & \text { centímetro } \\ \mathrm{mm} & \text { milímetro } \\ \mathrm{mCi} & \text { miliCurie } \\ { }^{\circ} \mathrm{C} & \text { graus Celsius } \\ \mathrm{X} & \text { versus } \\ \% & \text { por cento } \\ > & \text { maior que } \\ < & \text { menor que } \\ = & \text { igual a } \\ \leq & \text { menor ou igual a } \\ \geq & \text { maior ou igual a } \\ \mathrm{N} 0 & \text { sem metástase linfonodal } \\ \mathrm{N}+ & \text { com metástase linfonodal }\end{array}$




\section{SIGLAS}

\begin{tabular}{|c|c|}
\hline ACCCC & A.C.Camargo Cancer Center \\
\hline AJCC & American Joint Committee on Cancer \\
\hline ATA & American Thyroid Association \\
\hline ATP & adenosine triphosphate \\
\hline $\mathrm{BCG}$ & bacilo de Calmette-Guérin \\
\hline CCL & chemokine ligands \\
\hline CCR & chemokine receptor \\
\hline CD & cluster of differentiation \\
\hline CSF & colony-stimulating factors \\
\hline CTL & cytotoxic lymphocyte \\
\hline $\mathrm{DAB}$ & diaminobenzidina \\
\hline $\mathrm{DC}$ & dendritic cell \\
\hline DNA & deoxyribonucleic acid \\
\hline EET & extensão extra-tireoideana \\
\hline EGF & epitelial growth factor (fator de crescimento epitelial) \\
\hline EORTC & European Organization for Research and Treatment of Cancer \\
\hline EUA & Estados Unidos da América \\
\hline FOX & forkhead box \\
\hline HIF & hypoxia-inducible factor \\
\hline HLA-DR & human leukocyte antigen - antigen $D$ related \\
\hline IC & intervalo de confiança \\
\hline $\mathrm{IHQ}$ & imunohistoquímica \\
\hline IL & interleucina \\
\hline INCA & Instituto Nacional do Câncer \\
\hline LATS & Latin American Thyroid Society \\
\hline LPS & lipopolissacarídeo \\
\hline MAPK & mitogen-activated protein kinases \\
\hline $\mathrm{MHC}$ & major histocompatibility complex \\
\hline MMP & metaloproteinases \\
\hline MMR & macrophage manose receptor \\
\hline NK & natural killer \\
\hline
\end{tabular}




$\begin{array}{ll}\text { OMS } & \text { Organização Mundial de Saúde } \\ \text { PAAF } & \text { punção aspirativa com agulha fina } \\ \text { PBS } & \text { phosphate buffered saline } \\ \text { PD } & \text { programmed death } \\ \text { PDGF } & \text { platelet-derived growth factor } \\ \text { PD-L } & \text { programmed death-ligand } \\ \text { PTC } & \text { papillary thyroid carcinoma } \\ \text { RET } & \text { rearranged during transfection } \\ \text { RNA } & \text { ribonucleic acid } \\ \text { RR } & \text { risco relativo } \\ \text { SEER } & \text { Surveillance, Epidemiology, and End Results } \\ \text { TAM } & \text { tumor-associated macrophages } \\ \text { TAN } & \text { tumor-associated neutrophil } \\ \text { TGF } & \text { transforming growth factor } \\ \text { Th } & \text { Thelper lymphocyte } \\ \text { TIL } & \text { tumor-associated lymphocyte } \\ \text { TLC } & \text { tireoidite linfocítica crônica } \\ \text { TMA } & \text { tissue microarray } \\ \text { TNF } & \text { tumor necrosis factor / fator de necrose tumoral } \\ \text { Treg } & \text { T regulatory lymphocyte } \\ \text { UICC } & \text { Union for International Cancer Control } \\ \text { US } & \text { ultrassonografia } \\ \text { USP } & \text { Universidade de São Paulo } \\ \text { VEGF } & \text { vascular endotelial growth factor } \\ & \end{array}$




\section{FIGURAS}

Figura 1 Evolução no número de cirurgia por ano no Departamento de Cirurgia de Cabeça e Pescoço e Otorrinolaringologia do A. C. Camargo Cancer Center. Comparativo entre os anos 1990, 2000 e 2010 .....

Figura 2 Diagrama consort de fluxo de seleção de pacientes

Figura 3 (T) Micrografia exibe positividade imuno-histoquímica em linfócitos $\mathrm{T}$ em meio ao tecido neoplásico, demarcados pela coloração marrom (pelo revelador diaminobenzidina) (CD8, x200); (NT) Positividade em raros linfócitos em área não neoplásica (CD8, x200)

Figura 4 (T) Micrografia exibe positividade imuno-histoquímica em linfócitos $\mathrm{T}$ em meio ao tecido neoplásico, demarcados pela coloração marrom (pelo revelador diaminobenzidina) (CD4, x200); (NT) Positividade em raros linfócitos em área não neoplásica (CD4, x200).

Figura 5 (T) Micrografia exibe positividade imuno-histoquímica em linfócitos $\mathrm{T}$ em meio ao tecido neoplásico, demarcados pela coloração marrom (pelo revelador diaminobenzidina) (FOXP3, x200); (NT) Positividade em raros linfócitos em área não neoplásica (FOXP3, x200).

Figura 6 (T) Micrografia exibe positividade imuno-histoquímica em linfócitos $\mathrm{T}$ em meio ao tecido neoplásico, demarcados pela coloração marrom (pelo revelador diaminobenzidina) (CD68, x200); (NT) Positividade em raros linfócitos em área não neoplásica (CD68, x200)

Figura 7 (T) Micrografia exibe positividade imuno-histoquímica em linfócitos $\mathrm{T}$ em meio ao tecido neoplásico, demarcados pela coloração marrom (pelo revelador diaminobenzidina) (CD163, x200); (NT) Positividade em raros linfócitos em área não neoplásica (CD163, x200)

Figura 8: $\quad$ Sobrevida livre de recorrência dos 151 casos de carcinoma papilífero estudados

Figura 9 Sobrevida global dos 151 casos de carcinoma papilífero estudados.

Figura 10 Curvas de sobrevida, comparando tumores com e sem extensão extratireoidiana.

Figura 11 Curvas de sobrevida, comparando tumores com e sem metástase linfonodal 
Figura 12 Curvas de sobrevida, comparando tumores com extensão extratireoideana ou metástase linfonodal com tumores sem extensão extratireoidiana e sem metástase linfonodal.

Figura 13 Distribuição das leituras de densidade de células marcadas por anti-CD68 (Boxplot)

Figura 14 Distribuição das leituras de densidade de células marcadas por anti-CD4 (Boxplot)

Figura 15 Distribuição das leituras de densidade de células marcadas por anti-CD8 (Boxplot)

Figura 16 Distribuição das leituras de densidade de células marcadas por anti-CD163 (Boxplot).

Figura 17 Distribuição das leituras de densidade de células marcadas por anti-Foxp3 (Boxplot)

Figura 18 Distribuição das leituras de densidade de células marcadas por anti-Ki-67 (Boxplot)

Figura 19. Distribuição das leituras de densidade de células marcadas por anti-HLA-DR (Boxplot)...

Figura 20 Curvas de sobrevida livre de doença, comparando casos com densidade de células CD8+ em área não tumoral maior que 4 com casos com densidade menor ou igual a 4

Figura 21 Esquema do microambiente imune do carcinoma papilífero de tireoide com papel esperado das células. Setas verdes indicam efeito pró-tumoral e setas vermelhas, efeito antitumoral

Figura 22 Esquema do microambiente imune do carcinoma papilífero de tireoide com papel das células encontrado no estudo. Células representadas em cinza não foram estudadas. Setas verdes com interrogação indicam efeito pró-tumoral não conclusivo, setas vermelhas efeito antitumoral e setas cinza indicam que nenhum efeito foi encontrado 


\section{TABELAS}

Tabela 1 Marcadores utilizados neste estudo e sua função (provável marcação).

Tabela 2 Distribuição da casuística integral e casos selecionados para o estudo, de acordo com variáveis demográficas, clínicas, resultado da PAAF e terapêuticas

Tabela 3 Distribuição da casuística integral e casos selecionados para o estudo, de acordo com variáveis anatomopatológicas.....

Tabela 4 Número de células marcadas por campos microscópicos 50

Tabela 5 Coeficiente de correlação de Spearman entre marcadores .55

Tabela 6 Distribuição da densidade de células marcadas por faixa etária (ponto de corte 45 anos).

Tabela 7 Distribuição da densidade de células marcadas por faixa etária (ponto de corte 55 anos)

Tabela 8 Relação entre densidade de células marcadas e presença de extensão extratireoidiana.

Tabela 9 Relação entre densidade de células marcadas e presença de metástase linfonodal

Tabela 10 Relação entre média de densidade de marcação e presença de metástase linfonodal e extensão extratireoidiana

Tabela 11 Relação de metástase linfonodal com perfil imune, por diferentes agrupamentos, levando em consideração a densidade de células CD8+ e CD68+ nos tumores

Tabela 12 Relação de extensão extratireoidiana com perfil imune, por diferentes agrupamentos, levando em consideração a densidade das células CD8+ e CD68+ nos tumores.

Tabela 13 Relação de sobrevida livre de recorrência com perfil imune, por diferentes agrupamentos, levando em consideração densidade das células CD8+ e CD68+ nos tumores.

Tabela 14 Probabilidade de sobrevida livre de recorrência (nove recidivas)

Tabela 15 Risco Relativo $(\mathrm{RR})$ para ocorrência de recidivas e respectivo intervalo de confiança de $95 \%$ (95\% IC) estimados pelo modelo de regressão de Cox univariado para o marcador CD8nt 


\section{Resumo}

Lira RB. Microambiente imune no carcinoma papilifero de tireoide e sua relação com fatores prognósticos clínico-patológicos e sobrevida [tese]. São Paulo: Faculdade de Medicina, Universidade de São Paulo; 2016.

INTRODUÇÃO: A incidência de câncer da glândula tireoide é a que mais vem crescendo nas últimas décadas. Dentro desse grupo de diferentes neoplasias, o carcinoma papilífero, um dos carcinomas bem diferenciados, representa a maioria e tem prognóstico favorável, com sobrevida acima dos $90 \%$ em 5 anos. Embora sejam utilizadas diversas classificações de risco baseadas em diferentes fatores prognósticos, ainda não se consegue predizer quais pacientes terão maior chance de recorrência, metástases linfonodais e desfecho desfavorável, que se beneficiariam de um tratamento mais agressivo. Já foi demonstrado em diversos tipos de neoplasias que diferenças no perfil do infiltrado imune tumoral têm relação com prognóstico e resposta ao tratamento. Neste estudo caracterizou-se o microambiente imune do carcinoma papilifero através de marcadores imuno-histoquímicos de células inflamatórias e relacionou-se este perfil de infiltração com fatores prognósticos clínico-patológicos e com sobrevida livre de recorrência. MÉTODOS: Foram incluídos 151 casos selecionados com base em um banco de dados que incluiu todos os pacientes submetidos a tratamento cirúrgico para câncer de tireoide no A.C.Camargo Cancer Center entre 2008 e 2010. Casos com tireoidite significante foram excluídos. Estes tumores selecionados foram então submetidos a reação imuno-histoquímica com marcadores de células inflamatórias e foram analisados por dois patologistas experientes. As características clínicas e patológicas foram avaliadas, assim como as recorrências e sobrevida, relacionando-as com as leituras de células marcadas. As análises de sobrevida global e livre de doença foram realizadas pelo método de Kaplan-Meier, com comparação de curvas de sobrevida pelo teste de Logrank. RESULTADOS: Cento e cinquenta e um pacientes foram incluídos, sendo $130(86,1 \%)$ mulheres e $21(13.9 \%)$ homens. Multifocalidade foi encontrada em 41 (27.2\%), extensão extratireoidiana em 43 (28.5\%) e metástase linfonodal em 36 (23.8\%) casos. Apenas dois pacientes apresentaram metástase a distância. $\mathrm{O}$ tempo de seguimento médio foi 65,1 meses e observou-se nove $(6 \%)$ pacientes com recorrências de neoplasia. Os pacientes com tumores com metástase linfonodal e/ou extensão extratireoidiana apresentaram maior risco de recorrência. Dos marcadores analisados, uma maior densidade de CD8 (que marca linfócitos citotóxicos) na área peritumoral esteve associada a uma tendência a melhor sobrevida livre de recorrência: $97,1 \%$ versus $87,5 \%$ $(p=0,057)$, além de significativos menores índices de multifocalidade tumoral e de metástase linfonodal. A maior infiltração de linfócitos T CD8+ no tumor também se relacionou com menor ocorrência de metástase linfonodal nesta amostra $(18,4 \%$ versus $38,1 \%, p=0,011)$. Além disso, a densidade desta 
marcação, tanto no interior da lesão neoplásica como em área peritumoral foi significativamente maior nos casos de carcinomas papilíferos restritos à tireoide, ou seja, sem extensão extratireoidiana e sem metástases. Os demais marcadores analisados não apresentaram relação significativa e consistente com recorrência ou outros fatores prognósticos. CONCLUSÕES: Nas neoplasias malignas de tireoide, o microambiente imune parece ter uma relação com características patológicas de agressividade. Este estudo mostrou que em carcinoma papilífero de tireoide quando não associado à tireoidite significativa, a densidade do infiltrado tumoral e peritumoral por linfócitos T CD8+ está inversamente relacionada com chance de disseminação metastática linfonodal e, provavelmente, com recidiva da doença, sendo, portanto, um marcador de melhor prognóstico. Este dado sugere que estes linfócitos exercem efeito antitumoral no carcinoma papilífero de tireoide, corroborando a importância da resposta imune na evolução desta neoplasia.

Descritores: Neoplasias da glândula tireoide; Microambiente tumoral; Linfócitos T; Macrófagos; Ativação de macrófagos; Linfócitos CD8-positivos. 


\section{Abstract}

Lira RB. Immune microenvironment in papillary thyroid carcinoma and its relation with clinical-pathological prognostic factors and survival [Thesis]. São Paulo; "Faculdade de Medicina, Universidade de São Paulo"; 2016.

INTRODUCTION: Within the last few decades thyroid cancer has the fastest rising incidence rate among all malignancies. In this group of different neoplasms, the papillary carcinoma, one of the well-differentiated carcinomas, represents the great majority and has favorable prognosis, with overall survival rates above $90 \%$ in five years. Although several risk classifications based on different prognostic features have been used, they are not accurate to predict which patients will have higher chance of recurrence, lymphatic metastasis and worse outcome, benefiting from more aggressive treatment. It has been described in several kinds of malignancies that tumor related immune infiltration has relation with prognosis and response to treatment. In this study, we characterize the immune microenvironment in papillary thyroid carcinomas, using immunohistochemical markers to inflammatory cells, and relate it with clinical and pathological prognostic features and with recurrence free survival rates. METHODS: The 151 included cases were selected from a database that included all patients who underwent surgical treatment for thyroid cancer at A.C.Camargo Cancer Center between the years 2008 and 2010. Tumor with significant thyroiditis were excluded. The selected tumors were submitted to immunohistochemical reactions with markers of inflammatory cells and analysis in complete slides by two experienced pathologists. Clinical and pathological features were evaluated, as well as recurrence and survival, relating them with the reading of marked cells. Survival analysis were made using Kaplan-Meier method, comparing survival curves with the Logrank test. RESULTS: One hundred and fifty one patients were included, of which $130(86.1 \%)$ were females and $21(13.9 \%)$ males. Multifocal disease was found in 41 cases $(27.2 \%)$, extrathyroidal extension in $43(28.5 \%)$ and lymph node metastasis in 36 (23.8\%). Only two patients had distant metastasis. The mean follow-up time was 65.1 months and we observed nine $(6 \%)$ tumor recurrences. Tumors with lymph node metastasis and/or extrathyroidal extension showed significantly higher recurrence rates. Of the analyzed markers, the cases with a higher density of CD8 (which marks cytotoxic $\mathrm{T}$ lymphocytes) in peritumoral areas presented a trend to better recurrence-free survival: $97.1 \%$ versus $87.5 \%(p=0.057)$, in addition to lower rates of mutifocal tumors and lymph node metastasis. A higher infiltration rate of CD8+ T lymphocytes in the tumor also correlated with less risk of lymph node metastasis in this sample $(18.4 \%$ versus $38.1 \%, p=0.011)$. Besides that, the density of this marking both in the tumor and in peritumoral areas, was significantly higher in the papillary carcinomas limited to the thyroid gland (without extrathyroidal extension or metastasis). The other markers analyzed did not presented significant or consistent relation with 
recurrence or other prognostic factors. CONCLUSIONS: In thyroid cancer, the immune microenvironment seems to relate with pathological features of aggressiveness. This study showed that in papillary thyroid carcinomas without significant thyroiditis, the density of tumoral and peritumoral infiltration by CD8+ T lymphocytes is inversely related with lymph node metastasis rate and probably with recurrence, being therefore a marker of better prognosis. These data suggest that these lymphocytes play an anti-tumoral role in papillary thyroid carcinoma, supporting the implication of immune response in the progression of this neoplasm.

Descriptors: Thyroid gland neoplasms; Tumor microenvironment; TLymphocytes; Macrophages; Macrophage activation; CD8-positive lymphocytes. 


\section{Introdução}




\section{INTRODUÇÃO}

\subsection{CÂNCER DA GLÂNDULA TIREOIDE}

O termo câncer de tireoide abriga um grupo de tumores significativamente diferentes. De um lado, os chamados carcinomas bem diferenciados, englobando o carcinoma papilífero, o carcinoma folicular e o carcinoma de células de Hurthle apresentam singularidades, sobretudo no que diz respeito ao diagnóstico e melhor prognóstico. Ainda como tumores originados das células foliculares observam-se os carcinomas pouco diferenciados e os carcinomas indiferenciados ou anaplásicos, com evolução marcadamente mais desfavorável. Por outro lado, o carcinoma medular da tireoide originário da células $\mathrm{C}$ ou parafoliculares secreta calcitonina e apresenta diferenças importantes em seu comportamento e manejo ${ }^{1}$.

A neoplasia maligna da glândula tireoide é, entre todos os tipos de câncer, a que mais cresceu em incidência nos últimos anos, de acordo com a análise dos bancos de dados norte-americanos (SEER database). Esta incidência praticamente triplicou nos últimos 30 anos, passando de 4,3 casos por 100.000 pessoas, em 1973 , para 11,1 casos a cada 100.000 pessoas, em 2006. O crescimento foi ainda maior na incidência do carcinoma papilífero da tireoide que no mesmo período aumentou 3,2 vezes e, hoje, representa $90 \%$ de todas as neoplasias malignas tireoidianas. A mortalidade 
por neoplasia maligna tireoidiana, no entanto, permanece estável nos Estados Unidos da América (EUA) ${ }^{2}$.

No Brasil, embora as estimativas publicadas pelo INCA apontem também para um aumento na incidência, não existem dados precisos publicados sobre as variações na ocorrência do câncer de tireoide nos últimos anos. No entanto, o câncer de tireoide que não figurava entre as neoplasias mais frequentes, hoje representa $5 \%$ dos tumores malignos diagnosticados em mulheres, sendo estimados 11 casos para cada 100 mil mulheres brasileiras em 2012, o que o torna o quarto câncer mais incidente no sexo feminino ${ }^{3}$. Uma análise pontual da incidência e da mortalidade do câncer de tireoide em nosso País mostrou uma grande variação regional, provavelmente, secundária a diferenças na acessibilidade a métodos de diagnóstico e cobertura dos Registros de Câncer, além disso, mostrou também uma queda na mortalidade nas últimas 2 décadas do século passado ${ }^{4}$.

Ainda se discute se o aumento da incidência observado em diferentes lugares do mundo é real ou relativo, em razão da difusão e maior utilização de métodos diagnósticos, sobretudo ultrassonografia (US) e punção aspirativa por agulha fina (PAAF), como também no aumento da detecção de microcarcinomas em pacientes operados por doenças benignas ${ }^{5}$. Análises recentes apontam para um aumento do número de casos diagnosticados com tumores de todos os tamanhos, inclusive em tumores maiores que $5 \mathrm{~cm}$ (12\% por ano), além, obviamente, dos microcarcinomas $(19,2 \% \text { por ano })^{2,6}$. Estas análises mostram também algumas diferenças 
nesta velocidade de crescimento em subgrupos étnicos e de idade, o que sugere que haja de fato um aumento real, não atribuível somente à melhora da atenção médica e dos métodos diagnósticos ${ }^{7-10}$.

Nas últimas décadas, este aumento de incidência trouxe algumas consequências para a prática clínica. Em um levantamento do Departamento de Cirurgia de Cabeça e Pescoço e Otorrinolaringologia do A. C. Camargo Cancer Center, quando comparado o perfil dos casos tratados nesta instituição por câncer de tireoide na década de 1990 e no anos 2008, 2009 e 2010, foram observadas importantes diferenças: a média de tireoidectomias por câncer por ano passou de 28,7 para 269 , um aumento de quase dez vezes; o emprego do esvaziamento cervical lateral passou de 19,6\% para $3,6 \%$, refletindo uma queda proporcional no número de casos avançados; o carcinoma papilífero, que representava $87,3 \%$ dos casos, passou a representar $96,6 \%{ }^{11}$. Este óbvio aumento mudou o perfil de atendimento deste departamento, com aumento proporcional dos casos de doença tireoidiana, especialmente, câncer de tireoide (Figura 1) ${ }^{12}$. Estes números continuam a mudar e, em 2014, este departamento realizou 651 tireoidectomias por câncer (dados não publicados). Portanto, tratamos hoje muito mais casos do que na década de 1990, mas temos proporcionalmente menos tumores avançados. 


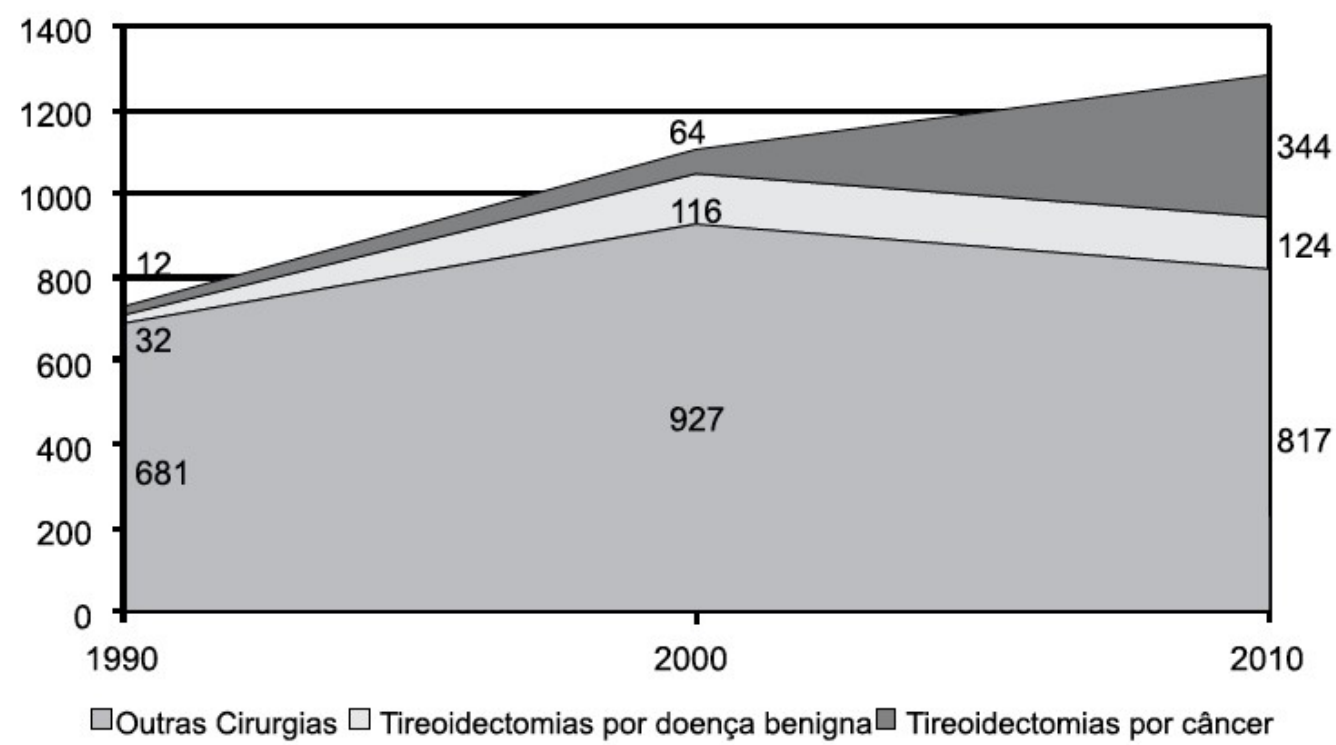

Figura 1 - Evolução no número de cirurgia por ano no Departamento de Cirurgia de Cabeça e Pescoço e Otorrinolaringologia do A. C. Camargo Cancer Center. Comparativo entre os anos 1990, 2000 e 2010

Diversos sistemas de estadiamento para predição de prognóstico nos cânceres de tireoide foram descritos, todos eles demonstrando, nos carcinomas papilíferos de tireoide, relação significativa com sobrevida específica para câncer: EORTC, Mayo Clinic (AGES), Memorial Sloan Kettering Cancer Center (GAMES), Lahey Clinic (AMES), AJCC/UICC TNM, Karolinska Hospital (DAMES), Mayo Clinic (MACIS), University of Chicago (Clinical Class), University of Bergan (SAG), Ohio State University, Noguchi Thyroid Clinic, University of Munster (Munster), National Thyroid Cancer Treatment Cooperative Study (NTCTCS), University of Alabama and M.D. Anderson (UAB \& MDA), Virgen de la Arrixaca University em Murcia (Murcia), Cancer Institute Hospital - Tokyo (CIH), Ankara Oncology Training and Research Hospital na Turquia (Ankara) ${ }^{13}$, sendo os sete primeiros os 
mais difundidos e utilizados. De forma geral, estes sistemas levam em conta sobretudo idade, tamanho do tumor, presença de extensão tumoral extratireoidiana e metástases, como os principais fatores clínico-patológicos de impacto prognóstico no carcinoma papilífero da tireoide. Outros fatores como grau de diferenciação tumoral, invasão vascular e ressecção cirúrgica adequada são utilizados em alguns dos sistemas supracitados.

A idade do paciente é apontada como o fator prognóstico de maior impacto na sobrevida no câncer bem diferenciado da tireoide, piorando progressivamente a partir dos 40 anos. As taxas de recorrência variam de $20 \%-40 \%$, sendo maior nos extremos de idade (menores que 10 anos e maiores que 60 anos). Cerca de 10\%-30\% dos carcinomas papilíferos apresentam-se como tumores localmente invasivos, macro ou microscopicamente e evoluem com o dobro de risco de recorrência e mortalidade de, aproximadamente, $30 \%$. As metástases a distância são a principal causa de mortalidade de pacientes com câncer de tireoide, ocorrendo em até $10 \%$ dos carcinomas papilíferos, a metade já presente no momento do diagnóstico, e têm impacto prognóstico negativo bem definido, mais importante no pacientes idosos ${ }^{14}$. A ocorrência de metástases linfonodais chega a $36 \%$ dos adultos portadores de carcinoma papilífero e até $80 \%$ nas crianças. No entanto, sua importância prognóstica permanece controversa, com alguns estudos mostrando relação com recorrência, metástases a distância e sobrevida, sobretudo nos pacientes com idade maior que 45 anos. Outro fator prognóstico bem estabelecido é a variante histológica tumoral, observando-se maior ocorrência de recidiva e pior 
sobrevida global nos tipos: células altas, sólido, trabecular e insular, sendo os três últimos considerados pouco diferenciados. O sexo masculino, embora menos acometido, apresenta taxas de extensão extratireoidiana, metástases, recorrência e mortalidade maiores ${ }^{1,14-17}$.

O tratamento do câncer bem-diferenciado de tireoide é cirúrgico na maioria dos casos, com taxas de sobrevida livre de doença em 5 anos de 90\%-97\% para o carcinoma papilífero, sendo, de acordo com dados americanos, $99,8 \%$ para tumores localizados, $97 \%$ para tumores regionalmente disseminados e $57,3 \%$ para tumores com metástases a distância ${ }^{18}$. Para os subtipos de carcinoma bem diferenciados, o tipo de cirurgia (total ou parcial) não parece afetar o resultado do tratamento, porém nos últimos anos vêm se realizando cada vez mais a tireoidectomia total. A associação do esvaziamento cervical e da iodoterapia adjuvante ainda são questões em constante debate, sendo o esvaziamento cervical eletivo ou profilático associado a uma maior incidência de complicações sem redução nas taxas de recorrência ${ }^{19}$. Nos últimos consensos das sociedades de especialistas em doenças tireoidianas, recomenda-se o esvaziamento cervical do compartimento central na presença de doença linfonodal clinicamente detectável ou tumor primário avançado (T3-4), às custas de maior morbidade, sobretudo no que diz respeito à hipocalcemia pósoperatória ${ }^{17,20}$. A iodoterapia adjuvante é realizada nos pacientes de alto risco para recorrência, reduzindo a incidência de recidiva e mortalidade específica nesta população ${ }^{14}$, sendo evitada nos pacientes de baixo risco ${ }^{17}$, 20. No entanto, ainda se discute que tipo de pacientes ou tumores 
apresentaria benefício com indicação do esvaziamento cervical do compartimento central profilático e da iodoterapia adjuvante, sobretudo nos grupos de risco moderado dos sistemas de estadiamento utilizados atualmente ${ }^{17,20}$, não havendo nenhum fator clínico-patológico capaz, hoje, de definir, dentro deste grupo, quais pacientes deveriam receber um tratamento mais agressivo.

O carcinoma papilífero é, portanto, uma doença cada vez mais incidente, mas, que mantém taxas de mortalidade e recorrência baixas após o tratamento cirúrgico, independente da extensão e agressividade desse tratamento. Sendo assim, a identificação de marcadores de comportamento mais agressivo, com maior tendência a disseminação regional ou a distância, que exigiria tratamento mais intenso, é fundamental.

\subsection{INFLAMAÇÃO E CÂNCER}

Inflamação é um processo fisiológico com fins de defesa para o organismo. Envolve diversos marcadores bioquímicos e migração de várias células diferentes para o sítio de inflamação, por meio de processos quimiotáticos e expressão de moléculas de adesão. Geralmente, o processo é autolimitado, no entanto, pode haver persistência anormal do mesmo por falha dos mecanismos que o fazem cessar, acarretando inflamação crônica. A relação entre câncer e inflamação crônica foi, inicialmente, proposta por Virchow, em 1863, sendo sustentada pela hipótese de lesão de DNA e 
ativação de oncogenes causadas pela agressão inflamatória e comprovada em diversos tipos histológicos ao longo dos anos, como esôfago, fígado, intestino, estômago, entre outros ${ }^{21}$. O exemplo clássico de carcinogênese relacionada à inflamação crônica ocorre nos pacientes portadores de doenças inflamatórias intestinais. Outras relações bem estabelecidas verificam-se no carcinoma gástrico relacionado à infecção pelo $H$. pylori e à inflamação crônica por ele causada, na asbestose e mesotelioma, na doença pulmonar obstrutiva crônica e câncer de pulmão, e na esofagite crônica e carcinoma de esôfago ${ }^{22,23}$.

Já foram identificados infiltrados tumorais de vários tipos de células inflamatórias, como linfócitos (CD4 e CD8), macrófagos, células dendríticas imaturas, mastócitos e células mielóides supressoras ${ }^{21}$. Uma rede de citocinas inflamatórias coordenada pelas células inflamatórias e pelas próprias células tumorais regula a interação com as células estromais e a matriz extracelular ${ }^{23}$.

\subsubsection{Tireoidite e câncer de tireoide}

A relação entre doenças tiroeidianas autoimunes e câncer de tireoide, particularmente o carcinoma papilífero, vem sendo frequentemente estudada. No entanto, esta relação persiste como alvo de debate, não estando bem estabelecida. Acreditamos que pacientes com tireoidite linfocítica crônica (TLC) tenham um maior risco de desenvolver carcinoma papilífero da tireoide ${ }^{24}$, sugerindo que a TLC possa ser uma condição préneoplásica e as duas doenças compartilhem rearranjos semelhantes no 
gene RET/PTC. Outra evidência implicando este gene na relação entre carcinoma de tireoide e TLC vem do achado de que grande parte dos pacientes expostos à radiação no acidente da usina nuclear de Chernobyl desenvolveram não só carcinoma papilifero induzido pela mutação no RET/PTC como também TLC ${ }^{21}$.

O papel da inflamação crônica associada ao carcinoma bem diferenciado de tireoide, na forma de TLC, também permanece controverso ${ }^{25-28}$. Kim et al. ${ }^{26}$ mostraram que a presença de tireoidite de Hashimoto associada ao carcinoma papilífero de tireoide é um fator preditivo independente para metástases linfonodais no compartimento central. Um outro estudo, de Jeong et al. ${ }^{28}$, analisou um grupo de 1.357 carcinomas papiliferos da tireoide e descreveu que pacientes com TLC associada eram mais jovens, predominantemente mulheres, com tendência a ter tumores menores e com menos extensão extratireoidiana. Entretanto, a TLC não foi um fator independente significante de bom prognóstico.

\subsection{RESPOSTA IMUNE E MICROAMBIENTE TUMORAL}

A presença de infiltrado por linfócitos e outras células inflamatórias no tumor e em tecidos peritumorais é clara evidência de resposta do sistema imune à presença de células neoplásicas no organismo. Esta imunogenicidade é mediada por antígenos tumorais que os distinguem de células normais ${ }^{29}$. 
O microambiente tumoral é formado por uma rede extremamente complexa de células estromais, tumorais e inflamatórias, além de diversas citocinas responsáveis por sinalizações entre todas estas células ${ }^{30-32}$. Este microambiente imune em que o tumor se desenvolve influencia vários parâmetros de seu comportamento, demonstrando inclusive, em câncer de mama, predição de sobrevida livre de doença e global ${ }^{33}$.

Esta relação entre a resposta imune e as células tumorais pode ser dividida em três fases: eliminação, equilíbrio e escape. Na eliminação, como sugerido pelo nome, as células tumorais são completamente eliminadas pelas células inflamatórias, sobretudo linfócitos T; na fase de equilíbrio, surgem células imunorresistentes, mas, simultaneamente, o sistema imune impede a profileração de células não resistentes e o foco tumoral permanece estável, sem progressão por tempo variável, podendo chegar a anos; no escape, o tumor desenvolve mecanismos para evitar ou controlar a resposta imunológica e passa a progredir ${ }^{34}$. Este complexo microambiente imune tumoral é formado por inúmeros componentes celulares e humorais. A seguir, descrevemos como vêm sendo estudados os papéis de parte das células e citocinas envolvidas nesse mecanismo.

\subsubsection{O papel dos macrófagos}

Os macrófagos representam até $50 \%$ da massa tumoral e desempenham papel de destaque no microambiente inflamatório e na dinâmica do estroma dos tumores sólidos, sendo as células imunes mais abundantes neste cenário ${ }^{35,36}$. Uma vez ativados, os macrófagos tornam-se 
a principal fonte de fatores de crescimento e citocinas, afetando sobremaneira o microambiente local ${ }^{22}$. Estes macrófagos podem ser ativados de formas diferentes, apresentando funções distintas e constituindo uma população heterogênea de células com papel regulador no processo inflamatório. Esquematicamente, os macrófagos podem ser classificados em tipo I (M1) ou classicamente ativado e tipo II (M2) ou alternativamente ativado ${ }^{35}$. $\mathrm{Na}$ verdade, esta classificação não representa completamente o contínuo de perfis de ativação que o macrófago pode apresentar. De forma geral, caracteriza-se como M2 todo estado de ativação diferente da ativação clássica. Esta ativação é influenciada basicamente por sinais locais do microambiente onde o macrófago se localiza. O estímulo de interferon-gama associado ou não a estímulo microbiológico (lipopolissacarídeo ou LPS) induz a diferenciação em M1, enquanto IL-4, IL-13, IL-10, imunocomplexos e corticoides induzem ativação alternativa ou M2. Os macrófagos M1 atuam pelos altos níveis de produção de TNF-alfa, IL-12 e IL-23 com consequente ativação de resposta tipo I de células $\mathrm{T}$ e ação citotóxica contra células tumorais por meio de óxido nítrico e radicais livres derivados do oxigênio. Já os macrófagos M2 produzem IL-10, CCL17, CCL22 e IL-1ra, suprimem a atividade inflamatória (Th1), promovem debridamento de restos celulares, angiogênese e remodelação tecidual, processos imprescindíveis no desenvolvimento e progressão tumoral.

Os macrófagos associados ao tumor são originários dos monócitos sanguíneos recrutados para o sítio tumoral pela ação de diversas quimiocinas, sobretudo CCL2, produzida pelas células tumorais (no câncer 
de mama, ovário, pâncreas) ${ }^{30}$ ou pelo próprios macrófagos tumorais, o que resulta em uma autoamplificação. Já no microambiente tumoral, os macrófagos são "bombardeados" por sinais para adaptar as novas células às necessidades tumorais, apresentando preferencialmente ativação alternada ou M2. Uma vez na intimidade do tumor, os macrófagos M2 estimulam direta e indiretamente o crescimento e progressão tumoral, por meio de mecanismos, como secreção do EGF (fator de crescimento epitelial), IL-6, TNF, CXCL-2, além de promover neoangiogênese pela secreção de VEGF, TGF-beta e PDGF estimulada pela ativação da via da HIF-1-alfa induzida por hipoxia tumoral. O macrófagos associados ao tumor estimulam a remodelação da matriz extracelular, fundamental no processo de invasão e metástase, por meio da produção de metaloproteases (MMPs), plasmina e ativadores do plasminogênio e modular à resposta imune ao tumor ${ }^{31}$. Corroborando as diversas possibilidades de diferenciação e ação, a literatura especializada aponta para diferentes associações de infiltração de macrófagos e comportamento tumoral, relacionando-se a melhor prognóstico em alguns tipos de tumor, como o osteossarcoma de alto grau ${ }^{37}$ e pior prognóstico em outros, como mama, pâncreas, linfoma de Hodgkin, pulmão (não pequenas células) e ovário ${ }^{33}$. Uma observação interessante é que em ratos mutados onde há uma polarização preferencial dos macrófagos em M2, há um crescimento acelerado de células tumorais transplantadas ${ }^{32}$.

Vários estudos, sobretudo em câncer de mama, evidenciam a relação positiva entre a densidade dos macrófagos associados ao tumor (TAMs) e progressão tumoral, metástases e, consequentemente, diminuição na 
sobrevida ${ }^{33,38}$. Além disso, os genes associados à diferenciação e infiltração tumoral dos TAMs são marcadores moleculares de pior prognóstico no câncer de mama e linfoma ${ }^{32}$.

Um estudo em modelo animal mostrou a importância do CCL2 no recrutamento de monócitos por células metastáticas de câncer de mama e o efeito promotor dos monócitos diferenciados em macrófagos M2 no crescimento destas metástases. Esta informação associada ao efeito prognóstico negativo da hiperexpressão do CCL2 nos cânceres humanos argumentam a favor do desenvolvimento de terapia-alvo contra o recrutamento e funcionamento do monócitos/macrófagos associados a tumor 39. Outro estudo em modelo animal mostrou que mutações no gene do CSF1 (fator estimulador de colônia), um fator de crescimento imbuído no recrutamento de monócitos, causou depleção da infiltração dos macrófagos associados ao tumor e atraso da progressão do câncer e do desenvolvimento de metástases, e a hiperexpressão do CSF-1 aumentou a densidade da infiltração dos TAMs e acelerou a progressão da doença ${ }^{40}$.

Estes experimentos genéticos juntos mostram uma relação causal entre a infiltração pelos macrófagos e o potencial maligno de alguns tumores 22. A presença de linfócitos $T$ CD4+, na ausência de uma resposta de linfócitos T CD8+ (CTLs) significativa, potencializa a atividade pró-tumoral dos TAM (CD68+), aumentando a metastização do adenocarcinoma de mama $^{41}$.

Baseados nestas informações, DeNardo e colaboradores ${ }^{33}$ demonstraram, no câncer de mama humano, uma relação inversa entre a 
infiltração estromal por CD68+ (TAM) e CD8+ (CTLs) e desenvolveram a hipótese de que um perfil imune tumoral caracterizado por alta densidade de células CD68+ e CD4+, associado à baixa densidade de CD8+ acarretaria em pior prognóstico, com aumento do risco de metástases e diminuição de taxas de sobrevida, assim como o perfil inverso implicaria melhora da sobrevida, representando tumores com menor tendência metastática. Este estudo também corroborou a importância do CSF-1 e expressão do CSF-1R nos macrófagos no processo de recrutamento e mostrou aumento da infiltração por TAMs em tumores expostos à terapia citotóxica (paclitaxel), em modelo animal.

O macrófago, portanto, desempenha um papel de destaque na regulação e atuação do microambiente imune ${ }^{35}$.

\subsubsection{O papel dos linfócitos}

Inicialmente, é preciso distinguir os diferentes tipos de linfócitos infiltrando tumores (TILs), pois eles apresentam diferentes funções no microambiente tumoral. Linfócitos T CD8+ citotóxicos (CTLs) são diretamente capazes de causar morte em células tumorais. Os linfócitos T CD4+ helper (Th) secretam citocinas e têm perfil heterogêneo a depender de sua ativação. Os linfócitos T CD4+ Th tipo 1 (Th1) ativam os CTLs, os Th tipo 2 (Th2) estimulam imunidade humoral e eosinófilos, tendo, portanto, atividade antitumoral menos efetiva. Além destes dois subtipos, há o linfócito T CD4+ regulatório (Treg) que suprime a ativação dos linfóticos efetores. Como já exposto, os macrófagos e as próprias células tumorais, por meio de 
complexos mecanismos de sinalização com secreção de citocinas, são responsáveis pelo recrutamento destas células e, consequentemente, pelo perfil de infiltrado tumoral e peritumoral ${ }^{31,42}$.

Geralmente, a forma usada para determinar efeito in vivo dos TILs é a quantificação destas células e comparação com características tumorais, prognóstico e sobrevida. Para analisar os dados já publicados, Gooden et al. ${ }^{42}$ realizaram uma revisão sistemática sobre o papel dos TILs em diferentes tipos de câncer que incluiu 52 estudos e uma metanálise com 33 estudos. Estes autores encontraram um papel prognóstico moderado desempenhado pelos TILs que, no entanto, se torna mais pronunciado quando analisadas as relações entre densidade de diferentes subtipos de TILs, como CD8+/FoxP3+, CD8+/CD4+ ou CD3+/CD8+.

\subsubsection{O papel de outras células inflamatórias}

Linfócitos denominados Natural Killer (NKs) são partes da resposta inata do sistema imune e são capazes de matar células que não expressem proteínas do complexo de histocompatibilidade (MHC) e de secretar citocinas regulatórias. Embora teoricamente estas células possam indicar resposta imune antitumoral, o que vem sendo demonstrado é que infiltração por NKs tem relação com tumores mais avançados e que, provavelmente, estas células sejam recrutadas pelo tumor e desempenhem papel prótumoral pela produção de fatores proangiogênicos (VEGF) ${ }^{43}$.

Células dendríticas (DCs) são células apresentadoras de antígenos muito eficientes. Infiltração tumoral por DCs maduras estimula resposta 
antitumoral pelo recrutamento de linfócitos $\mathrm{T}$, entretanto, os tumores podem impedir infiltração das DCs, bloquear ou modificar sua maturação e, desta forma, transformá-las em células pró-tumorais, com secreção de citocinas pró-angiogênicas e inibição de resposta imune antitumoral ${ }^{44,45}$.

Os neutrófilos representam 50\%-70\% dos leucócitos circulantes e seu papel no microambiente tumoral ainda não está claro. Neutrófilos associados a tumor (TANs) podem, de forma semelhante ao que ocorre nos macrófagos e quando, especificamente, estimulados pelas células neoplásicas e outros componentes do microambinete do tumor para tal, assumir fenótipo antitumoral (N1) ou pró-tumoral (N2). Assumindo o perfil N2 de ativação, os neutrófilos suprimem o sistema imune adaptativo e facilitam angiogênese e metástase, também de forma similar aos TAMs M2 ${ }^{46}$.

\subsubsection{Microambiente imune do câncer de tireoide}

Em pacientes com carcinoma papilífero de tireoide sem intervenção cirúrgica, é possível que em boa parte dos casos o tumor possa ser contido pelo sistema imune do paciente e não progredindo para formas mais agressivas ou avançadas. Mas, em um grupo destes tumores haveria um escape ao sistema imune com consequente evolução para metástases, progressão local ou desdiferenciação ${ }^{47,48}$. A grande questão então seria identificar previamente quais seriam os casos mais propensos a este escape, reforçando a necessidade de melhor entendimento da relação entre este carcinoma e os sistemas imunes dos hospedeiros, já que o simples fato dos carcinomas de tireoide progredirem em um ambiente tão densamente 
infiltrado por linfócitos, como na presença de tireoidite, sugerirem algum grau de imunomodulação ${ }^{49}$.

A prevalência de infiltrado linfocítico é maior em carcinomas papilíferos que em doenças benignas da tireoide ${ }^{50}$; no entanto, a presença de tireoidite associada ao carcinoma papilífero pode favorecer um melhor prognóstico ${ }^{25}$, assim como a presença e proliferação de linfócitos associados ao carcinoma papilífero da tireoide, que demonstrou relação negativa com recorrência da doença ${ }^{51}$. No entanto, a resposta imune ao câncer tireoidiano parece ser complexa, envolvendo infiltração de diversos tipos de linfócitos ${ }^{52}$.

A densidade do infiltrado de mastócitos parece ser mais alta em carcinomas papilíferos da tireoide do que em tecido tireoideano normal. Além disso, este infiltrado correlacionou-se com infiltração capsular e, consequentemente, com crescimento e invasividade desse tumor, em uma série de 96 casos analisada por Guarino et al. ${ }^{21}$. Em uma análise de 121 casos de carcinoma papilífero publicada em 1996, detectou-se presença de macrófagos associados ao tumor em $71 \%$ dos casos, sem sinais de atividade fagocitária na grande maioria (56\% dos casos). Nos $15 \%$ dos tumores onde havia atividade fagocitária contra células neoplásicas, detectou-se associação com infiltrado de células dendríticas e linfócitos, caracterizando, nestes casos, um complexo processo imunológico antitumoral. Isto pareceu afetar o comportamento do carcinoma, observando-se, neste grupo de pacientes, estádios menos avançados, uma 
tendência a menor ocorrência de metástases a distância e resultados oncológicos mais favoráveis ${ }^{53}$.

Em um estudo demonstrou-se que a densidade de macrófagos associados ao tumor foi significativamente maior em carcinomas pouco diferenciados e anaplásicos que em carcinomas bem diferenciados. Além disso, nos tumores pouco diferenciados, esta densidade teve impacto importante, relacionando-se positivamente com extensão extratireoidiana e diminuição de taxas de sobrevida, sugerindo que estes macrófagos associados ao carcinoma da tireoide desempenhem um papel ativo e de destaque na regulação do microambiente imune do tumor e facilitando a progressão da doença, não sendo apenas mais um marcador prognóstico ${ }^{54}$. Subsequentemente, o mesmo grupo em um estudo experimental induziu carcinoma papilifero de tireoide em ratos por meio de ativação do oncogene BRAF $^{\mathrm{V} 600 \mathrm{E}}$ para avaliar o papel dos TAMs na progressão tumoral. Foi observado que esta ativação aumentou a expressão de CSF1 e CCL2, citocinas que recrutam TAMs. O bloqueio desta via durante a ativação do BRAF diminuiu significativamente a densidade de TAMs e a progressão dos carcinomas papilíferos, resultando em tumores mais bem diferenciados e menores. Neste modelo, não foi possível analisar a relação destas intervenções com o desenvolvimento de metástases ${ }^{55}$. A densidade de infiltração por TAMs em carcinomas papilíferos de tireoide também foi analisada por Qing et al. ${ }^{56}$. Neste estudo de 103 tumores, houve correlação positiva entre infiltração por TAMs no tumor primário e taxas de metástase linfonodal, sugerindo papel funcional destes macrófagos na progressão 
tumoral. Entretanto, resultados conflitantes também já foram encontrados, com presença de TAMs associando-se favoravelmente com sobrevida livre de recorrência, embora mais uma vez relacionados positivamente com prevalência de metástases ao diagnóstico ${ }^{57,58}$. Uma hipótese que deve ser levada em consideração para explicação desta diferença de comportamento encontrado em diferentes estudos, às vezes, com o mesmo tipo de tumor ${ }^{59}$, é a influência que o microambiente tumoral está causando nos TAMs em cada amostra, havendo a possibilidade de macrófagos com diferente ativação estarem sendo agrupados e analisados em conjunto, exibindo a complexidade envolvida neste tipo de avaliação ${ }^{58}$.

Cunha et al. ${ }^{57}$, por meio de análise de tissue micro-array (TMA) com marcadores imuno-histoquímicos, demonstraram que a infiltração tumoral por células inflamatórias e também a presença de TLC estão relacionadas com prognóstico mais favorável, e que a presença de TLC parece modular o microambiente imune tumoral. O mesmo grupo, analisando os mesmos casos por meio de análise de micro-RNA, demonstrou, paradoxalmente, que a expressão de PD-L1 ou B7H1 está associada com maior densidade de infiltrado inflamatório e com características de maior agressividade tumoral 60. Em outra publicação, os mesmos autores também analisaram a expressão do Foxp3 em Tregs e células tumorais, e sua relação com fatores de agressividade tumoral em carcinomas diferenciados de tireoide, com resultados pouco conclusivos e diferentes relações com agressividade tumoral a depender do tipo de marcação (nuclear versus citoplasmática; Tregs versus células tumorais) ${ }^{61}$. A expressão de Foxp3 em Tregs, células 
tumorais de carcinoma papilífero e linfonodos também foi estudada por outros autores, relacionando-se positivamente com agressividade tumoral ${ }^{62-}$ ${ }^{64}$. De forma semelhante ao já descrito para TAMs, também pode haver falta de uniformidade nas correlações entre infiltrados linfocíticos tumorais e fatores prognósticos, o que vem sendo atribuído por autores a um efeito de overshadow por tireoidite linfocítica, que obscurece a diversidade funcional e fenotípica dos TILs no carcinoma de tireoide, dificultando inclusive a interpretação de dados publicados que frequentemente incluem casos com tireoidite linfocítica ${ }^{47,58}$.

Ao analisarem carcinomas anaplásicos da tireoide, Caillou e colaboradores ${ }^{36}$ demonstraram, por meio de análise imuno-histoquímica, presença maciça de macrófagos associados ao tumor, formando pelas ramificações citoplasmáticas, uma espécie de rede de suporte em volta de células malignas e de vasos sanguíneos, além de apresentar comunicações intercelulares (gap junctions) entre os macrófagos entre si e destes com as células tumorais, demonstrando o substrato anatomopatológico que permite que estas células imunes desempenhem toda a função pró-tumoral que lhes é atribuída. Outro achado interessante é que carcinomas foliculares são capazes de recrutar TAMs, enquanto os adenomas foliculares, não ${ }^{65}$.

Outras células parecem ter impacto na modulação do microambinete tumoral de carcinomas papilíferos, como os NK e os mastócitos. Um estudo mostrou correlação positiva entre subpopulações específicas de NK com progressão tumoral nestes pacientes, evidenciando mais um potencial alvo para tratamentos futuros ${ }^{66}$. Outro trabalho relacionou a densidade de 
infiltração por mastócitos em carcinoma papilífero de tireoide com presença de extensão extratireoidiana e demonstrou, in vitro, que as células de carcinoma recrutam os mastócitos que, por sua vez, ajudam na proliferação e invasividade destas células neoplásicas ${ }^{67}$.

Alguns experimentos tentaram relacionar mutações genéticas, sobretudo no RET/PTC3, com alteração do infiltrado linfocítico específico, sugerindo que esta mutação possa induzir recrutamento de células supressoras do processo imune e, consequentemente, promover progressão tumoral ${ }^{68}$. Adicionalmente, foi demonstrado que a via BRAF-MAPK induz produção e secreção de citocinas imunomoduladoras em melanoma, como IL10, VEGF e IL6, também encontradas em carcinomas tireoidianos ${ }^{21}$. Stassi et al. demonstraram que a secreção das citocinas IL4 e IL10 por linfócitos T CD4+ induz proteção contra ação de drogas antineoplásicas ${ }^{69}$. Além deste, uma série de outros mecanismos envolvendo mutações genéticas, citocinas secretadas pelo tumor e seu papel na regulação do microambiente imune tumoral e na remodelação do estroma tumoral vêm sendo estudados. O papel destas alterações depende do tipo de infiltrado tumoral encontrado, podendo ter efeito pró ou antitumoral. Este, no entanto, é um processo complexo, que ainda não foi completamente elucidado ${ }^{21}$.

Em conjunto, estes e outros dados já descritos suportam a hipótese de que o microambiente imune tumoral nos carcinomas papiliferos da glândula tireoide afeta a progressão tumoral e, consequentemente, o prognóstico. Análise do microambiente pode ajudar a esclarecer a resposta imune dos pacientes a seus tumores e os mecanismos que os tumores 
utilizam para evadir dessa resposta e até usar o sistema imune em seu favor, e como o balanço entre atividade imune antitumoral e pró-tumoral pode ser importante na evolução ou eliminação de neoplasias malignas, o que, por sua vez, permite identificação de tumores mais agressivos que se beneficiariam de tratamento e seguimentos mais intensivos, além de expor potenciais alvos para futuras terapias-alvo ${ }^{58}$.

\subsection{IMUNOTERAPIA}

Desde o fim do século XIX, vem sendo documentado o uso de imunoestimulantes no tratamento do câncer, como o bacilo de CalmetteGuerin (BCG), que já mostrou claro benefício no tratamento de alguns tumores sólidos, como o carcinoma de bexiga. A partir de 1970, com a descrição de ativação de linfócitos contra tumores, a imunoterapia ganhou novo impulso e desde então, com melhor entendimento da resposta imune e microambiente tumoral em toda sua complexidade vem ganhando espaço no tratamento de doenças como melanoma, especialmente, na última década 47,70

Em câncer de tireoide, o primeiro estudo com imunoterapia data de 1975, publicado por Amino et al. ${ }^{71}$. Três pacientes com doença locorregional agressiva e/ou metástase a distância receberam uma vacina produzida a partir do seu próprio tumor e um deles apresentou redução tumoral para um terço da carga inicial. Até a última década, pouco foi estudado sobre o papel 
desse tipo de terapia nos tumores tireoidianos. Entretanto, nos últimos anos, um crescimento do corpo de literatura sobre imunologia em câncer de tireoide vem seguindo a revitalização do estudo de imunoterapia para outros tumores $^{47}$.

Demonstrada a influência do microambiente imune em parâmetros importantes do comportamento tumoral, como risco de recorrência, extensão extratireoidiana, metástases linfonodais ou a distância, adquire-se um alvo potencial para terapêutica, objetivando mudanças na constituição da população celular desse microambiente, sobretudo macrófagos CD68+ e linfócitos CD4+ e CD8+. Poderia também ser empregada a análise desta marcação para definir a indicação de iodoterapia adjuvante nos casos de risco moderado. Além disso, o desenvolvimento de métodos pré ou intraoperatórios (PAAF ou congelação dos tumores) fidedignos na determinação do perfil de microambiente imune poderiam interferir diretamente na conduta terapêutica cirúrgica, por exemplo, indicando realização de esvaziamento cervical do compartimento central eletivo nos casos de maior risco para metástase linfonodal, de acordo com o perfil.

DeNardo e colaboradores ${ }^{33}$ trabalharam na hipótese de que 0 bloqueio da infiltração dos macrófagos associados ao tumor (TAMs) facilitaria a infiltração de linfócitos $T$ CD8+ $(C T L)$ e a repolarização dos linfócitos $\mathrm{T}$ CD4+ em direção à resposta Th1, o que mudaria o microambiente imune pró-tumoral para antitumoral. Estas alterações fariam as células do adenocarcinoma mamário tornarem-se mais susceptíveis às terapias citotóxicas (quimioterapia ou radiação ionizante). Em modelo 
animal, estes autores bloqueram a via de sinalização do CSF-1, pelo anticorpo monoclonal e inibidor competitivo de ATP específico para CSF-1 e cKIT, e associaram terapia citotóxica a este bloqueio, observando lentificação do desenvolvimento tumoral, redução do desenvolvimento de carcinomas de alto-grau e diminuição de metástases pulmonares, além de diminuição da densidade vascular tumoral e aumento de infiltração de linfócitos CD4+ e CD8+ no tumor primário, reprogramando o microambiente imune tumoral e aumentando a resposta à terapia citotóxica. Esta é apenas uma das possíveis estratégias descritas na procura por agentes imunoterápicos efetivos. Além da eliminação dos TAMs do microambiente tumoral, outros potenciais alvos são a maturação de células dendríticas e inibição do efeito imunossupressivo dos Tregs e moléculas imunomoduladoras ${ }^{47}$.

Até o momento, não há disponível tratamento eficiente para câncer avançado de tireoide, incluindo carcinomas pouco diferenciados e anaplásicos, além de carcinomas papilíferos metastáticos iodorrefratários. Neste cenário, nos últimos anos foram publicados estudos fase 3 mostrando resultados promissores no uso de inibidores da tirosina-quinase sorafenib e lenvatinib no carcinoma bem-diferenciado resistente à iodoterapia ${ }^{72,} 73$. Ainda assim, com a possibilidade de desenvolvimento de novas terapiasalvo, torna-se cada vez mais importante o melhor conhecimento sobre potenciais alvos para estas drogas, incluindo outras células do microambiente tumoral, como TAMs e TILs $^{74}$. 
2 Objetivos 


\section{OBJETIVOS}

\subsection{OBJETIVO PRINCIPAL}

Caracterizar o microambiente imune de uma amostra de carcinomas papilíferos de tireoide sem tireoidite por meio da determinação do perfil de infiltração tumoral por linfócitos e macrófagos.

\subsection{OBJETIVOS SECUNDÁRIOS}

1 Relacionar diferenças do perfil de infiltração tumoral por linfócitos e macrófagos com fatores clínico-patológicos prognósticos bem estabelecidos neste tipo de câncer, bem como sua influência no risco de metástases linfonodais e a distância e extensão tumoral extratireoidiana;

2 Analisar o impacto do perfil de infiltração tumoreal por linfócitos e macrófagos na sobrevida livre de recorrência após tratamento cirúrgico oncológico. 
3 Métodos 


\section{MÉTODOS}

\subsection{SELEÇÃO DE PACIENTES}

Este estudo baseia-se em uma análise retrospectiva de todos casos de neoplasia maligna da glândula tireoide tratados cirurgicamente no A. C. Camargo Cancer Center, de 1 de janeiro de 2008 a 31 de dezembro de 2010, que eram 780 carcinomas papilíferos de tireoide. Todos os pacientes submetidos a cirurgia nesta instituição assinam o Termo de Consentimento Livre e Esclarecido (TCLE) que permite a utilização de todos os dados clínicos e patológicos que constem em seu prontuário, resguardando-se o sigilo sobre a identidade do paciente. Este estudo foi apreciado e aprovado pela Comitê de Ética em Pesquisa do A.C.Camargo Cancer Center, sob o número 1.663/12, em 18 de Julho de 2012 (Anexo 1). Foram levantadas informações epidemiológicas, clínicas e patológicas desses pacientes, por meio da revisão dos prontuários eletrônicos no sistema MV2000® em computadores da instituição, com uso de uma ficha padronizada de registro de dados (Anexo 2). Com base no banco de dados criado a partir destas informações, selecionamos os casos a serem estudados. Inicialmente, por limitações de ordem financeira e logística no que se refere ao número de leituras a serem realizadas pela equipe de anatomia patológica, planejamos a análise em cortes completos de dez marcadores em cerca de 150 casos, 
idealmente divididos em grupos numericamente semelhantes de casos iniciais sem metástases, casos localmente agressivos e casos metastáticos.

Foram excluídos casos com informação clínica ou patológica incompleta (105) ou que foram perdidos de seguimento (211), até o momento da seleção dos casos para análise patológica. Em seguida, procuramos nos arquivos do laboratório de anatomia patológica da instituição os blocos de parafina e lâminas referentes aos 464 casos remanescentes. Foram então excluídos 253 casos, cujo material biológico estava indisponível (participando de outros projetos, enviados para laboratório externo, etc.) ou considerado inadequado ou insuficiente para confecção de, pelo menos, 20 novas lâminas para análise por marcadores imuno-histoquímicos. Todos os blocos de parafina e lâminas de hematoxilina e eosina resgatados do arquivo foram revistos por dois anatomopatologistas com experiência em patologia de cabeça e pescoço e endócrina, que analisaram o material seguindo os seguintes critérios de elegibilidade:

1) critérios anatomopatológicos diagnósticos para carcinoma papilífero de tireoide, em sua forma usual ou variantes descritas;

2) lesões com dimensões superiores a 1,0 mm; e

3) ausência de sinais de tireoidite difusa significativa.

Outros 60 casos foram então excluídos por não conformidade com os critérios anatomopatológicos supracitados. Após a seleção de casos do estudo, foram escolhidos e separados pelos anatomopatologistas os blocos de parafina correspondentes às lâminas mais representativas de lesão, que foram aquelas que representaram as incidências de cortes com maiores 
dimensões, maiores graus de atipia e, preferencialmente, com amostragem representativa de parênquima tireoidiano ao redor.

Os blocos escolhidos foram confrontados com as lâminas para conferência de material. A partir disso, foram realizadas novas secções destes, com confecção de lâminas para realização das reações imunohistoquímicas.

Ao final deste processo, foram obtidos 151 casos com todas as informações clínicas de tratamento e seguimento presentes, além de blocos e lâminas adequados para análise imuno-histoquímica em questão disponíveis.

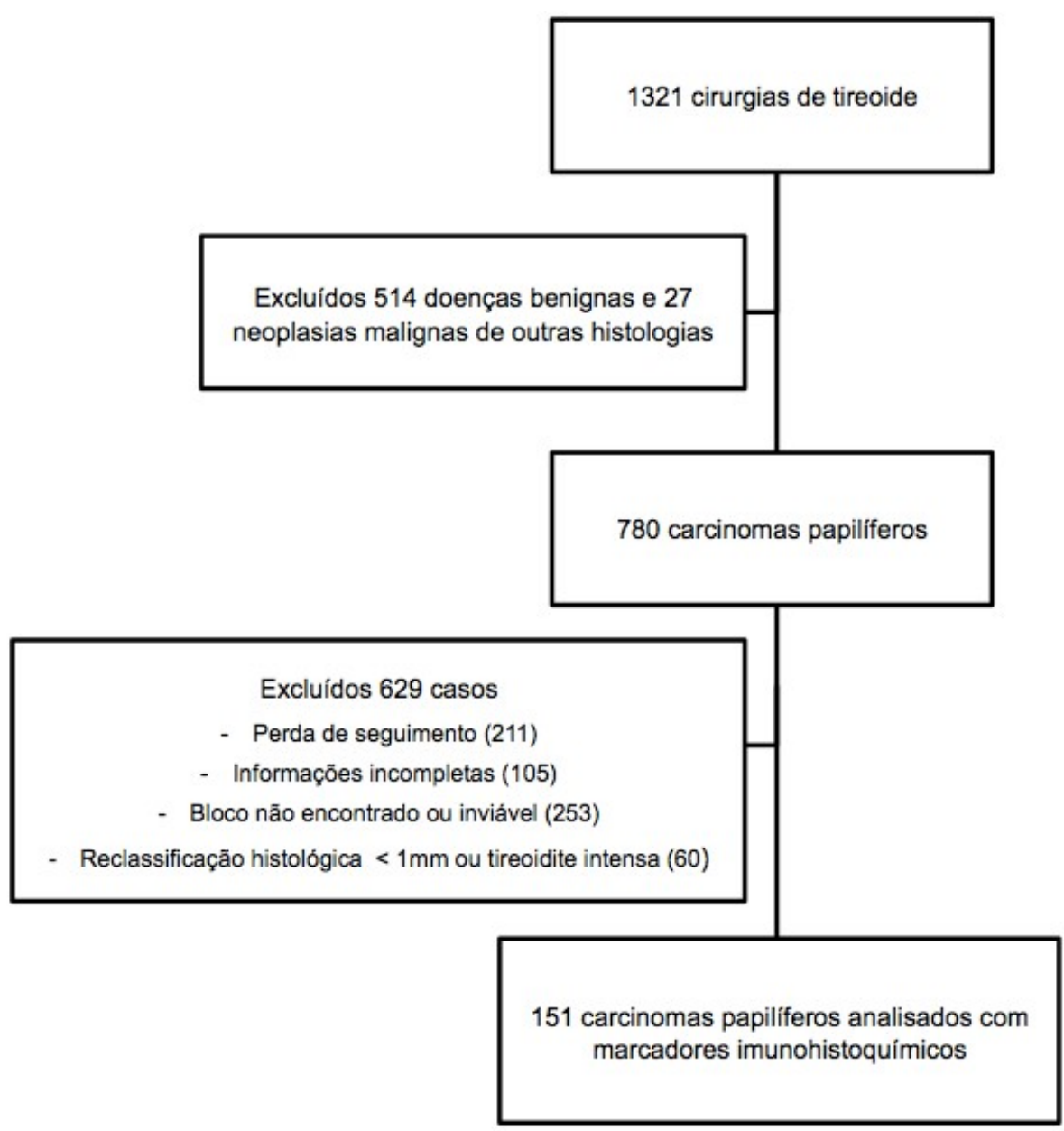

Figura 2 - Diagrama consort de fluxo de seleção de pacientes 


\subsection{ANÁLISE DOS MARCADORES}

As lâminas preparadas com base nos casos selecionados foram submetidas à coloração por imuno-histoquímica pelos marcadores listados na Tabela 1.

Tabela 1 - Marcadores utilizados neste estudo e sua função (provável marcação)

\begin{tabular}{|c|c|c|c|c|}
\hline MARCADORES & CLONE & MARCA & DILUIÇÃO & FUNÇÃO \\
\hline Anti-CD163 & 10D6 & Abcam & $\begin{array}{l}\text { Anticorpo já } \\
\text { pronto para uso }\end{array}$ & Macrófagos M2 \\
\hline Anti-CD68 & KP-1 & Ventana & $\begin{array}{l}\text { Anticorpo já } \\
\text { pronto para uso }\end{array}$ & Macrófagos \\
\hline Anti-CD4 & SP35 & Ventana & $\begin{array}{l}\text { Anticorpo já } \\
\text { pronto para uso }\end{array}$ & $\begin{array}{c}\text { Linfócito T } \\
\text { helper - MHC II }\end{array}$ \\
\hline Anti-CD8 & SP57 & Ventana & $\begin{array}{l}\text { Anticorpo já } \\
\text { pronto para uso }\end{array}$ & $\begin{array}{l}\text { Linfócito T } \\
\text { citotóxico - } \\
\text { MHC I }\end{array}$ \\
\hline Anti-FOXP3 & 236A/E7 & Abcam & $1 / 50$ & $\begin{array}{l}\text { Linfócito T } \\
\text { regulador - } \\
\text { Núcleo }\end{array}$ \\
\hline Anti-Ki-67 & $30-9$ & Ventana & $\begin{array}{l}\text { Anticorpo já } \\
\text { pronto para uso }\end{array}$ & $\begin{array}{l}\text { Atividade } \\
\text { proliferativa } \\
\text { celular }\end{array}$ \\
\hline Anti-HLA-DR & LN3 & Affymetrix & $1 / 1600$ & $\begin{array}{c}\text { Macrófagos - } \\
\text { MHC II }\end{array}$ \\
\hline Anti-CD206* & $\begin{array}{c}\text { NÃO } \\
\text { PADRONIZADO }\end{array}$ & $\begin{array}{c}\text { NÃO } \\
\text { PADRONIZADO }\end{array}$ & $\begin{array}{c}\text { NÃO } \\
\text { PADRONIZADO }\end{array}$ & $\begin{array}{c}\text { MMR } \\
\text { (macrophage } \\
\text { manose } \\
\text { receptor) - } \\
\text { fagocitose }\end{array}$ \\
\hline Anti-CD123 & $\begin{array}{c}\text { NÃO } \\
\text { PADRONIZADO }\end{array}$ & $\begin{array}{c}\text { NÃO } \\
\text { PADRONIZADO }\end{array}$ & $\begin{array}{c}\text { NÃO } \\
\text { PADRONIZADO }\end{array}$ & Receptor de IL-3 \\
\hline $\mathrm{CD}_{2} \mathrm{~A}^{* *}$ & $\begin{array}{c}\text { NÃO } \\
\text { PADRONIZADO }\end{array}$ & $\begin{array}{c}\text { NÃO } \\
\text { PADRONIZADO }\end{array}$ & $\begin{array}{c}\text { NÃO } \\
\text { PADRONIZADO }\end{array}$ & $\begin{array}{l}\text { Ativação de } \\
\text { Linfócitos T } \\
\text { (TNF-alfa) }\end{array}$ \\
\hline
\end{tabular}


Os marcadores Anti-CD123, Anti-CD206 e CD2A foram excluídos pela impossibilidade de padronização na análise imuno-histoquímica.

A reação imuno-histoquímica foi realizada utilizando o seguinte protocolo do Laboratório de Imuno-histoquímica do Departamento de Anatomia Patológica do A. C. Camargo Cancer Center:

1. desparafinização e hidratação dos cortes histológicos: 3 banhos em Xilol (5 minutos cada), quatro banhos de álcool, lavagem por 5 minutos em água corrente;

2. recuperação antigênica na Pascal (Câmara de Pressão) em solução Citrato $\mathrm{pH} 6,0$ à $125^{\circ} \mathrm{C}$ (30 segundos). Lavagem em água corrente por 5 minutos;

3. bloqueio da peroxidase endógena: três banhos de 5 minutos cada com Peróxido de Hidrogênio 10 volumes, seguidos de lavagem em PBS;

4. bloqueio de proteínas: 20 minutos com Bloqueador de Proteínas (DAKO);

5. incubação do anticorpo primário por 2 horas à temperatura ambiente em câmara úmida, seguida de lavagem em PBS;

6. incubação com anticorpo secundário (Advance HRP Link - DAKO) por 30 minutos (Ta);

7. lavagem em PBS;

8. incubação com Polímero (Advance HRP enzyme - DAKO) por 30 minutos (Ta);

9. lavagem em PBS; 
10. revelação da reação com cromógeno diaminobenzidine (DAB) 5 minutos (Kit Liquid DAB+ Substrate Chromogen System; Dako Cytomation, Carpinteria, Califórnia);

11. lavagem em água corrente;

12. contracoloração com hematoxilina de Harris por 2 minutos;

13. lavagem em água corrente por 5 minutos; e

14. desidratação em álcool, Xilol, montagem em meio permanente.

A padronização de interpretação pelos dois anatomopatologistas levou em consideração a positividade esperada para cada marcador por tipo celular, sendo feita a quantificação por contagem direta de células positivas. Para os marcadores CD4, CD8, CD68, CD163, FOXP3 e Ki-67 foram avaliados quatro campos distintos de grande aumento (x200) nas áreas de carcinoma papilífero (denominadas tumoral ou T) e em áreas subsequentes de tecido tireoidiano não neoplásico (denominadas não tumoral ou NT). Para isso, considerou-se o centro do tumor, evitando-se áreas de interface ao tecido não neoplásico. Em virtude do grande número de células positivas para HLA-DR, a contagem destas foi realizada em cinco campos de grande aumento (x400). A avaliação e quantificação de células foi realizada em microscópio óptico convencional previamente padronizado (Olympus, BX41, com campo de aumento x200, $1.1 \mathrm{~mm}$ ). Vide exemplo abaixo: 

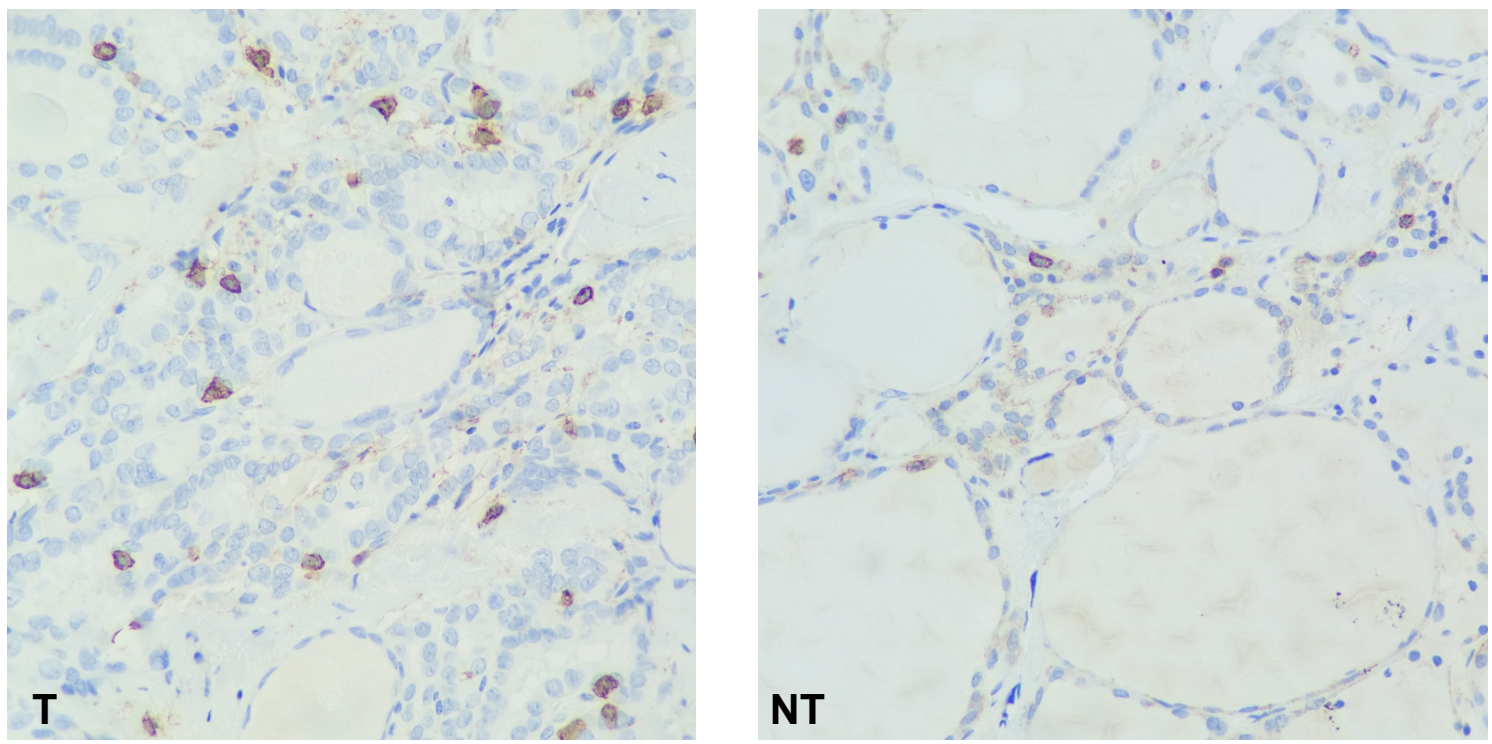

Figura 3 - (T) Micrografia exibe positividade imuno-histoquímica em linfócitos $\mathrm{T}$ em meio ao tecido neoplásico, demarcados pela coloração marrom (pelo revelador diaminobenzidina). (CD8, x200); (NT) Positividade em raros linfócitos em área não neoplásica (CD8, x200)
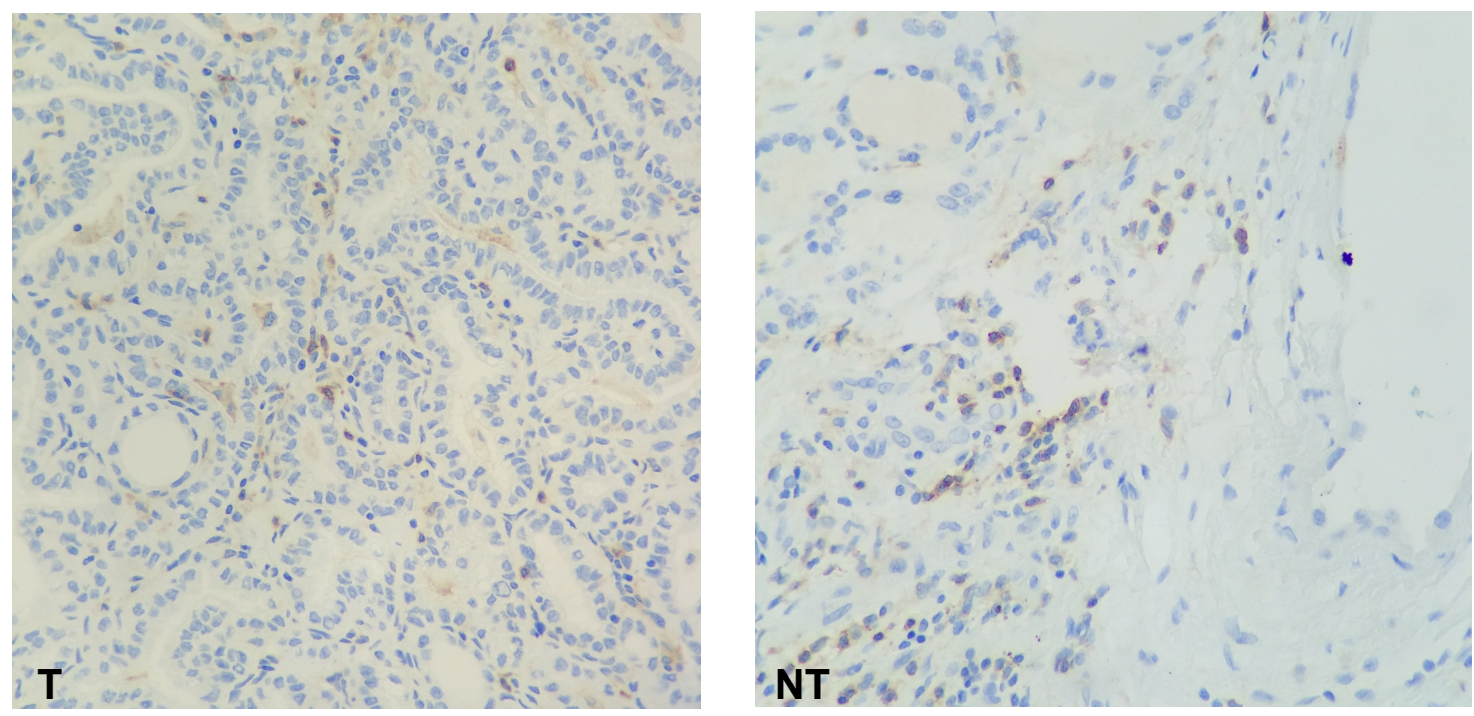

Figura 4 - (T) Micrografia exibe positividade imuno-histoquímica em linfócitos $\mathrm{T}$ em meio ao tecido neoplásico, demarcados pela coloração marrom (pelo revelador diaminobenzidina). (CD4, x200); (NT) Positividade em raros linfócitos em área não neoplásica (CD4, x200) 

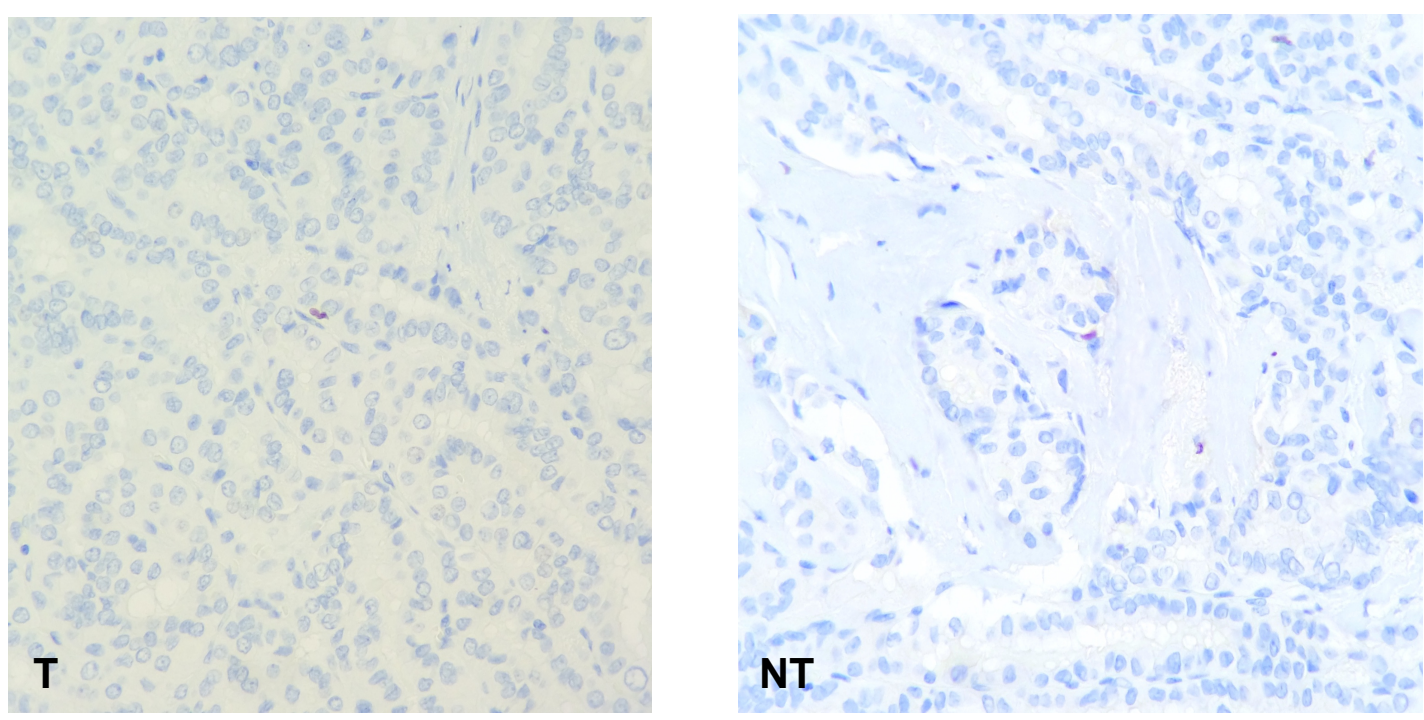

Figura 5 - (T) Micrografia exibe positividade imuno-histoquímica em linfócitos $\mathrm{T}$ em meio ao tecido neoplásico, demarcados pela coloração marrom (pelo revelador diaminobenzidina). (FOXP3, x200); (NT) Positividade em raros linfócitos em área não neoplásica (FOXP3, x200).
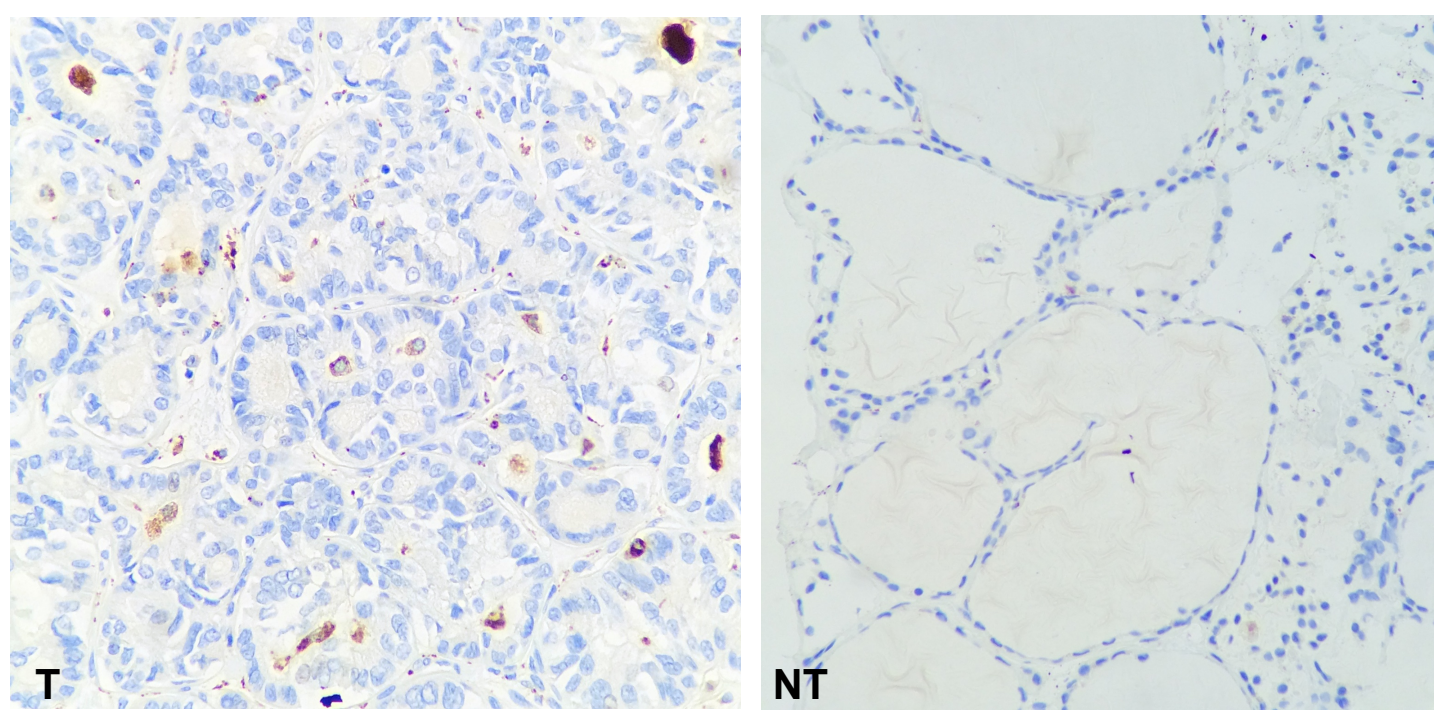

Figura 6 - (T) Micrografia exibe positividade imuno-histoquímica em linfócitos $\mathrm{T}$ em meio ao tecido neoplásico, demarcados pela coloração marrom (pelo revelador diaminobenzidina). (CD68, x200); (NT) Positividade em raros linfócitos em área não neoplásica (CD68, x200) 

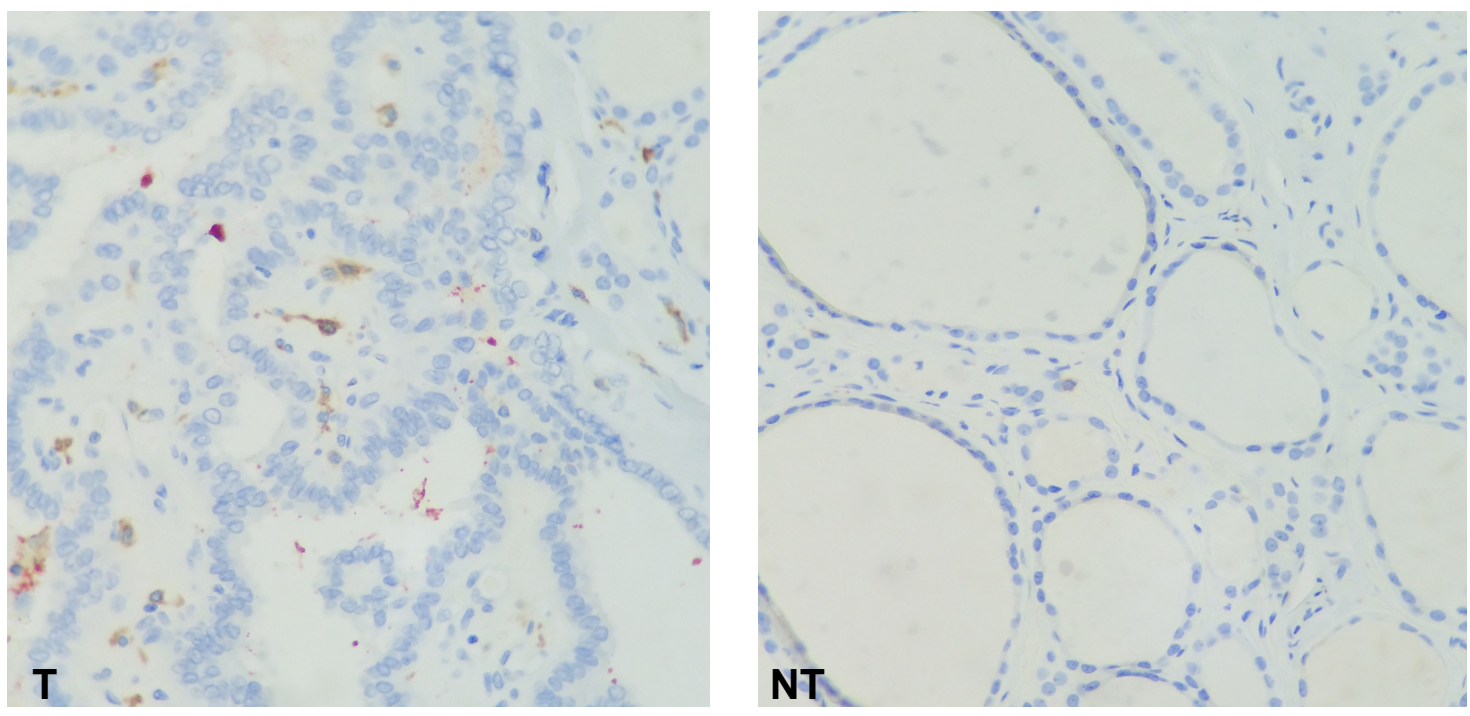

Figura 7 - (T) Micrografia exibe positividade imuno-histoquímica em linfócitos $\mathrm{T}$ em meio ao tecido neoplásico, demarcados pela coloração marrom (pelo revelador diaminobenzidina). (CD163, x200); (NT) Positividade em raros linfócitos em área não neoplásica (CD163, x200)

A contagem absoluta de células inequivocamente marcadas por cada reação imuno-histoquímica foi então inserida no banco de dados no caso correspondente para posterior análise numérica e estatística.

\subsection{ANÁLISE ESTATÍSTICA}

Para análise estatística, foi utilizado o software Stata 12.0. As análises de sobrevida global e livre de doença foram realizadas pelo método de Kaplan-Meier, com comparação de curvas de sobrevida pelo Teste de Logrank. O tempo de seguimento foi considerado a partir da data da cirurgia até a data da última informação e, para os casos de óbito, até a data do falecimento. O período entre a data da cirurgia até ocorrência de recidiva foi 
considerado para cálculo da probabilidade de sobrevida livre de doença (ou livre de recorrência). Na comparação das medidas de contagem de células marcadas por imuno-histoquímica foram utilizados os Testes $U$ de MannWhitney para comparação de dois grupos e o Teste de Kruskal-Wallis para três ou mais grupos. Em tabelas de contingência para comparação de variáveis categóricas, foi usado o Teste de Qui-quadrado; em tabelas 2×2 o Teste de Fisher foi aplicado quando, pelo menos, uma frequência esperada foi menor que 5. O Coeficiente de Correlação de Spearman foi utilizado para verificar as correlações entre os marcadores.

Além da análise da relação individual entre marcadores e variáveis clínico-patológicas, outras possibilidades foram exploradas por meio da criação de novas variáveis pelo agrupamento de variáveis iniciais. As variáveis de metástase linfonodal e extensão extratireoidiana foram agrupadas, criando uma nova classificação para os casos, denominando-se como tumores limitados à glândula tireoide aqueles sem extensão e sem metástases linfonodais. Além disso, foram agrupados casos que consideramos com perfil imune desfavorável ou desfavorável ao tumor, baseando-se na densidade de células marcadas por anti-CD8 e anti-CD68. Por fim, foram calculadas a razão entre a densidade de células CD8+ e a densidade de células CD68+ individualmente, criando uma nova variável para posterior análise em conjunto com as demais já formadas. 
4 Resultados 


\section{RESULTADOS}

\subsection{RESULTADOS EPIDEMIOLÓGICOS E CLÍNICOS}

Nesta amostra de 151 pacientes com carcinoma papilífero de tireoide, houve $130(86,1 \%)$ mulheres e 21 homens (13,9\%). A idade variou entre 14 e 80 anos, com mediana de 42 anos e média 42,6 anos (desvio-padrão 13,4). Previamente à cirurgia, $124(81,5 \%)$ pacientes eram eutireoidianos, 23 $(15,2 \%)$ eram hipotireoideos e quatro $(2,6 \%)$ eram hipertireoideos. História de exposição à radiação era presente em seis (4\%) casos e diagnóstico de outro câncer sincrônico ou metacrônico foi registrado em 16 (10,6\%), sendo três em cabeça e pescoço, três de pele, dois de mama, dois de próstata, quatro linfoproliferativos, um de reto e um Schwannoma maligno. Um total de $77(51 \%)$ dos pacientes negaram ter familiares com câncer, e 17 (11,3\%) tinham familiares com câncer de tireoide e 50 (33,1\%) com outros tipos de neoplasia maligna. A ultrassonografia cervical pré-operatória diagnosticou bócio uninodular em $69(45,7 \%)$ e multinodular nos demais $(54,3 \%)$. Já a punção aspirativa por agulha fina, que não foi realizada em dez $(6,7 \%)$ dos casos, sugeriu lesão folicular em 37 (24,5\%) e carcinoma em 102 (67,5\%), tendo resultado insatisfatório em apenas dois (1,3\%). Apenas nove $(5,9 \%)$ pacientes tiveram diagnóstico pré-operatório de metástase linfonodal. 


\subsection{TRATAMENTO REALIZADO}

Do ponto de vista do tratamento empregado, 137 (90,7\%) pacientes foram submetidos à tireoidectomia total, um $(0,7 \%)$ parcial, seis $(4 \%)$ parcial seguida de totalização, e sete $(4,6 \%)$ a cirurgias ampliadas. Esvaziamento cervical do compartimento central (nível VI) uni ou bilateral foi realizado em 36 pacientes $(23,8 \%)$, dos quais nove $(5,9 \%)$ incluíram-se também os níveis cervicais laterais (II-V). A iodoterapia adjuvante foi utilizada em 101 (67\%) dos casos.

\subsection{RESULTADOS ANATOMOPATOLÓGICOS}

A análise anatomopatológica destes 151 carcinomas papilíferos, descreveu 84 (55,6\%) como variante clássica; 47 (31,1\%) variante folicular; dois $(1,3 \%)$ oncocíticos, dois $(1,3 \%)$ esclerosantes e um $(0,7 \%)$ não capsulado. Os $15(9,9 \%)$ demais não foram subclassififcados. O tamanho dos tumores variou de 4 a $40 \mathrm{~mm}$, com mediana de $10 \mathrm{~mm}$ e média 11,2 mm. Multifocalidade foi presente em $41(27,2 \%)$ e extensão extratireoidiana em 43 (28,5\%). Metástase linfonodal foi confirmada no exame anatomopatológico em $37(24,5 \%)$ pacientes. Apenas um paciente foi diagnosticado com metástase a distância, durante realização de pesquisa de corpo inteiro e iodoterapia adjuvante. 


\subsection{COMPARAÇÃO DA AMOSTRA DO ESTUDO COM O TOTAL DE CASOS}

Um total de 780 carcinomas papiliferos de tireoide foram tratados no A. C. Camargo Cancer Center, de 1 de janeiro de 2008 à 31 de dezembro de 2010. Estes casos representam, portanto, o perfil de atendimento do serviço naquele período. Comparando a amostra formada pelos 151 casos selecionados para este estudo com o total de casos tratados, não foram encontradas diferenças significativas de distribuição referentes às características clínicas, epidemiológicas e tratamento realizado (Tabela 2). 
Tabela 2 - Distribuição da casuística integral e casos selecionados para o estudo, de acordo com variáveis demográficas, clínicas, resultado da PAAF e terapêuticas

\begin{tabular}{|c|c|c|c|c|}
\hline \multirow[b]{2}{*}{ Variável } & \multirow[b]{2}{*}{ Categoria / Medidas } & \multicolumn{2}{|c|}{ Frequência (\%) / Medidas } & \multirow[b]{2}{*}{$\mathrm{P}$} \\
\hline & & $\begin{array}{c}\text { AMOSTRA } \\
(\mathrm{N}=151)\end{array}$ & $\begin{array}{c}\text { BANCO INICIAL } \\
(\mathrm{N}=780)\end{array}$ & \\
\hline \multirow{3}{*}{ Idade (anos) } & Variação & $14-80$ & $10-88$ & 0,54 \\
\hline & Mediana & 42,0 & 44 & \\
\hline & Média (desvio-padrão) & $42,6(13,4)$ & $44,3(13,4)$ & \\
\hline \multirow{2}{*}{ Gênero } & Feminino & $130(86,1)$ & $641(82,2)$ & 0,243 \\
\hline & Masculino & $21(13,9)$ & $139(17,8)$ & \\
\hline \multirow{4}{*}{$\begin{array}{l}\text { USG Pré- } \\
\text { Operatória }\end{array}$} & Não & $1(0,7)$ & $6(0,8)$ & \\
\hline & Uninodular & $68(45,0)$ & $340(43,6)$ & 0,749 \\
\hline & Multinodular & $82(54,3)$ & $429(55)$ & \\
\hline & Sem informação & 0 & $9(0,6)$ & \\
\hline \multirow{5}{*}{ PAAF } & Não & $10(6,7)$ & $65(8,3)$ & 0,075 \\
\hline & Benigno & $0(0)$ & $34(4,4)$ & \\
\hline & Padrão folicular & $37(24,5)$ & $217(27,8)$ & \\
\hline & Maligno & $102(67,5)$ & $456(58,5)$ & \\
\hline & Insatisfatório & $2(1,3)$ & $5(0,6)$ & \\
\hline \multirow{4}{*}{$\begin{array}{l}\text { Função } \\
\text { Tireoideana }\end{array}$} & Eutireoidismo & $124(81,5)$ & $655(84)$ & 0,483 \\
\hline & Hipotireoidismo & $23(15,2)$ & $105(13,5)$ & \\
\hline & Hipertireoidismo & $4(2,6)$ & $17(2,2)$ & \\
\hline & Sem informação & 0 & $3(0,4)$ & \\
\hline \multirow{3}{*}{$\begin{array}{l}\text { Exposição à } \\
\text { Radiação }\end{array}$} & Não & $145(96)$ & $732(93,8)$ & 0,429 \\
\hline & $\operatorname{Sim}$ & $6(4,0)$ & $22(2,8)$ & \\
\hline & Sem informação & 0 & $26(3,3)$ & \\
\hline Outro câncer & Sim & $16(10,6)$ & $77(9,9)$ & 0,786 \\
\hline \multirow{4}{*}{ História familiar } & Não & $77(51,0)$ & $390(50)$ & 0,909 \\
\hline & Câncer de tireoide & $13(8,6)$ & $66(8,5)$ & \\
\hline & Outros cânceres & $50(33,1)$ & $284(36,4)$ & \\
\hline & Tireoide + Outros & $4(2,7)$ & $13(1,7)$ & \\
\hline \multirow{6}{*}{$\begin{array}{l}\text { Estadiamento T } \\
\text { clínico }\end{array}$} & Ignorada & $7(4,6)$ & $27(3,5)$ & \\
\hline & сT0 & $1(0,7)$ & $4(0,5)$ & \\
\hline & cT1 & $118(78,1)$ & $532(68,2)$ & 0,029 \\
\hline & cT2 & $20(13,2)$ & $173(22,2)$ & \\
\hline & cT3 & $8(5,3)$ & $30(3,8)$ & \\
\hline & cTx & $4(2,7)$ & $41(5,3)$ & \\
\hline \multirow{3}{*}{$\begin{array}{l}\text { Estadiamento } \mathrm{N} \\
\text { clínico }\end{array}$} & $\mathrm{cNO}$ & $142(94,0)$ & $752(96,4)$ & 0,172 \\
\hline & $\mathrm{cN} 1$ & $2(1,3)$ & $6(0,8)$ & \\
\hline & $\mathrm{cN} 2$ & $7(4,6)$ & $22(2,8)$ & \\
\hline \multirow{4}{*}{$\begin{array}{l}\text { Tipo de } \\
\text { tireoidectomia }\end{array}$} & Total & $137(90,7)$ & $703(90,1)$ & \\
\hline & Parcial & $1(0,7)$ & $13(1,7)$ & 0,385 \\
\hline & Ampliada & $7(4,6)$ & $21(2,7)$ & \\
\hline & $\begin{array}{l}\text { Parcial seguida de } \\
\text { totalização }\end{array}$ & $6(4)$ & $33(5,5)$ & \\
\hline \multirow{4}{*}{$\begin{array}{l}\text { Esvaziamento } \\
\text { Cervical }\end{array}$} & Não & $115(76,2)$ & $636(81,5)$ & 0,141 \\
\hline & Central & $27(17,9)$ & $120(15,4)$ & \\
\hline & Lateral & $1(0,7)$ & $2(0,3)$ & \\
\hline & Central + Lateral & $8(5,3)$ & $22(2,8)$ & \\
\hline \multirow{2}{*}{$\begin{array}{l}\text { lodoterpia pós- } \\
\text { operatória }\end{array}$} & Não & $50(33,1)$ & $246(31,6)$ & 0,704 \\
\hline & Sim & $101(67,0)$ & $534(68,5)$ & \\
\hline
\end{tabular}


Entretanto, como esperado, a comparação de variáveis patológicas mostra diferenças com a amostra do estudo, compreendendo um número relativo significativamente maior de casos com extensão extratireoidiana ( $28,5 \%$ versus $15 \%)$ e metástases linfonodais $(23,8 \%$ versus $14,4 \%)$, com consequentes estadiamento $\mathrm{pT}$ e $\mathrm{pN}$ mais avançados. Curiosamente, a multifocalidade foi significativamente menos frequente na amostra do estudo $(27,2$ versus $36,4 \%)$ (Tabela 3$)$.

Tabela 3 - Distribuição da casuística integral e casos selecionados para o estudo, de acordo com variáveis anatomopatológicas

\begin{tabular}{|c|c|c|c|c|}
\hline \multirow[b]{2}{*}{ Variável } & \multirow[b]{2}{*}{ Categoria / Medidas } & \multicolumn{2}{|c|}{ Frequência (\%) / Medidas } & \multirow[b]{2}{*}{$\mathrm{P}$} \\
\hline & & AMOSTRA (N=151) & BANCO INICIAL N=780 & \\
\hline \multirow{2}{*}{ Multifocalidade } & Não & $110(72,8)$ & $496(63,6)$ & \multirow[t]{2}{*}{0,029} \\
\hline & Sim & $41(27,2)$ & $284(36,4)$ & \\
\hline \multirow{6}{*}{$\begin{array}{l}\text { Extensão } \\
\text { extratireoidea }\end{array}$} & Não & $108(71,5)$ & $663(85)$ & \multirow[t]{6}{*}{$<0,0001$} \\
\hline & Gordura & $36(23,8)$ & $97(12,4)$ & \\
\hline & Musculo & $1(0,7)$ & $5(0,6)$ & \\
\hline & Traqueia & $2(1,3)$ & $3(0,4)$ & \\
\hline & Outro & $3(2,0)$ & $11(1,4)$ & \\
\hline & $\begin{array}{c}\text { Gordura + Traqueia + } \\
\text { Outro }\end{array}$ & $1(0,7)$ & $1(0,1)$ & \\
\hline \multirow{5}{*}{$\begin{array}{l}\text { Estadiamento T } \\
\text { patológico }\end{array}$} & pT1a & $73(48,3)$ & $431(55,2)$ & \multirow[t]{5}{*}{0,007} \\
\hline & $\mathrm{pT} 1 \mathrm{~b}$ & $26(17,2)$ & $156(20)$ & \\
\hline & pT2 & $9(6,0)$ & $64(8,2)$ & \\
\hline & pT3 & $37(24,5)$ & $111(14,2)$ & \\
\hline & pT4a & $6(4,0)$ & $18(2,4)$ & \\
\hline \multirow{3}{*}{$\begin{array}{l}\text { Estadiamento } \mathrm{N} \\
\text { patológico }\end{array}$} & pNO & $115(76,2)$ & $668(85,6)$ & \multirow[t]{3}{*}{0,014} \\
\hline & $\mathrm{pN} 1 \mathrm{a}$ & $28(18,5)$ & $88(11,3)$ & \\
\hline & $\mathrm{pN} 1 \mathrm{~b}$ & $8(5,3)$ & $24(3,1)$ & \\
\hline
\end{tabular}




\subsection{SEGUIMENTO}

O tempo de seguimento médio foi de 65,1 meses (variando de 14 a 87 meses). Neste período, foram observadas nove (6\%) recorrências, com tempo até ocorrência da recidiva, variando de 0,9 a 62,5 meses (mediana 31 meses, média 29,7 meses). Todos as nove recorrências ocorreram em tumores que apresentavam um destes dois fatores (sete apresentavam metástase linfonodal e extensão extratireoidiana; um apresentava mestástase linfonodal, mas não extensão extratireoidiana; um apresentava extensão extratireoidiana, mas não metástase linfonodal). Todos haviam sido tratados com tireoidectomia total (ou ampliada) com esvaziamento cervical e iodoterapia adjuvante (à exceção de um caso que não foi submetido ao esvaziamento cervical). Oito recidivas foram cervicais e uma a distância. Ocorreram dois óbitos por outras causas, e 14 (9,3\%) perdas de seguimento tardias (após 2 anos de seguimento). Além destes, dois pacientes estão vivos, mas com doença em atividade (estável). Os demais $133(88,1 \%)$ estão vivos e sem doença, mantendo seguimento.

Em 5 anos, a sobrevida livre de recorrência nesta amostra foi $94,4 \%$ (Figura 8) e a sobrevida global foi 99,3\% (Figura 9). 


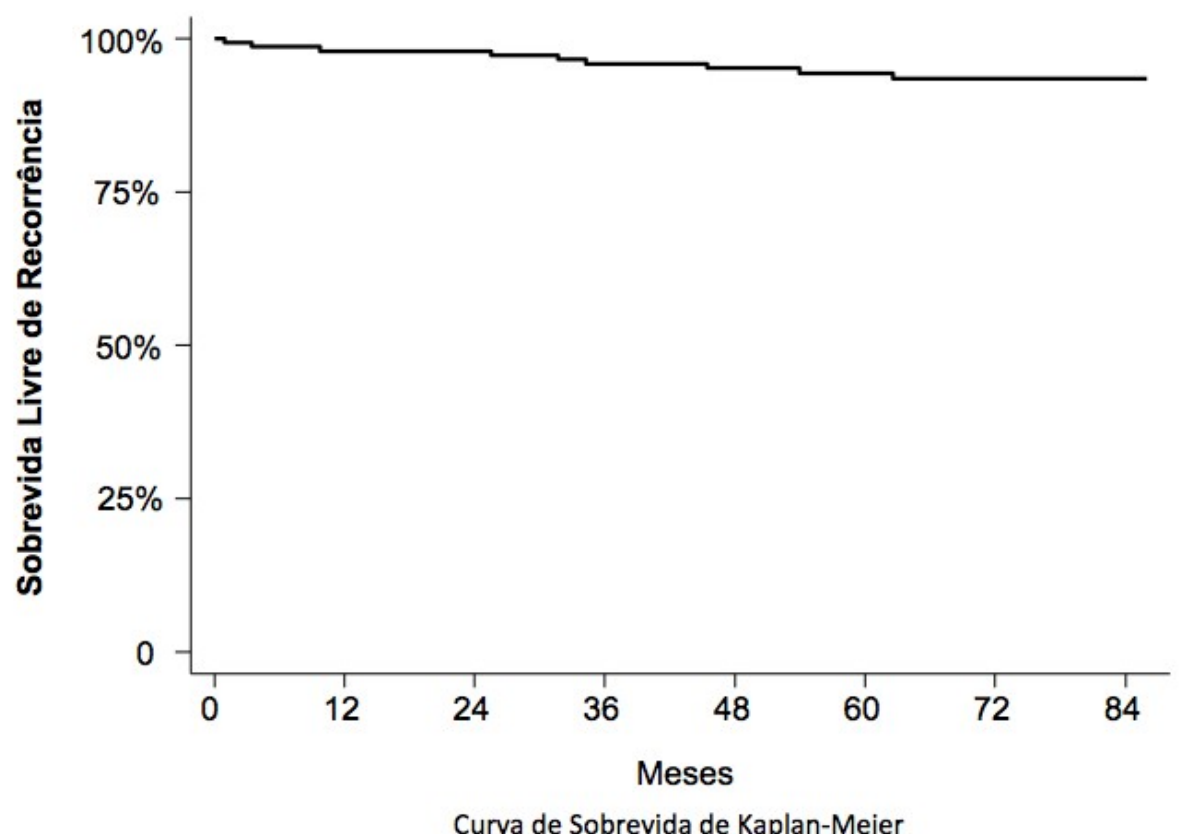

Figura 8 - Sobrevida livre de recorrência dos 151 casos de carcinoma papilífero estudados

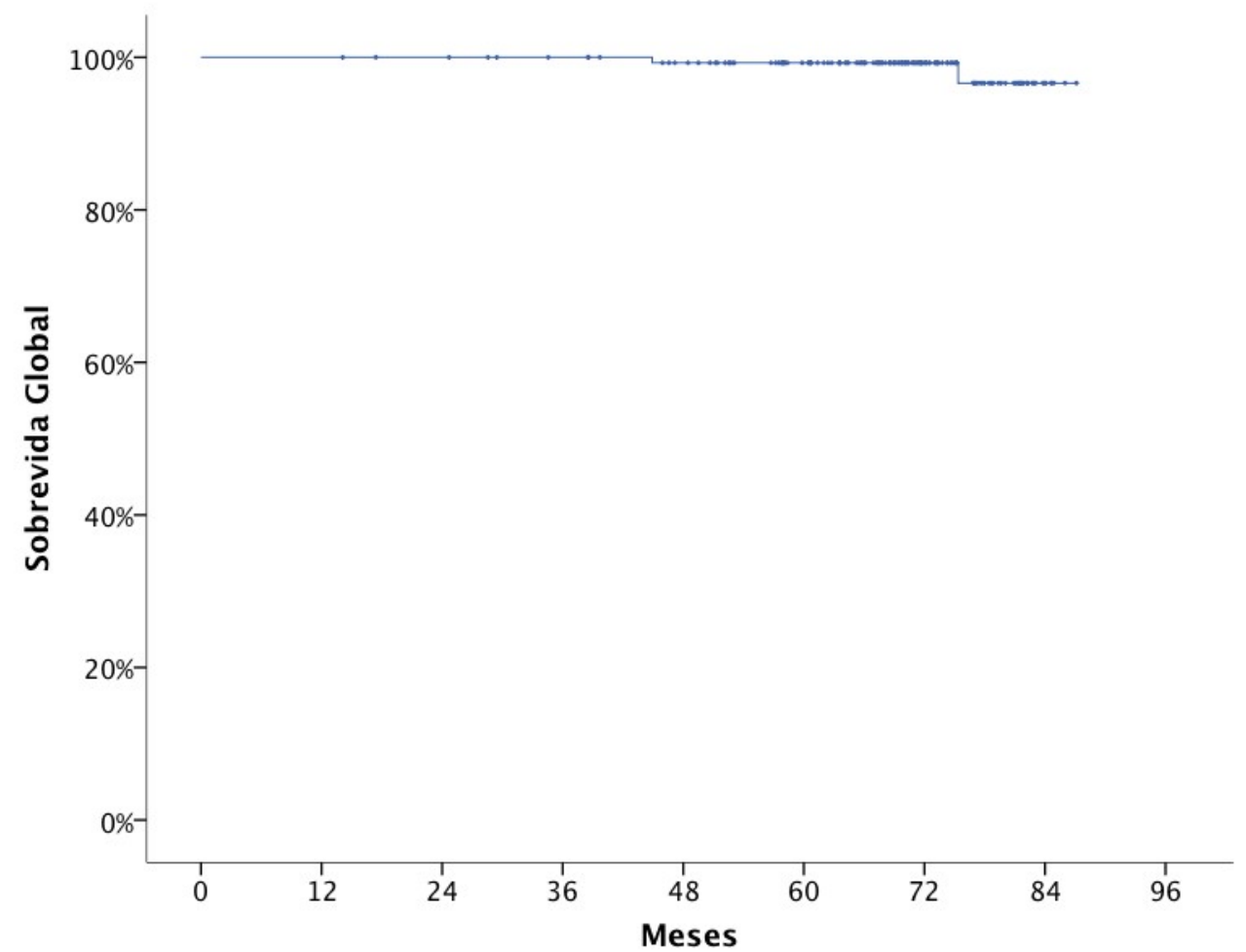

Figura 9 - Sobrevida global dos 151 casos de carcinoma papilífero estudados 
Como esperado, alguns fatores patológicos demonstraram impacto significativo na incidência de recorrências e consequente impacto negativo na sobrevida livre de recorrência. Neste cenário, destacaram-se a existência de metástase linfonodal confirmada por análise patológica $(\mathrm{pN}+)$ e presença de extensão extratireoidiana, associadas ou não (Figuras 10, 11, 12). Nesta amostra, todas as recorrências ocorreram em pacientes com extensão extratireoidiana e/ou metástase linfonodal (confirmados após o tratamento cirúrgico inicial) e, nestes pacientes, a sobrevida livre de recorrência em 5 anos foi $85,6 \%$. Comparando ao grupo sem estes fatores, em que a sobrevida livre de recorrência em 5 anos foi 100\%, encontramos uma diferença estatisticamente significativa $(p<0,001)$.

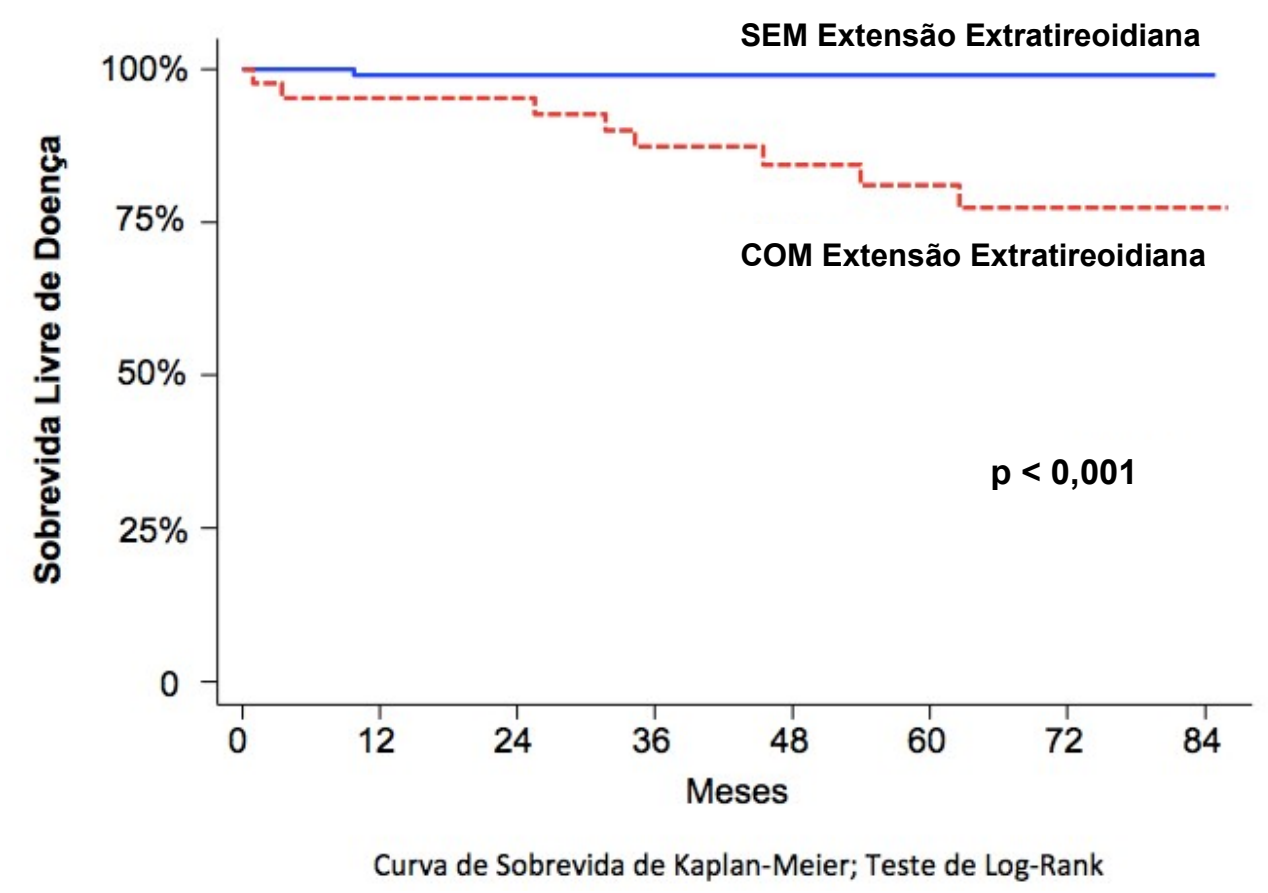

Figura 10 - Curvas de sobrevida, comparando tumores com e sem extensão extratireoidiana 


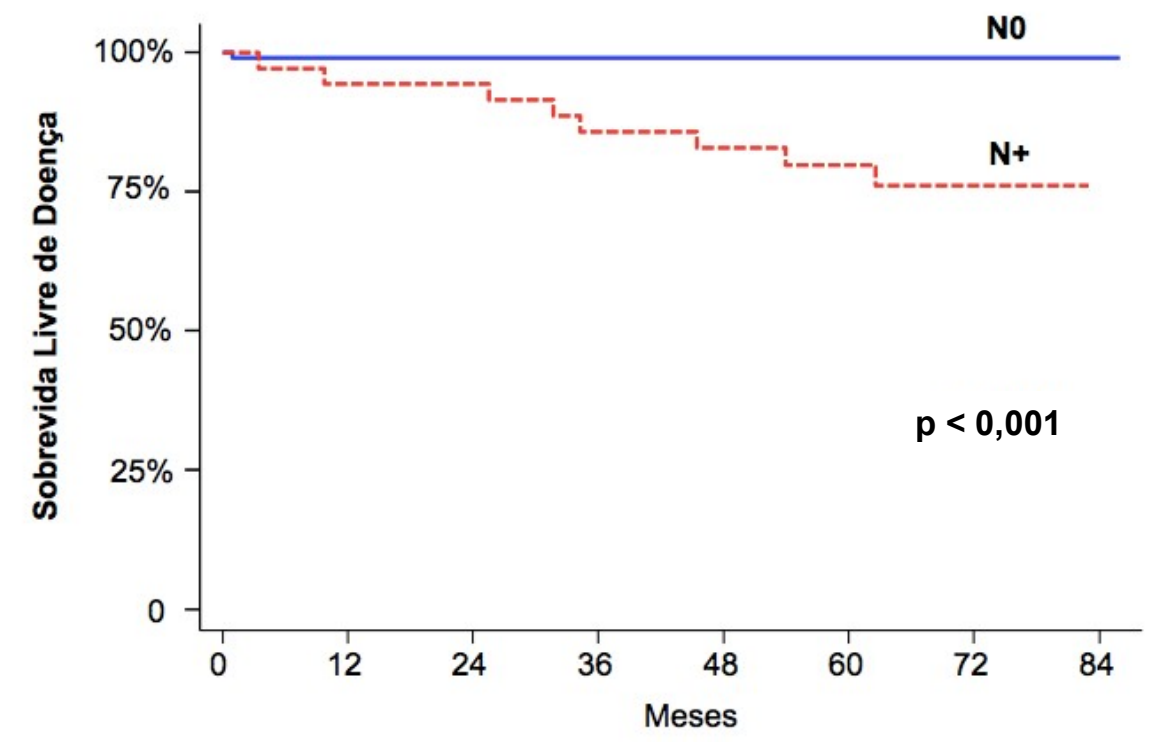

Curva de Sobrevida de Kaplan-Meier; Teste de Log-Rank

Figura 11 - Curvas de sobrevida, comparando tumores com e sem metástase linfonodal



Curva de Sobrevida de Kaplan-Meier; Teste de Log-Rank

Figura 12 - Curvas de sobrevida, comparando tumores com extensão extratireoidlana ou metástase linfonodal com tumores sem extensão extratireoidlana e sem metástase linfonodal 


\subsection{MARCADORES IMUNO-HISTOQUÍMICOS}

4.6.1 Caracterização do microambiente imune (leitura de marcadores)

As medidas adquiridas com base na leitura dos marcadores pelos anatomopatologistas, de acordo com a metodologia determinada, expressas pelo número de células marcadas nos campos microscópicos, são apresentadas nos dados da Tabela 4 e nas Figuras 13-19. 
Tabela 4 - Número de células marcadas por campos microscópicos

\begin{tabular}{|c|c|c|}
\hline Variável & Medidas & Medidas \\
\hline CD68t & $\begin{array}{l}\mathrm{N} \\
\text { Variação } \\
\text { Mediana } \\
\text { Média (desvio-padrão) }\end{array}$ & $\begin{array}{c}151 \\
0-68 \\
11 \\
14,6(12,5)\end{array}$ \\
\hline CD68nt & $\begin{array}{l}\mathrm{N} \\
\text { Variação } \\
\text { Mediana } \\
\text { Média (desvio-padrão) }\end{array}$ & $\begin{array}{c}150 \\
0-23 \\
4 \\
4,5(3,9)\end{array}$ \\
\hline $\mathrm{CD} 4 \mathrm{t}$ & $\begin{array}{l}\mathrm{N} \\
\text { Variação } \\
\text { Mediana } \\
\text { Média (desvio-padrão) }\end{array}$ & $\begin{array}{c}151 \\
0-20 \\
5 \\
5,5(4,0)\end{array}$ \\
\hline CD4nt & $\begin{array}{l}\mathrm{N} \\
\text { Variação } \\
\text { Mediana } \\
\text { Média (desvio-padrão) }\end{array}$ & $\begin{array}{c}151 \\
0-20 \\
3 \\
3,3(2,9)\end{array}$ \\
\hline CD8t & $\begin{array}{l}\mathrm{N} \\
\text { Variação } \\
\text { Mediana } \\
\text { Média (desvio-padrão) }\end{array}$ & $\begin{array}{c}151 \\
0-20 \\
5 \\
6,8(4,5)\end{array}$ \\
\hline CD8nt & $\begin{array}{l}\mathrm{N} \\
\text { Variação } \\
\text { Mediana } \\
\text { Média (desvio-padrão) }\end{array}$ & $\begin{array}{c}151 \\
0-20 \\
5 \\
5,4(4,4)\end{array}$ \\
\hline CD163t & $\begin{array}{l}\mathrm{N} \\
\text { Variação } \\
\text { Mediana } \\
\text { Média (desvio-padrão) }\end{array}$ & $\begin{array}{c}151 \\
0-18 \\
5 \\
5,6(4,0)\end{array}$ \\
\hline CD163nt & $\begin{array}{l}\mathrm{N} \\
\text { Variação } \\
\text { Mediana } \\
\text { Média (desvio-padrão) }\end{array}$ & $\begin{array}{c}151 \\
0-14 \\
2 \\
2,3(2,2)\end{array}$ \\
\hline Foxpt3t & $\begin{array}{l}\text { N } \\
\text { Variação } \\
\text { Mediana } \\
\text { Média (desvio-padrão) }\end{array}$ & $\begin{array}{c}77 \\
0-12 \\
0 \\
0,69(2,1)\end{array}$ \\
\hline Foxp3nt & $\begin{array}{l}\mathrm{N} \\
\text { Variação } \\
\text { Mediana } \\
\text { Média (desvio-padrão) }\end{array}$ & $\begin{array}{c}77 \\
0-10 \\
0 \\
0,44(1,5)\end{array}$ \\
\hline Ki67t & $\begin{array}{l}\mathrm{N} \\
\text { Variação } \\
\text { Mediana } \\
\text { Média (desvio-padrão) }\end{array}$ & $\begin{array}{c}151 \\
0-125 \\
15 \\
19,5(18,7)\end{array}$ \\
\hline Ki67nt & $\begin{array}{l}\mathrm{N} \\
\text { Variação } \\
\text { Mediana } \\
\text { Média (desvio-padrão) }\end{array}$ & $\begin{array}{c}151 \\
0-35 \\
3 \\
4,4(4,6)\end{array}$ \\
\hline HLADRt & $\begin{array}{l}\mathrm{N} \\
\text { Variação } \\
\text { Mediana } \\
\text { Média (desvio-padrão) }\end{array}$ & $\begin{array}{c}145 \\
10-142 \\
67 \\
70(28,8)\end{array}$ \\
\hline HLADRnt & $\begin{array}{l}\text { N } \\
\text { Variação } \\
\text { Mediana } \\
\text { Média (desvio-padrão) }\end{array}$ & $\begin{array}{c}145 \\
1-53 \\
13 \\
15,3(10,4)\end{array}$ \\
\hline
\end{tabular}




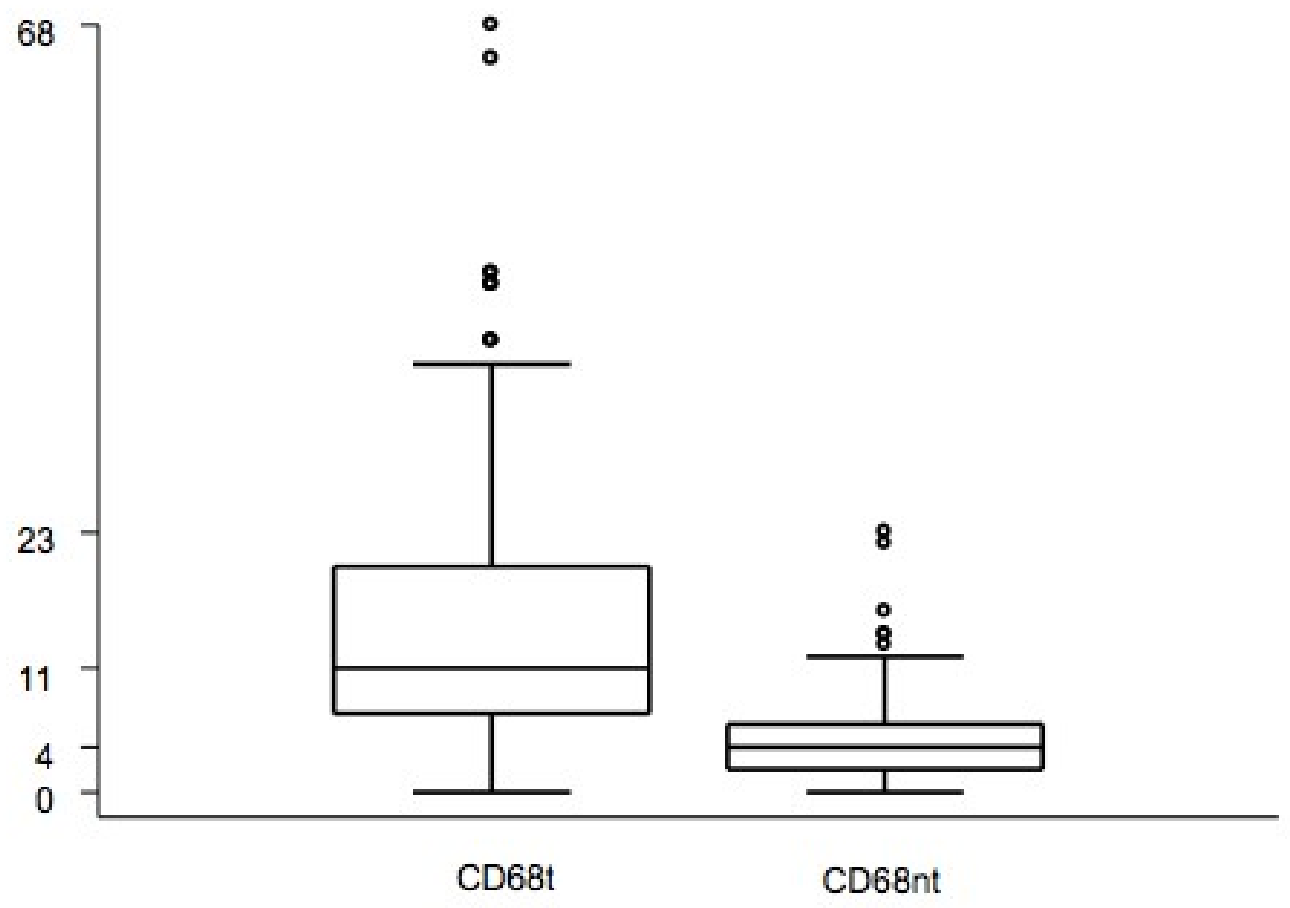

Figura 13 - Distribuição das leituras de densidade de células marcadas por anti-CD68 (Boxplot)

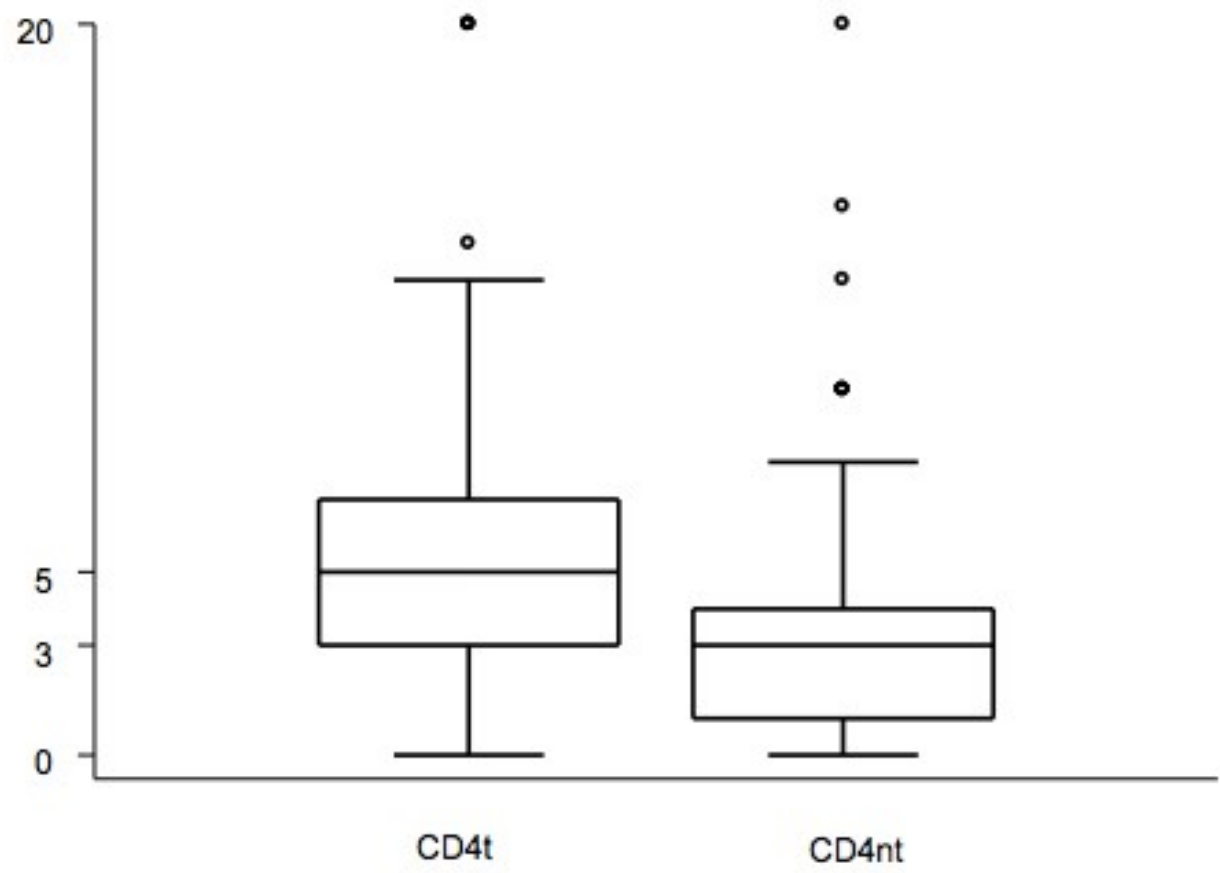

Figura 14 - Distribuição das leituras de densidade de células marcadas por anti-CD4 (Boxplot) 


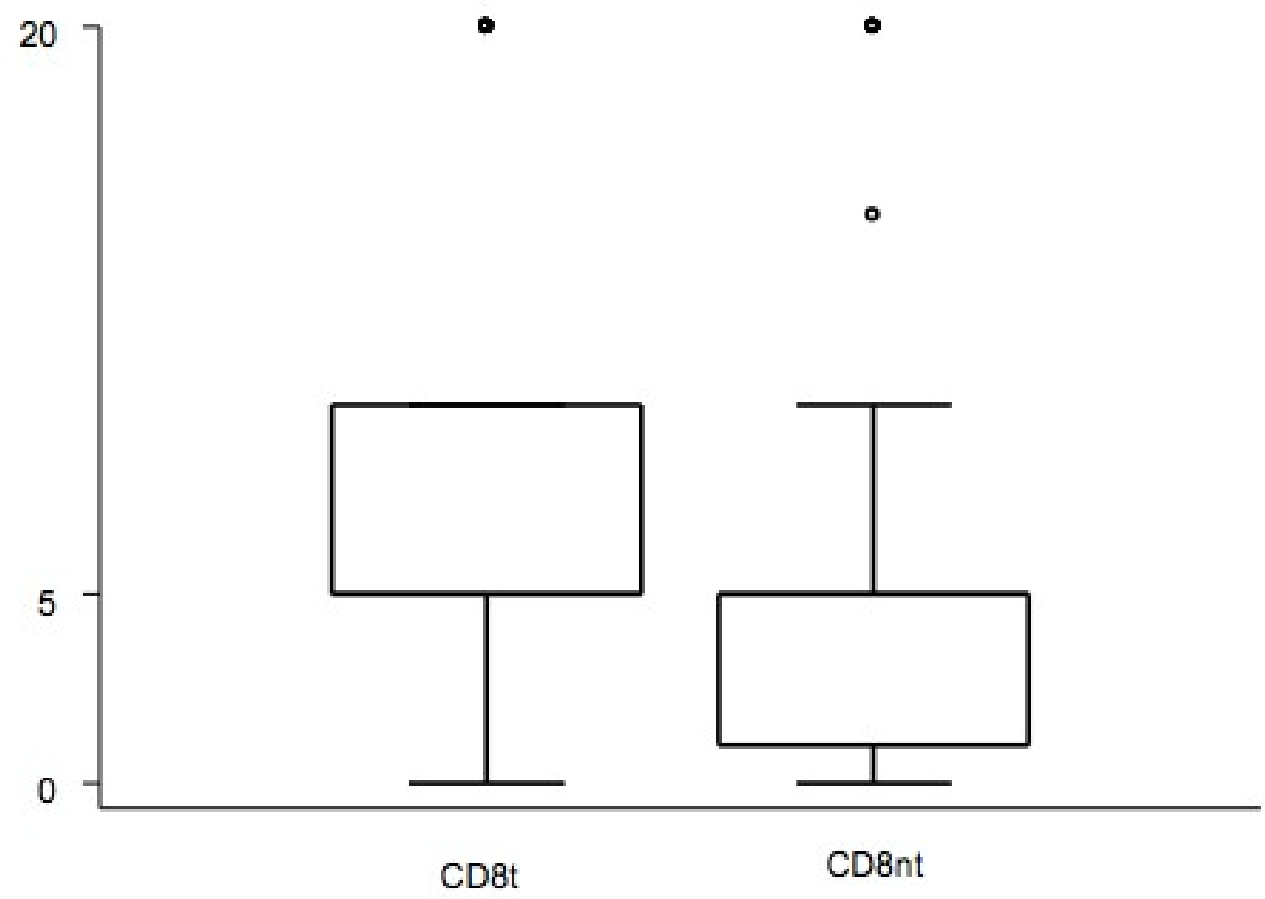

Figura 15 - Distribuição das leituras de densidade de células marcadas por anti-CD8 (Boxplot)

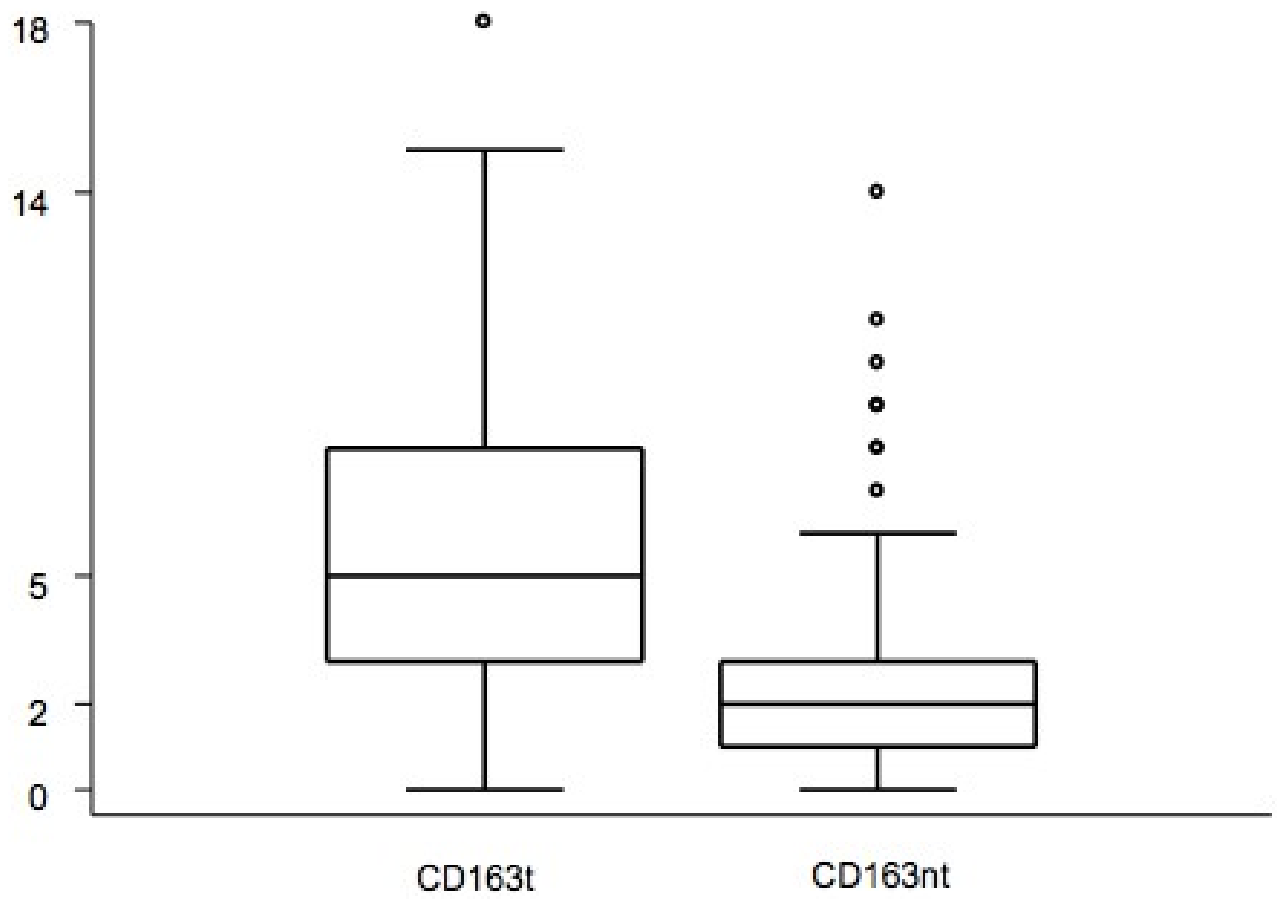

Figura 16 - Distribuição das leituras de densidade de células marcadas por anti-CD163 (Boxplot) 


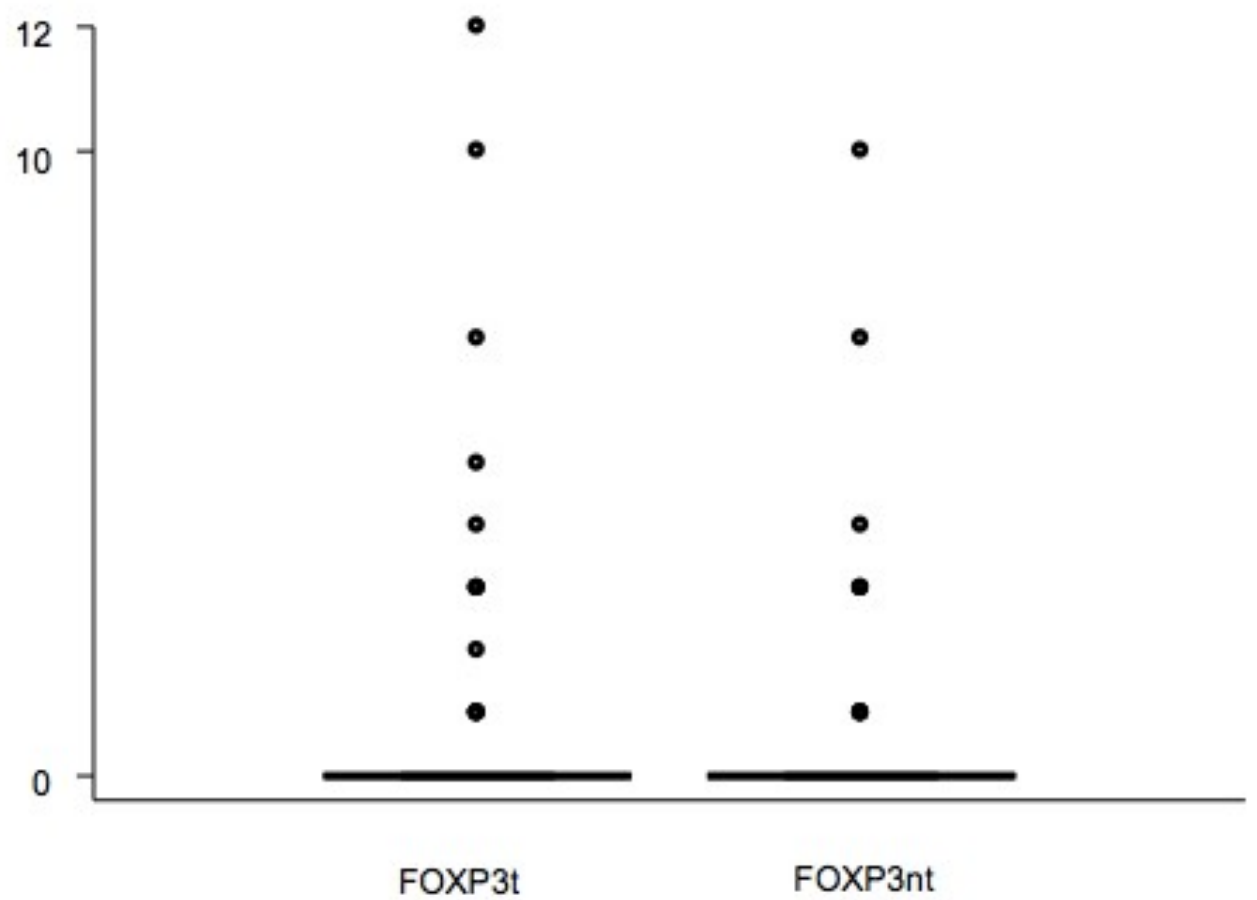

Figura 17 - Distribuição das leituras de densidade de células marcadas por anti-Foxp3 (Boxplot)

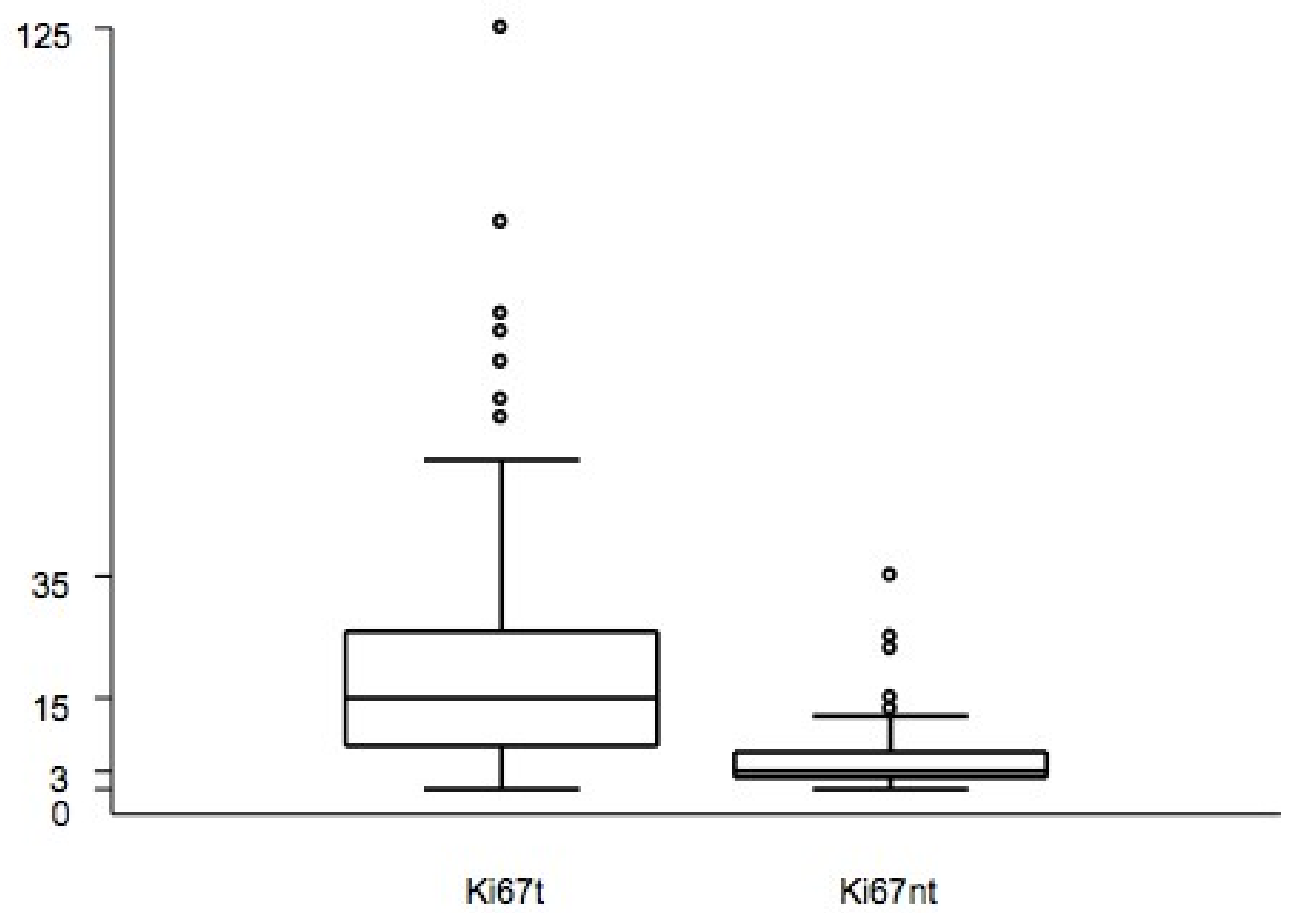

Figura 18 - Distribuição das leituras de densidade de células marcadas por anti-Ki-67 (Boxplot) 


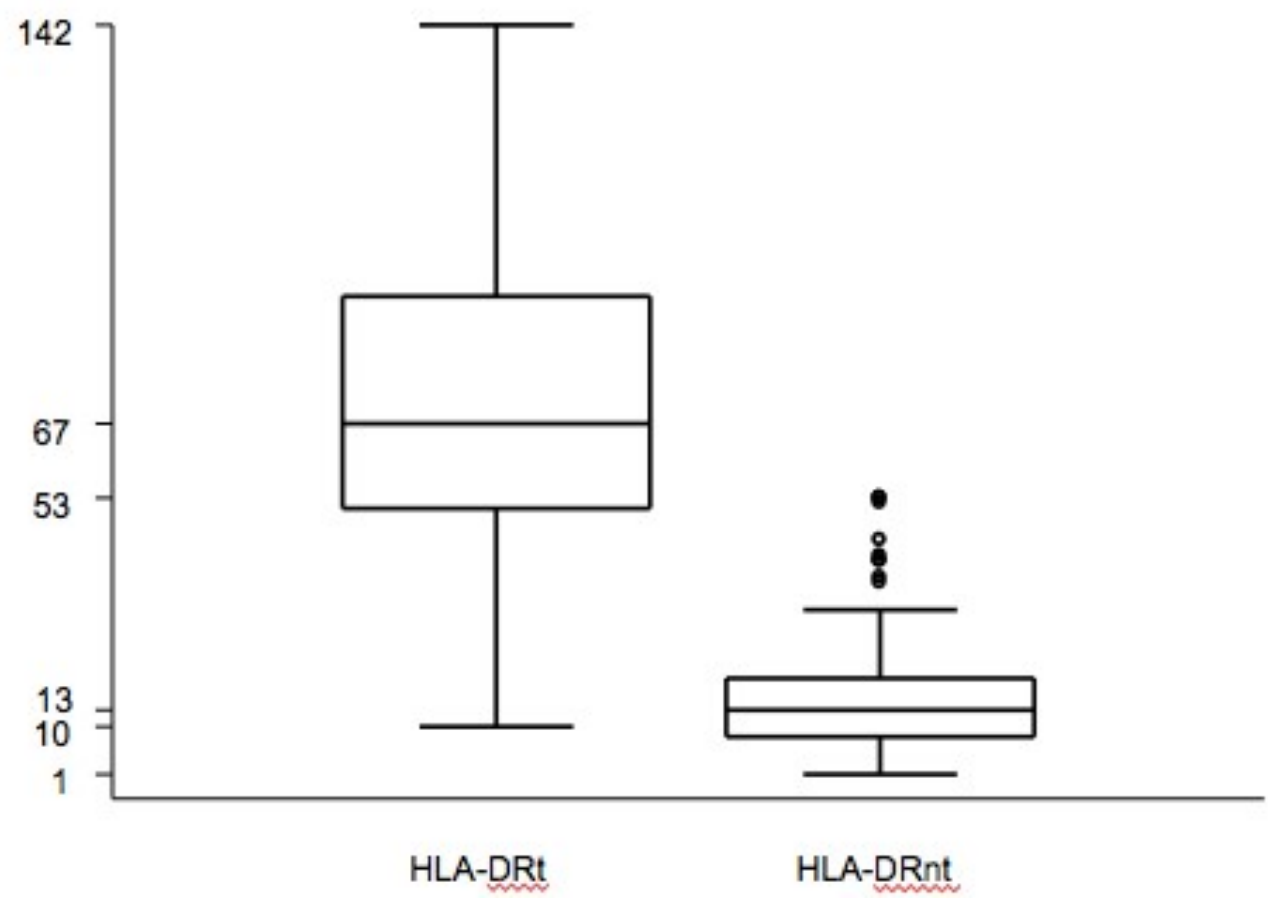

Figura 19 - Distribuição das leituras de densidade de células marcadas por anti-HLA-DR (Boxplot)

O teste de correlação entre todos os marcadores foi realizado, mostrando correlação positiva significativa entre a medição de todos os marcadores tumorais com seus respectivos não tumorais, como demonstrado nos dados da tabela abaixo. Além destas, duas outras correlações mostraram-se significativas:

- Correlação negativa $(-0,173 ; p=0,034)$ entre a densidade do CD68nt e a densidade do CD4nt;

- Correlação positiva $(0,218 ; p=0,007)$ entre as densidades CD68 e Ki67, em tecido tumoral; 
Tabela 5 - Coeficiente de correlação de Spearman entre marcadores

\begin{tabular}{|c|c|c|c|c|c|c|c|c|c|c|c|c|c|}
\hline & CD68t & CD68nt & CD4t & CD4nt & CD8t & CD8nt & CD163t & CD163nt & Foxpt3t & Foxpt3nt & Ki67t & Ki67nt & $\begin{array}{l}\text { HLA- } \\
\text { DRt }\end{array}$ \\
\hline \multicolumn{14}{|l|}{ CD68t } \\
\hline \multirow[t]{2}{*}{ CD68nt } & 0,545 & & & & & & & & & & & & \\
\hline & $<0,001^{*}$ & & & & & & & & & & & & \\
\hline \multirow[t]{2}{*}{ CD4t } & $-0,091$ & $-0,054$ & & & & & & & & & & & \\
\hline & 0,264 * & $0,514^{*}$ & & & & & & & & & & & \\
\hline \multirow[t]{2}{*}{ CD4nt } & $-0,133$ & $-0,173$ & 0,421 & & & & & & & & & & \\
\hline & $0,104^{*}$ & $0,034^{*}$ & $<0,001^{*}$ & & & & & & & & & & \\
\hline \multirow[t]{2}{*}{ CD8t } & $-0,066$ & $-0,115$ & 0,056 & $-0,018$ & & & & & & & & & \\
\hline & $0,420^{*}$ & $0,162^{*}$ & $0,495^{*}$ & $0,824^{*}$ & & & & & & & & & \\
\hline \multirow[t]{2}{*}{ CD8nt } & 0,054 & -103 & $-0,015$ & $-0,028$ & 0,540 & & & & & & & & \\
\hline & $0,511^{*}$ & $0,208^{\star}$ & $0,852^{*}$ & $0,733^{*}$ & $<0,001^{*}$ & & & & & & & & \\
\hline \multirow[t]{2}{*}{ CD163t } & 0,043 & $-0,082$ & 0,003 & $-0,022$ & 0,007 & $-0,014$ & & & & & & & \\
\hline & $0,597^{*}$ & $0,317^{\star}$ & $0,967^{*}$ & $0,790^{*}$ & $0,936^{*}$ & $0,862^{*}$ & & & & & & & \\
\hline \multirow[t]{2}{*}{ CD163nt } & $-0,035$ & $-0,087$ & $-0,061$ & 0,035 & 0,044 & 0,125 & 0,479 & & & & & & \\
\hline & $0,667^{*}$ & $0,292^{*}$ & $0,454^{*}$ & $0,668^{*}$ & $0,587^{*}$ & $0,125^{*}$ & $<0,001^{*}$ & & & & & & \\
\hline \multirow[t]{2}{*}{ Foxpt3t } & $-0,031$ & $-0,095$ & $-0,108$ & 0,046 & 0,093 & 0,027 & $-0,020$ & 0,020 & & & & & \\
\hline & $0,786^{*}$ & $0,413^{*}$ & $0,349^{*}$ & $0,891^{*}$ & $0,423^{*}$ & $0,813^{*}$ & $0,863^{*}$ & $0,866^{*}$ & & & & & \\
\hline \multirow[t]{2}{*}{ Foxp3nt } & $-0,011$ & 0,026 & $-0,132$ & 0,066 & 0,060 & $-0,045$ & $-0,047$ & $-0,038$ & 0,795 & & & & \\
\hline & $0,923^{*}$ & $0,820^{*}$ & $0,253^{*}$ & $0,571^{*}$ & $0,604^{*}$ & $0,695^{*}$ & $0,683^{*}$ & 0,742 & $<0,001^{*}$ & & & & \\
\hline \multirow[t]{2}{*}{ Ki67t } & 0,218 & 0,081 & 0,107 & $-0,016$ & $-0,087$ & 0,014 & $-0,050$ & $-0,134$ & $-0,017$ & $-0,048$ & & & \\
\hline & $0,007^{*}$ & $0,327^{\star}$ & $0,193^{*}$ & $0,845^{\star}$ & $0,288^{*}$ & $0,868^{*}$ & $0,543^{*}$ & $0,100^{*}$ & $0,886^{*}$ & $0,679^{*}$ & & & \\
\hline \multirow[t]{2}{*}{ Ki67nt } & 0,010 & 0,037 & 0,005 & $-0,008$ & $-0,007$ & 0,116 & 0,013 & 0,008 & $-0,002$ & 0,084 & 0,389 & & \\
\hline & $0,898^{*}$ & $0,652^{*}$ & $0,953^{*}$ & $0,923^{*}$ & $0,930^{*}$ & $0,157^{*}$ & $0,877^{*}$ & $0,921^{*}$ & $0,989^{*}$ & $0,469^{*}$ & $<0,001^{*}$ & & \\
\hline \multirow[t]{2}{*}{ HLA-DRt } & 0,023 & $-0,003$ & $-0,025$ & 0,099 & 0,114 & $-0,074$ & $-0,029$ & 0,117 & 0,114 & 0,053 & $-0,092$ & $-0,043$ & \\
\hline & 0,782 * & $0,968^{\star}$ & $0,769^{*}$ & $0,233^{*}$ & $0,173^{*}$ & $0,377^{*}$ & $0,728^{*}$ & $0,162^{*}$ & $0,335^{*}$ & $0,658^{*}$ & $0,269^{*}$ & $0,611^{*}$ & \\
\hline \multirow[t]{2}{*}{ HLA-DRnt } & 0,057 & 0,153 & 0,084 & 0,021 & 0,045 & 0,029 & 0,000 & 0,157 & $-0,005$ & 0,022 & $-0,070$ & 0,079 & 0,403 \\
\hline & $0,499^{*}$ & $0,071^{*}$ & $0,319^{*}$ & $0,805^{*}$ & $0,594^{*}$ & $0,729^{*}$ & $0,999^{*}$ & $0,062^{*}$ & $0,965^{*}$ & $0.854^{*}$ & $0,410^{*}$ & 0,352 * & $<0,001^{*}$ \\
\hline
\end{tabular}

*p-valor

\subsubsection{Relação entre marcadores e fatores clínico-patológicos}

Foram exploradas possíveis associações entre os marcadores e diversas variáveis clínicas e patológicas, com foco especial em idade, extensão extratireoidiana e metástases linfonodais. 


\subsubsection{Relação entre marcadores e faixa etária}

Não encontramos diferenças significativas entre as densidades de nenhum marcador analisado nas diferentes faixas etárias, mesmo usando diferentes pontos de corte (inferior e superior a 45 anos ou 55 anos) (Tabelas 6 e 7 ).

Tabela 6 - Distribuição da densidade de células marcadas por faixa etária (ponto de corte 45 anos)

\begin{tabular}{|c|c|c|c|c|}
\hline Variável & Medidas & $\begin{array}{l}\leq 45 \text { anos } \\
\text { Freq. (\%) }\end{array}$ & $\begin{array}{l}>45 \text { anos } \\
\text { Freq. (\%) }\end{array}$ & $\mathrm{p}$-valor \\
\hline \multirow{2}{*}{ CD68t } & $\leq 11$ & $42(55,3)$ & $34(44,7)$ & 0,673 \\
\hline & $>11$ & $44(58,7)$ & $31(41,3)$ & \\
\hline \multirow{2}{*}{ CD68nt } & $\leq 4$ & $53(55,8)$ & $42(44,2)$ & 0,615 \\
\hline & $>4$ & $33(60,0)$ & $22(40,0)$ & \\
\hline \multirow{2}{*}{ CD4t } & $\leq 5$ & $51(56,0)$ & $40(44,0)$ & 0,781 \\
\hline & $>5$ & $35(58,3)$ & $25(41,7)$ & \\
\hline \multirow{2}{*}{ CD4nt } & $\leq 2$ & $39(53,4)$ & $34(46,6)$ & 0,397 \\
\hline & $>2$ & $47(60,3)$ & $31(39,7)$ & \\
\hline \multirow{2}{*}{ CD8t } & $\leq 5$ & $53(57,6)$ & $39(42,4)$ & 0,839 \\
\hline & $>5$ & $33(55,9)$ & $26(44,1)$ & \\
\hline \multirow{2}{*}{ CD8nt } & $\leq 4$ & $26(61,9)$ & $16(38,1)$ & 0,446 \\
\hline & $>4$ & $60(55,0)$ & $49(45,0)$ & \\
\hline \multirow{2}{*}{ CD163t } & $\leq 5$ & $50(56,2)$ & $39(43,8)$ & 0,818 \\
\hline & $>5$ & $36(58,1)$ & $26(41,9)$ & \\
\hline \multirow{2}{*}{ CD163nt } & $\leq 2$ & $56(57,1)$ & $42(42,9)$ & 0,949 \\
\hline & $>2$ & $30(56,6)$ & $23(43,4)$ & \\
\hline \multirow{2}{*}{ Foxpt3t } & $\leq 0$ & $40(62,5)$ & $24(37,5)$ & 0,756 * \\
\hline & $>0$ & $7(53,8)$ & $6(46,2)$ & \\
\hline \multirow{2}{*}{ Foxp3nt } & $\leq 0$ & $41(61,2)$ & $26(38,8)$ & 0,999 * \\
\hline & $>0$ & $6(60,0)$ & $4(40,0)$ & \\
\hline \multirow{2}{*}{ Ki67t } & $\leq 15$ & $42(54,6)$ & $35(45,4)$ & 0,542 \\
\hline & $>15$ & $44(59,5)$ & $30(40,5)$ & \\
\hline \multirow{2}{*}{ Ki67nt } & $\leq 3$ & $43(53,8)$ & $37(46,2)$ & 0,399 \\
\hline & $>3$ & $43(60,6)$ & $28(39,4)$ & \\
\hline \multirow{2}{*}{ HLADRt } & $\leq 67$ & $47(64,4)$ & $26(35,6)$ & 0,080 \\
\hline & $>67$ & $36(50,0)$ & $36(50,0)$ & \\
\hline \multirow{2}{*}{ HLADRnt } & $\leq 13$ & $42(56,0)$ & $33(44,0)$ & 0,791 \\
\hline & $>13$ & $39(58,2)$ & $28(41,8)$ & \\
\hline
\end{tabular}

p-valor obtido pelo Teste de Frequências do Qui-quadrado

* $p$-valor obtido pelo Teste Exato de Fisher 
Tabela 7 - Distribuição da densidade de células marcadas por faixa etária (ponto de corte 55 anos)

\begin{tabular}{|c|c|c|c|c|}
\hline Variável & Medidas & $\begin{array}{l}\leq 55 \text { anos } \\
\text { Freq. (\%) }\end{array}$ & $\begin{array}{l}>55 \text { anos } \\
\text { Freq. (\%) }\end{array}$ & $\mathrm{p}$-valor \\
\hline \multirow{2}{*}{ CD68t } & $\leq 11$ & $64(84,2)$ & $12(15,8)$ & \multirow[t]{2}{*}{0,799} \\
\hline & $>11$ & $62(82,7)$ & $13(17,3)$ & \\
\hline \multirow{2}{*}{ CD68nt } & $\leq 4$ & $81(85,3)$ & $14(14,7)$ & \multirow[t]{2}{*}{0,579} \\
\hline & $>4$ & $45(81,8)$ & $10(18,2)$ & \\
\hline \multirow{2}{*}{ CD4t } & $\leq 5$ & $76(83,5)$ & $15(16,5)$ & \multirow[t]{2}{*}{0,976} \\
\hline & $>5$ & $50(83,3)$ & $10(16,7)$ & \\
\hline \multirow{2}{*}{ CD4nt } & $\leq 2$ & $58(79,4)$ & $15(20,6)$ & \multirow[t]{2}{*}{0,202} \\
\hline & $>2$ & $68(87,2)$ & $10(12,8)$ & \\
\hline \multirow{2}{*}{ CD8t } & $\leq 5$ & $77(83,7)$ & $15(16,3)$ & \multirow[t]{2}{*}{0,917} \\
\hline & $>5$ & $49(83,0)$ & $10(17)$ & \\
\hline \multirow{2}{*}{ CD8nt } & $\leq 4$ & $38(90,5)$ & $4(9,5)$ & \multirow[t]{2}{*}{0,149} \\
\hline & $>4$ & $88(80,7)$ & $21(19,3)$ & \\
\hline \multirow{2}{*}{ CD163t } & $\leq 5$ & $74(83,2)$ & $15(16,8)$ & \multirow[t]{2}{*}{0,906} \\
\hline & $>5$ & $52(83,9)$ & $10(16,1)$ & \\
\hline \multirow{2}{*}{ CD163nt } & $\leq 2$ & $82(83,7)$ & $16(16,3)$ & \multirow[t]{2}{*}{0,918} \\
\hline & $>2$ & $44(83,0)$ & $9(17)$ & \\
\hline \multirow{2}{*}{ Foxpt3t } & $\leq 0$ & $57(89,1)$ & $7(10,9)$ & \multirow[t]{2}{*}{0,359 * } \\
\hline & $>0$ & $10(76,9)$ & $3(23,1)$ & \\
\hline \multirow{2}{*}{ Foxp3nt } & $\leq 0$ & $60(89,6)$ & $7(10,4)$ & \multirow[t]{2}{*}{$0,117^{*}$} \\
\hline & $>0$ & $7(70,0)$ & $3(30)$ & \\
\hline \multirow{2}{*}{ Ki67t } & $\leq 15$ & $64(83,1)$ & $13(16,9)$ & \multirow[t]{2}{*}{0,912} \\
\hline & $>15$ & $62(83,8)$ & $12(16,2)$ & \\
\hline \multirow{2}{*}{ Ki67nt } & $\leq 3$ & $66(82,5)$ & $14(17,5)$ & \multirow[t]{2}{*}{0,741} \\
\hline & $>3$ & $60(84,5)$ & $11(15,5)$ & \\
\hline \multirow{2}{*}{ HLADRt } & $\leq 67$ & $61(83,6)$ & $12(16,4)$ & \multirow[t]{2}{*}{0,970} \\
\hline & $>67$ & $60(83,3)$ & $12(16,7)$ & \\
\hline \multirow{2}{*}{ HLADRnt } & $\leq 13$ & $63(84,0)$ & $12(16,0)$ & \multirow[t]{2}{*}{0,667} \\
\hline & $>13$ & $58(86,6)$ & $9(13,4)$ & \\
\hline
\end{tabular}

p-valor obtido pelo Teste de Frequências do Qui-quadrado

* p-valor obtido pelo Teste Exato de Fisher 


\subsubsection{Relação entre marcadores e extensão extratireoidiana do carcinoma papilífero}

De todos os marcadores analisados, dois apresentaram relação estatisticamente significativa com a presença de extensão extratireoidiana: tumores com densidade menor ou igual a cinco células CD8+ em quatro campos de grande aumento (x200) tinham mais frequentemente extensão extratireoidiana $(33,7 \%$ versus $20,3 \%, p=0,008)$; de modo similar, tumores com densidade menor ou igual a cinco células CD163+ em quatro campos de grande aumento (x200) também tinham mais frequentemente extensão extratireoidiana $(37,1 \%$ versus $16,1 \%, p=0,005)$. Os outros marcadores estudados não demonstraram, tanto em área tumoral como não tumoral, relação com este achado anatomopatológico (Tabela 8). 
Tabela 8 - Relação entre densidade de células marcadas e presença de extensão extratireoidiana

\begin{tabular}{|c|c|c|c|c|}
\hline Variável & Medidas & $\begin{array}{c}\text { Não } \\
\text { Freq. (\%) }\end{array}$ & $\begin{array}{c}\text { Sim } \\
\text { Freq. (\%) }\end{array}$ & $p$-valor \\
\hline \multirow{2}{*}{ CD68t } & $\leq 11$ & $51(67,1)$ & $25(32,9)$ & \multirow[t]{2}{*}{0,226} \\
\hline & $>11$ & $57(76,0)$ & $18(24,0)$ & \\
\hline \multirow{2}{*}{ CD68nt } & $\leq 4$ & $66(69,5)$ & $29(30,5)$ & \multirow[t]{2}{*}{0,508} \\
\hline & $>4$ & $41(74,6)$ & $14(25,4)$ & \\
\hline \multirow{2}{*}{ CD4t } & $\leq 5$ & $64(70,3)$ & $27(29,7)$ & \multirow[t]{2}{*}{0,689} \\
\hline & $>5$ & $44(73,3)$ & $16(26,7)$ & \\
\hline \multirow{2}{*}{ CD4nt } & $\leq 2$ & $50(68,5)$ & $23(31,5)$ & \multirow[t]{2}{*}{0,425} \\
\hline & $>2$ & $58(74,4)$ & $20(25,6)$ & \\
\hline \multirow{2}{*}{ CD8t } & $\leq 5$ & $61(66,3)$ & $31(33,7)$ & \multirow[t]{2}{*}{0,008} \\
\hline & $>5$ & $47(79,7)$ & $12(20,3)$ & \\
\hline \multirow{2}{*}{ CD8nt } & $\leq 4$ & $28(66,7)$ & $14(33,3)$ & \multirow[t]{2}{*}{0,412} \\
\hline & $>4$ & $80(73,4)$ & $29(26,6)$ & \\
\hline \multirow{2}{*}{ CD163t } & $\leq 5$ & $56(62,9)$ & $33(37,1)$ & \multirow[t]{2}{*}{0,005} \\
\hline & $>5$ & $52(83,9)$ & $10(16,1)$ & \\
\hline \multirow{2}{*}{ CD163nt } & $\leq 2$ & $68(69,4)$ & $30(30,6)$ & \multirow[t]{2}{*}{0,429} \\
\hline & $>2$ & $40(75,5)$ & $13(24,5)$ & \\
\hline \multirow{2}{*}{ Foxpt3t } & $\leq 0$ & $47(73,4)$ & $17(25,4)$ & \multirow[t]{2}{*}{0,279 * } \\
\hline & $>0$ & $12(92,3)$ & $1(7,7)$ & \\
\hline \multirow{2}{*}{ Foxp3nt } & $\leq 0$ & $50(74,6)$ & $18(26,9)$ & \multirow[t]{2}{*}{$0,437^{*}$} \\
\hline & $>0$ & $9(90,0)$ & $1(10,0)$ & \\
\hline \multirow{2}{*}{$\mathrm{Ki67t}$} & $\leq 15$ & $55(71,4)$ & $22(28,6)$ & \multirow[t]{2}{*}{0,979} \\
\hline & $>15$ & $53(71,6)$ & $21(28,4)$ & \\
\hline \multirow{2}{*}{ Ki67nt } & $\leq 3$ & $57(71,2)$ & $23(28,8)$ & \multirow[t]{2}{*}{0,937} \\
\hline & $>3$ & $51(71,8)$ & $20(28,2)$ & \\
\hline \multirow{2}{*}{ HLADRt } & $\leq 67$ & $51(69,9)$ & $22(30,1)$ & \multirow[t]{2}{*}{0,616} \\
\hline & $>67$ & $53(73,6)$ & $19(26,4)$ & \\
\hline \multirow{2}{*}{ HLADRnt } & $\leq 13$ & $57(76,0)$ & $18(24,0)$ & \multirow[t]{2}{*}{0,432} \\
\hline & $>13$ & $47(70,2)$ & $20(29,8)$ & \\
\hline
\end{tabular}

p-valor obtido pelo Teste de Frequências do Qui-quadrado

* p-valor obtido pelo Teste Exato de Fisher 


\subsubsection{Relação entre marcadores e metástase linfonodal}

Metástases linfonodais foram detectadas em 36 (23,8\%) casos, e oito $(5,3 \%)$ destes apresentaram metástases no compartimento cervical lateral. Casos com densidade em área tireoidiana não tumoral menor ou igual a quatro células CD8+ em quatro campos de grande aumento (x200) apresentaram-se, mais frequentemente, com metástases linfonodais $(38,1 \%$ versus 18,4\%, $p=0,011$ ) (Tabela 9). Além disso, a densidade média das células CD68+ em área tumoral foi significativamente maior nos casos com metástase linfonodal em cadeia cervical lateral (21,1 versus 14,3, $p=0,042)$. 
Tabela 9 - Relação entre densidade de células marcadas e presença de metástase linfonodal

\begin{tabular}{|c|c|c|c|c|}
\hline Variável & Medidas & $\begin{array}{c}\text { pNO } \\
\text { Freq. (\%) }\end{array}$ & $\begin{array}{c}\text { pN1 } \\
\text { Freq.(\%) }\end{array}$ & $p$-valor \\
\hline \multirow{2}{*}{ CD68t } & $\leq 11$ & $54(71,0)$ & $22(29,0)$ & 0,138 \\
\hline & $>11$ & $61(81,3)$ & $14(18,7)$ & \\
\hline \multirow{2}{*}{ CD68nt } & $\leq 4$ & $71(74,7)$ & $24(25,3)$ & 0,634 \\
\hline & $>4$ & $43(78,2)$ & $12(21,8)$ & \\
\hline \multirow{2}{*}{$\mathrm{CD} 4 \mathrm{t}$} & $\leq 5$ & $69(75,8)$ & $22(24,2)$ & 0,905 \\
\hline & $>5$ & $46(76,7)$ & $14(23,3)$ & \\
\hline \multirow{2}{*}{ CD4nt } & $\leq 2$ & $53(72,6)$ & $20(27,4)$ & 0,321 \\
\hline & $>2$ & $62(79,5)$ & $16(20,5)$ & \\
\hline \multirow{2}{*}{ CD8t } & $\leq 5$ & $67(72,8)$ & $25(27,2)$ & 0,230 \\
\hline & $>5$ & $48(81,4)$ & $11(18,6)$ & \\
\hline \multirow{2}{*}{ CD8nt } & $\leq 4$ & $26(61,9)$ & $16(38,1)$ & 0,011 \\
\hline & $>4$ & $89(81,6)$ & $20(18,4)$ & \\
\hline \multirow{2}{*}{ CD163t } & $\leq 5$ & $68(76,4)$ & $21(23,6)$ & 0,932 \\
\hline & $>5$ & $47(75,8)$ & $15(24,2)$ & \\
\hline \multirow{2}{*}{ CD163nt } & $\leq 2$ & $75(76,5)$ & $23(24,5)$ & 0,884 \\
\hline & $>2$ & $40(75,5)$ & $13(24,5)$ & \\
\hline \multirow{2}{*}{ Foxpt3t } & $\leq 0$ & $46(71,9)$ & $18(28,1)$ & $0,167^{*}$ \\
\hline & $>0$ & $12(92,3)$ & $1(7,7)$ & \\
\hline \multirow{2}{*}{ Foxp3nt } & $\leq 0$ & $49(73,1)$ & $18(26,9)$ & $0,436^{*}$ \\
\hline & $>0$ & $9(90,0)$ & $1(10,0)$ & \\
\hline \multirow{2}{*}{ Ki67t } & $\leq 15$ & $62(80,5)$ & $15(19,5)$ & 0,200 \\
\hline & $>15$ & $53(71,6)$ & $21(28,4)$ & \\
\hline \multirow{2}{*}{ Ki67nt } & $\leq 3$ & $62(77,5)$ & $18(22,5)$ & 0,681 \\
\hline & $>3$ & $53(74,6)$ & $18(25,4)$ & \\
\hline \multirow{2}{*}{ HLADRt } & $\leq 67$ & $55(75,3)$ & $18(24,7)$ & 0,883 \\
\hline & $>67$ & $55(76,4)$ & $17(23,6)$ & \\
\hline \multirow{2}{*}{ HLADRnt } & $\leq 13$ & $56(74,7)$ & $19(25,3)$ & 0,532 \\
\hline & $>13$ & $53(79,1)$ & $14(20,9)$ & \\
\hline
\end{tabular}

p-valor obtido pelo Teste de Frequências do Qui-quadrado

* $p$-valor obtido pelo Teste Exato de Fisher 


\subsubsection{Outras análises de possível associação entre microambiente imune e fatores prognósticos}

Para a análise combinada dos dois fatores patológicos prognósticos mais importantes em nossa amostra, metástase linfonodal e extensão extratireoidiana, criamos uma variável que combina ambos, agrupando de um lado os casos limitados à glândula tireoide, ou seja, que não demonstraram extensão para fora da glândula nem metástases linfonodais, e de outro lado, os casos que não estavam limitados à tireoide, apresentando extensão extratireoidiana e/ou metástases linfonodais. Esta variável, conforme relatado previamente, apresentou impacto prognóstico significativo na incidência de recorrência, relacionou-se com a densidade de células CD8+ tanto intratumorais como em área não tumoral: tumores limitados à tireoide tiveram média de densidade significativamente maior destas células quando comparados aos casos com tumor não limitado à tireoide $(7,4$ versus $5,8, p=0,04$ em área tumoral; 6,1 versus $4,3, p=0,03$ em área não tumoral). Demais marcadores foram igualmente analisados, mas não demonstraram relação significante (Tabela 10). 
Tabela 10 - Relação entre média de densidade de marcação e presença de metástase linfonodal e extensão extratireoidiana

\begin{tabular}{|c|c|c|c|c|}
\hline \multirow{2}{*}{ Variável } & \multirow{2}{*}{ Medidas } & \multicolumn{2}{|c|}{ pN e Extensão Extratireoidiana } & \multirow{2}{*}{$p$-valor } \\
\hline & & pNO e Sem EET & pN1 e/ou Com EET & \\
\hline \multirow{4}{*}{ CD68t } & $\mathrm{N}$ & 90 & 61 & 0,316 \\
\hline & Variação & $0-68$ & $0-46$ & \\
\hline & Mediana & 13 & 10 & \\
\hline & Média (dp) & $15,5(13,5)$ & $13,3(10,9)$ & \\
\hline \multirow{4}{*}{ Cd68nt } & $\mathrm{N}$ & 89 & 61 & 0,903 \\
\hline & Variação & $0-23$ & $0-16$ & \\
\hline & Mediana & 4,0 & 4,0 & \\
\hline & Média (dp) & $4,6(4,3)$ & $4,4(3,4)$ & \\
\hline \multirow{4}{*}{$\mathrm{Cd} 4 \mathrm{t}$} & $\mathrm{N}$ & 90 & 61 & 0,881 \\
\hline & Variação & $0-20$ & $1-14$ & \\
\hline & Mediana & 5,0 & 5,0 & \\
\hline & Média (dp) & $5,6(4,5)$ & $5,3(3,3)$ & \\
\hline \multirow{4}{*}{ Cd4nt } & $\mathrm{N}$ & 90 & 61 & 0,755 \\
\hline & Variação & $0-20$ & $0-10$ & \\
\hline & Mediana & 3,0 & 3,0 & \\
\hline & Média (dp) & $3,4(3,3)$ & $3,1(2,2)$ & \\
\hline \multirow{4}{*}{ Cd8t } & $\mathrm{N}$ & 90 & 61 & 0,040 \\
\hline & Variação & $1-20$ & $0-20$ & \\
\hline & Mediana & 5,0 & 5,0 & \\
\hline & Média (dp) & $7,4(4,9)$ & $5,8(3,7)$ & \\
\hline \multirow{4}{*}{ Cd8nt } & $\mathrm{N}$ & 90 & 61 & 0,039 \\
\hline & Variação & $1-20$ & $0-10$ & \\
\hline & Mediana & 5,0 & 5,0 & \\
\hline & Média (dp) & $6,1(5,0)$ & $4,3(3,1)$ & \\
\hline \multirow{4}{*}{ Cd163t } & $\mathrm{N}$ & 90 & 61 & 0,458 \\
\hline & Variação & $0-18$ & $0-15$ & \\
\hline & Mediana & 5,0 & 5,0 & \\
\hline & Média (dp) & $5,8(4,1)$ & $5,3(3,8)$ & \\
\hline \multirow{4}{*}{ Cd163t } & $\mathrm{N}$ & 90 & 61 & 0,486 \\
\hline & Variação & $0-14$ & $0-9$ & \\
\hline & Mediana & 2,0 & 2,0 & \\
\hline & Média (dp) & $2,4(2,4)$ & $2,1(1,9)$ & \\
\hline \multirow{4}{*}{ FOXp3t } & $\mathrm{N}$ & 49 & 28 & 0,123 \\
\hline & Variação & $0-10$ & $0-12$ & \\
\hline & Mediana & 0,0 & 0,0 & \\
\hline & Média (dp) & $0,7(1,8)$ & $0,7(2,6)$ & \\
\hline \multirow{4}{*}{ FOXp3nt } & $\mathrm{N}$ & 49 & 28 & 0,293 \\
\hline & Variação & $0-7$ & $0-10$ & \\
\hline & Mediana & 0,0 & 0,0 & \\
\hline & Média (dp) & $0,4(1,3)$ & $0,5(1,9)$ & \\
\hline \multirow{4}{*}{ Ki67t } & $\mathrm{N}$ & 90 & 61 & 0,908 \\
\hline & Variação & $0-125$ & $0-54$ & \\
\hline & Mediana & 14,0 & 16,0 & \\
\hline & Média (dp) & $21,3(22,4)$ & $16,9(11,1)$ & \\
\hline \multirow{4}{*}{ Ki67nt } & $\mathrm{N}$ & 90 & 61 & 0,825 \\
\hline & Variação & $0-23$ & $0-35$ & \\
\hline & Mediana & 3,0 & 3,0 & \\
\hline & Média (dp) & $4,2(3,8)$ & $4,7(5,6)$ & \\
\hline \multirow{4}{*}{ HLADRt } & $\mathrm{N}$ & 86 & 59 & 0,917 \\
\hline & Variação & $10-140$ & $12-142$ & \\
\hline & Mediana & 68,5 & 64,0 & \\
\hline & Média (dp) & $69,4(28,4)$ & $70,9(29,6)$ & \\
\hline \multirow{4}{*}{ HLADRnt } & $\mathrm{N}$ & 86 & 56 & 0,770 \\
\hline & Variação & $3-53$ & $1-53$ & \\
\hline & Mediana & 13,0 & 12,5 & \\
\hline & Média (dp) & $15,4(10,2)$ & $15,1(10,9)$ & \\
\hline
\end{tabular}

$\mathrm{DP}=$ desvio-padrão $\quad \mathrm{p}$ - valor obtido pelo teste $U$ de Mann-Whitney 
Outras correlações significativas foram observadas:

- Em casos com tumores maiores que $10 \mathrm{~mm}$, foi encontrada maior densidade média da marcação em tecido não tumoral pelo anti-CD4 $(3,8$ versus $2,9, p=0,042)$;

- Em casos com tumores multifocais, foi encontrada uma menor densidade média de marcação em tecido não tumoral pelo anti-CD8 $(4,0$ versus $5,9, p=0,016)$;

As combinações de alguns marcadores na tentativa de criar diferentes perfis de resposta imunológica ao carcinoma papilífero de tireoide também foram analisadas. Neste cenário, destacamos dois agrupamentos realizados levando em conta a combinação da densidade de infiltração por células CD8+ e CD68+, ou seja, linfócitos T citotóxicos e macrófagos:

- Agrupamos casos que consideramos com perfil imune desfavorável ao tumor, com densidade CD8+ $>5$ e CD68+ $\leq 11$ e os confrontamos com os tumores com CD8+ $\leq 5$ e CD68t $>11$, considerado perfil favorável ao tumor. Não foi encontrada relação com sobrevida livre de recorrência, extensão extratireoidiana ou metástase linfonodal (Tabelas 11, 12, 13).

- Calculamos a relação entre a densidade de células CD8+ sobre a densidade de células CD68+ individualmente. Esperamos que quanto maior o valor desta razão menos favorável ao tumor o infiltrado imune seja, e definimos o ponto de corte pela mediana, agrupando novamente os casos em dois grupos. Também não 
encontramos relação com sobrevida livre de recorrência, extensão extratireoidiana ou metástase linfonodal (Tabelas 11, 12, 13).

Tabela 11 - Relação de metástase linfonodal com perfil imune, por diferentes agrupamentos, levando em consideração a densidade das células CD8+ e CD68+ nos tumores

\begin{tabular}{lcccc}
\hline Variável & Medidas & $\begin{array}{c}\text { pN0 } \\
\text { Freq. }(\%)\end{array}$ & $\begin{array}{c}\text { pN1 } \\
\text { Freq. (\%) }\end{array}$ & p-valor \\
\hline \multirow{2}{*}{ CD8t/CD68t } & $\leq 0,42$ & $53(77,9)$ & $15(22,1)$ & 0,581 \\
& $>0,42$ & $48(73,8)$ & $17(26,2)$ & \\
CD8t X CD68t & CD8t $\leq 5$ e CD68t $>11$ & $36(80,0)$ & $9(20,0)$ & 0,943 \\
& CD8t $>$ 5 e CD68t $\leq 11$ & $23(79,3)$ & $6(20,7)$ & \\
\hline
\end{tabular}

Tabela 12 - Relação de extensão extratireoidiana com perfil imune, por diferentes agrupamentos, levando em consideração a densidade das células CD8+ e CD68+ nos tumores

\begin{tabular}{lcccc}
\hline Variável & Medidas & $\begin{array}{l}\text { Sem EET } \\
\text { Freq. (\%) }\end{array}$ & $\begin{array}{l}\text { Com EET } \\
\text { Freq. (\%) }\end{array}$ & p-valor \\
\hline \multirow{2}{*}{ CD8t/CD68t } & $\leq 0,42$ & $48(70,6)$ & $20(29,4)$ & 0,982 \\
& $>0,42$ & $46(70,8)$ & $19(29,2)$ & \\
\multirow{2}{*}{ CD8t X CD68t } & CD8t $\leq 5$ e CD68t $>11$ & $32(71,1)$ & $13(28,9)$ & 0,653 \\
& CD8t $>5$ e CD68t $\leq 11$ & $22(75,9)$ & $7(24,1)$ & \\
\hline
\end{tabular}

Tabela 13 - Relação de sobrevida livre de recorrência com perfil imune, por diferentes agrupamentos, levando em consideração a densidade das células CD8+ e CD68+ nos tumores

\begin{tabular}{lcccc}
\hline Variável & Categoria & $\mathrm{N}$ & $\begin{array}{c}\text { Sobrevida livre de } \\
\text { recorrências 5-anos } \\
(\%)\end{array}$ & p-valor \\
\hline \multirow{2}{*}{ CD8t/CD68t } & $\leq 0,42$ & 68 & 93,9 & 0,959 \\
& $>0,42$ & 65 & 95,0 & \\
\multirow{2}{*}{ CD8t X CD68t } & CD8t $\leq 5$ e CD68t $>11$ & 45 & 93,2 & 0,535 \\
& CD8t $>$ 5 e CD68t $\leq 11$ & 29 & 93,0 & \\
\hline
\end{tabular}




\subsubsection{Relação entre marcadores e sobrevida}

Dos marcadores analisados, nenhum apresentou correlação estatisticamente significativa com a sobrevida livre de recorrência. No entanto, nos casos com menor infiltração do anti-CD8 não tumoral $(<4)$, houve uma piora na sobrevida livre de doença em 5 anos $(87,5 \%$ x 97,1\%; $p=0,057)$ (Tabela 14$)$. O risco relativo $(R R)$ de recorrência no casos com densidade de células CD8 positivas em área não tumoral $\leq 4$ foi 3,32 maior quando comparado ao grupo com densidade $>4$, com intervalo de confiança de 0,89 - 12,39 (Tabela 15 e Figura 20). 
Tabela 14 - Probabilidade de sobrevida livre de recorrência (nove recidivas)

\begin{tabular}{|c|c|c|c|c|}
\hline Variável & Categoria & $\mathrm{N}$ & $\begin{array}{c}\text { Sobrevida livre de } \\
\text { recorrências 5-anos } \\
(\%)\end{array}$ & $p$-value \\
\hline \multirow{2}{*}{ CD68t } & $\leq 11$ & 76 & 94,2 & \multirow[t]{2}{*}{0,694} \\
\hline & $>11$ & 75 & 94,5 & \\
\hline \multirow{2}{*}{ CD68nt } & $\leq 4$ & 95 & 93,4 & \multirow{2}{*}{0,345} \\
\hline & $>4$ & 55 & 95,9 & \\
\hline \multirow{2}{*}{ CD4t } & $\leq 5$ & 91 & 94,3 & \multirow[t]{2}{*}{0,669} \\
\hline & $>5$ & 60 & 94,6 & \\
\hline \multirow{2}{*}{ CD4nt } & $\leq 2$ & 73 & 95,4 & \multirow[t]{2}{*}{0,790} \\
\hline & $>2$ & 78 & 93,4 & \\
\hline \multirow{2}{*}{ CD8t } & $\leq 5$ & 92 & 94,2 & \multirow[t]{2}{*}{0,726} \\
\hline & $>5$ & 59 & 94,8 & \\
\hline \multirow{2}{*}{ CD8nt } & $\leq 4$ & 42 & 87,5 & \multirow[t]{2}{*}{0,057} \\
\hline & $>4$ & 109 & 97,1 & \\
\hline \multirow{2}{*}{ CD163t } & $\leq 5$ & 89 & 92,7 & \multirow[t]{2}{*}{0,251} \\
\hline & $>5$ & 62 & 96,8 & \\
\hline \multirow{2}{*}{ CD163nt } & $\leq 2$ & 98 & 94,4 & \multirow[t]{2}{*}{0.892} \\
\hline & $>2$ & 53 & 94,3 & \\
\hline \multirow{2}{*}{ Foxpt3t } & $\leq 0$ & 64 & 93,5 & \multirow[t]{2}{*}{0,285} \\
\hline & $>0$ & 13 & 100,0 & \\
\hline \multirow{2}{*}{ Foxp3nt } & $\leq 0$ & 67 & 93,8 & \multirow[t]{2}{*}{0,355} \\
\hline & $>0$ & 10 & 100,0 & \\
\hline \multirow{2}{*}{ Ki67t } & $\leq 15$ & 77 & 93,2 & \multirow[t]{2}{*}{0,784} \\
\hline & $>15$ & 74 & 95,7 & \\
\hline \multirow{2}{*}{ Ki67nt } & $\leq 3$ & 80 & 93,5 & \multirow[t]{2}{*}{0,900} \\
\hline & $>3$ & 71 & 95,4 & \\
\hline \multirow{2}{*}{ HLADRt } & $\leq 67$ & 73 & 92,5 & \multirow[t]{2}{*}{0,724} \\
\hline & $>67$ & 72 & 95,7 & \\
\hline \multirow{2}{*}{ HLADRnt } & $\leq 13$ & 75 & 95,9 & \multirow[t]{2}{*}{0,621} \\
\hline & $>13$ & 67 & 95,4 & \\
\hline
\end{tabular}

p-valor obtido pelo Teste de Logrank 
Tabela 15 - Risco Relativo (RR) para ocorrência de recidivas e respectivo intervalo de confiança de $95 \%$ (95\% IC) estimados pelo modelo de regressão de Cox univariado para o marcador CD8nt

\begin{tabular}{lccccc}
\hline Variável & Categoria & $\mathrm{N}$ & $\mathrm{RR}$ & $95 \%$ IC & $\mathrm{p}$-valor \\
\hline \multirow{2}{*}{ CD8nt } & $>4$ & 109 & 1,0 & Ref. & 0,073 \\
& $\leq 4$ & 42 & 3,32 & $0,89-12,39$ & \\
\hline
\end{tabular}

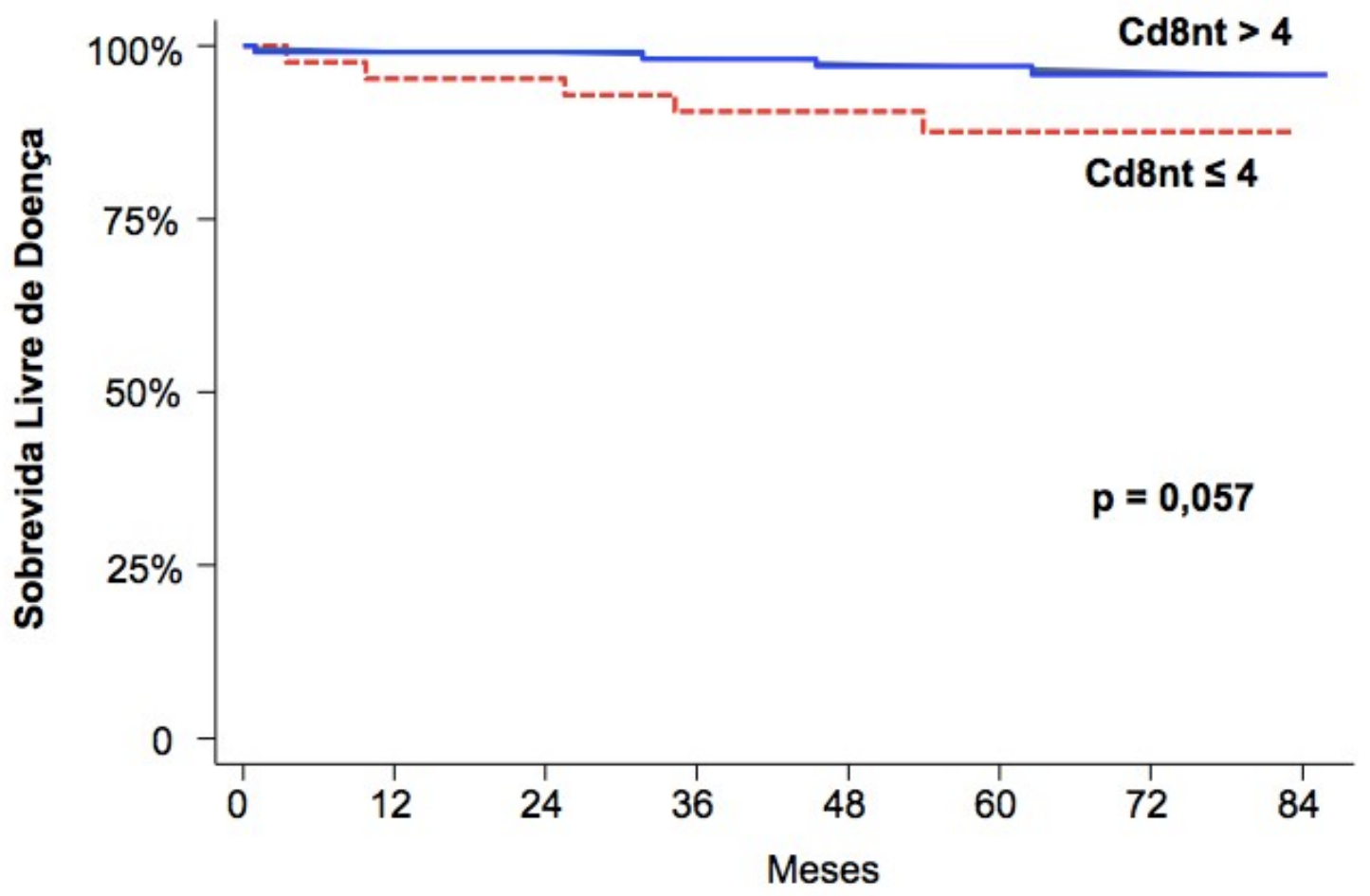

Curva de Sobrevida de Kaplan-Meier; Teste de Log-Rank

Figura 20 - Curvas de sobrevida livre de doença, comparando casos com densidade de células CD8+ em área não tumoral maior que 4 com casos com densidade menor ou igual a 4 
Não houve nenhuma morte por câncer na amostra durante o período de seguimento, o que impossibilitou a análise relacionando o microambiente tumoral ou marcadores imuno-histoquímicos e sobrevida câncer específica ou global. 


\section{DISCUSSÃO}

O importante aumento na incidência do carcinoma papilífero de tireoide que vem acontecendo nas últimas três décadas está também associado a mudanças significativas no perfil dos casos. Houve uma

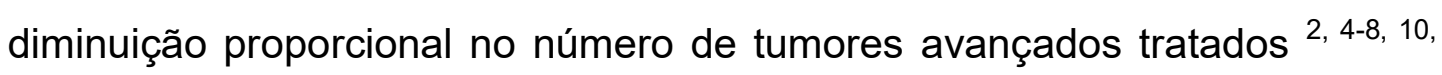
${ }^{12,75-78}$, o que foi reiterado por estudo realizado por nosso grupo incluindo casuística aqui analisada ${ }^{11}$. Embora a intenção inicial na seleção dos pacientes para estudo fosse balancear o número de casos iniciais e avançados, a amostra analisada neste estudo aproximou-se mais desta realidade atual, já que a comparação entre estes 151 casos selecionados e incluídos e o banco de dados original com todos 780 casos de carcinoma papilifero tratados no A. C. Camargo Cancer Center nos anos de 2008, 2009 e 2010, não demonstrou diferenças significativas na distribuição por características clínico-epidemiológicas e de tratamento realizado.

Previamente ao tratamento, apenas $6 \%$, aproximadamente, dos pacientes analisados foram diagnosticados como portadores de tumor localmente avançado ou metástase linfonodal. Esta prevalência foi de, aproximadamente, $4 \%$ quando avaliados todos os pacientes tratados naquele período. No entanto, considerando fatores patológicos mais determinantes do ponto de vista prognóstico, pudemos observar que a prevalência de extensão extratireoidiana e metástases linfonodais no grupo dos 780 pacientes tratados foi de aproximadamente $15 \%$, significativamente 
menor que os $28,5 \%$ de tumores extratireoidianos e $23,8 \%$ com metástase linfonodal observados na amostra do estudo, o que se explica pelos métodos de seleção dos casos para inclusão.

Certamente, o tempo de seguimento médio de pouco mais de 5 anos poderá ser considerado baixo em se tratando de uma doença de comportamento indolente que pode recidivar em até 10 ou 20 anos após o tratamento inicial ${ }^{79-81}$. Entretanto, as nove recidivas observadas reafirmaram o impacto prognóstico significativo da presença de extensão extratireoidiana e metástases linfonodais nesta doença, já bem descritas na literatura ${ }^{19,82,83}$. Em nosso estudo, nenhum paciente com tumor limitado à tireoide, ou seja, sem metástase ou extensão extratireoidiana, evoluiu com recorrência da doença, e a sobrevida livre de recorrência nos pacientes com metástase ou extensão extratireoidiana foi $85,6 \%$, significativamente menor $(p<0,001)$. Metástases a distância só foram diagnosticadas em dois pacientes e não houve óbitos relacionados à doença neste estudo, o que limitou nosso poder de análise para esses eventos.

No início 2012, momento da concepção inicial deste projeto, muito pouco havia sido publicado sobre o estudo do microambiente imune no carcinoma papilífero de tireoide, com poucos trabalhos analisando diretamente a relação de células imunes específicas com comportamento tumoral ${ }^{54,64,67,84}$. Mesmo levando em consideração estudos realizados em outros tipos de tumores, especialmente carcinomas mamários, onde a literatura já era mais abundante ${ }^{31,38-41,59,85-87}$, a metodologia utilizada para análise imuno-histoquímica deste microambiente mostrava-se bastante 
heterogênea entre os autores. Neste cenário de natural incerteza optamos por evitar análise em tissue micro-array, utilizando então análises em cortes inteiros incluindo área tumoral e não tumoral com contagem de células positivas para cada marcador em número preestabelecido de campos, a exemplo do utilizado até então nos trabalhos de Ugolini et al. e French et al. 64, 84. De forma semelhante, a seleção dos marcadores para o estudo também se mostrou difícil pela falta de informações na literatura médica sobre marcadores melhor estabelecidos, com o intuito de caracterizar e explorar o microambiente tumoral dos carcinomas papiliferos, realçando, no momento de sua concepção, o caráter exploratório deste estudo. Extrapolando o conhecimento produzido em outras linhagens tumorais, especialmente carcinomas mamários, focamos em marcadores que pudessem destacar, especialmente, macrófagos e linfócitos em suas variadas diferenciações ${ }^{33,36,41,61,64,87,88}$. No carcinoma mamário, onde o conhecimento sobre o papel do infiltrado imune já é amplo, há uma tendência à padronização da leitura e interpretação do infiltrado linfocitário, sem utilização de marcadores imuno-histoquímicos e dando preferência às leituras realizadas nas áreas estromais do tumor. No entanto, precisamos lembrar que a densidade desse infiltrado é maior nesses carcinomas e que ainda persistem diversas controvérsias nesta padronização que, ao abrir mão da análise de subpopulações dos linfócitos, pode dificultar o entendimento deste complexo processo. O grupo de estudo responsável por estas recomendações também sugere análises em cortes inteiros, evitando 
uso de tissue micro-arrays e evitando leituras em áreas "quentes" (hot spots) 89

As densidades de células positivas pelos marcadores selecionados tiveram, de forma geral, medianas em torno de cinco células na maioria dos marcadores. Dos marcadores imunes, apenas o CD68 em área tumoral apresentou densidade maior que dez células nos campos padronizados. Essa caracterização sugere que o carcinoma papilífero é menos densamente povoado por células imunes que outros carcinomas, como demonstrado por Ryder et al. ${ }^{54}$.

Nesta amostra, a correlação positiva significativa foi demonstrada em todos os marcadores tumorais quando comparados a seus respectivos em área não tumoral, sugerindo que a resposta imune ocorre de forma similar no tumor e em seu entorno formado por tecido tireoidiano normal, permitindo-nos interpretar os resultados das densidades tumorais ou não tumorais de forma semelhante.

Os achados mais significativos deste estudo ocorreram na análise da relação dos marcadores com os fatores clínico-patológicos que têm impactos prognósticos bem descritos, inclusive como já exposto previamente. Neste cenário, destacamos a presença de extensão extratireoidiana pelo tumor e de metástases linfonodais, sinais óbvios de agressividade tumoral local e potencial de disseminação.

Publicações recentes, ao analisarem de forma mais específica a infiltração e caracterização do microambinete imune tumoral nos carcinomas papilíferos de tireoide, permitem comparação com resultados obtidos em 
nosso estudo, contribuindo para melhor interpretação dos resultados. Estes estudos têm repetidamente demonstrado a importância da resposta do sistema imunológico no comportamento tumoral de diferentes maneiras ${ }^{49,55}$, $56,58,60,62,64-66,74,84,90-98$.

A densidade de infiltração de TAMs mostrou-se baixa em nossa amostra de tumores, corroborando informação já publicada por outros autores ${ }^{54}$. Encontramos uma relação inversa significativa entre a marcação por CD163, que reflete densidade de macrófagos M2 ou alternadamente ativados e presença de extensão extratireoidiana, sugerindo um papel antitumoral aos macrófagos CD163+. Além disso, analisando os demais marcadores relacionados aos TAMs, encontramos uma relação positiva entre a densidade de células CD68+, marcador geral de macrófagos, no tumor com a presença de metástases linfonodais em cadeias laterais e uma correlação positiva significativa entre células CD68+ e Ki67, sugerindo papel pró-tumoral no processo de proliferação e metástase por parte destas células. Densidade de células HLA-DR+, marcador de macrófagos M1 classicamente ativados, não apresentou relação com nenhum fator prognóstico. Ao confrontarmos este resultado com a já conflitante experiência de outros autores, aumentamos a controvérsia existente. Como já detalhado previamente, alguns grupos demonstraram relação positiva entre densidade de TAMs e extensão do tumor primário ou presença de metástases linfonodais $55,56,90,97$, e outros autores questionaram este impacto prognóstico negativo, reportando associação favorável com sobrevida livre de recorrência ${ }^{57,58}$. O papel dos TAMs associados ao 
carcinoma papilífero não está completamente esclarecido, e parece ser variável dependendo de sua ativação e de fatores regulatórios ainda não definidos, a exemplo do que acontece em outros tumores ${ }^{59}$.

Em uma das primeiras publicações a demonstrar $\mathrm{o}$ potencial prognóstico dos TILs em carcinomas papilíferos de tireoide, foi demonstrado que a presença destes linfócitos reduziu risco de recorrência ${ }^{51}$. De modo semelhante, um estudo de marcadores imuno-histoquímicos em TMA mostrou que o infiltrado linfocitário no tumor e tireoidite linfocítica estão relacionados com prognóstico mais favorável, e que a tireoidite parece influenciar o microambiente imune dos carcinomas papiliferos ${ }^{57}$. Entretanto, outras publicações falharam em demonstrar esta relação 54,84 , provavelmente, por não levarem em conta a importância das subpopulações celulares e como a ativação destas células pelo microambiente pode tornálas pró- ou antitumorais em sua atividade. Diferente do que vem sendo demonstrado em câncer de mama, onde a densidade linfocitária tem papel prognóstico definido ${ }^{89}$, talvez tenhamos que especificar os subtipos de linfócitos ao analisar seu impacto em carcinoma papilífero de tireoide. Três marcadores foram utilizados em nosso estudo para caracterização do perfil de infiltrado linfocitário: CD4, CD8 e Foxp3. Respectivamente, são específicos dos linfócitos helper, citotóxicos e reguladores. Embora tenhamos excluído os casos com tireoidite intensa, sabemos que a glândula tireoide é um órgão onde o infiltrado linfocitário é bastante prevalente e que, consequentemente, a análise da densidade e subpopulações de linfócitos poderia ser impactada. No entanto, temos evidências publicadas sugerindo a 
capacidade imunomoduladora dos carcinomas papiliferos, modificando o perfil do infiltrado imune local. Ao comparar o perfil de infiltração linfocítica entre tireodite e carcinomas tireoidianos, Imam et al. ${ }^{49}$ encontraram claras diferenças, demonstrando tumores infiltrados, preferencialmente, por linfócitos reguladores ou inativos com baixa densidade de linfócitos ativos CD8+ ou CD4+. Em nossa amostra, tumores com menor densidade de células CD8+ apresentaram com mais frequência extensão extratireoidiana. De modo similar, a menor densidade de células CD8+ em área tireoidiana não tumoral relacionou-se com maior ocorrência de metástases linfonodais e multifocalidade. Além disso, casos com tumores limitados à tireoide, ou seja, sem metástase ou extensão extratireoidiana, demonstraram média significativamente maior de infiltração por células $\mathrm{CD}^{+}$, tanto em área tumoral como não tumoral. Outro achado interessante foi o aumento do risco de recorrência nos casos com menor infiltrado de linfócitos CD8+, com risco relativo de 3,32 (95\% IC $0,89-12,39 ; p=0,07)$, com consequente menor sobrevida livre de recorrência em 5 anos $(87,5 \%$ versus $97,1 \%, p=0,057)$, que embora tenham ocorrido de forma não estatisticamente significativa, corroboram outros achados no sentido de afirmar o papel antitumoral que os linfócitos CD8 parecem exercer no microambiente imune dos carcinomas papiliferos de tireoide. A infiltração por linfócitos CD4+ e/ou Foxp3+ não demonstrou relação com sobrevida ou fatores prognósticos em nosso estudo, à exceção da observação de maior densidade média de linfócitos CD4+ em área tireoidiana nos casos com tumores maiores que $10 \mathrm{~mm}$ quando comparados aos microcarcinomas. Este achado isolado nos parece 
insuficiente para atribuir um papel significativo a linfócitos CD4+ e Foxp3+ no microambiente, em nossa amostra.

De maneira geral, nosso estudo foi capaz de reafirmar o papel antitumoral realizado pelos linfócitos $T$ citotóxicos CD8+ (CTL), resultando em prognóstico mais favorável nos tumores mais infiltrados por estas células, já demonstrado de maneira consistente em metanálise, incluindo diversos tumores sólidos ${ }^{42}$. A associação entre infiltrado linfocitário específico e prognóstico no carcinoma papilífero de tireoide também já foi explorada por alguns autores. French et al. ${ }^{64}$ também encontraram relação positiva de infiltrado por linfócitos CD4+ com tamanho do tumor, achado semelhante ao descrito em nossa amostra. O mesmo estudo, que utilizou imuno-histofluorescência, também descreveu relação positiva entre infiltrado por linfócitos Treg (Foxp3+) com metástase linfonodal e relação inversa entre razão CD8/Treg e tamanho do tumor. Posteriormente, os mesmos autores, estudando material obtido de linfonodos, relataram que a maior densidade de linfóctios Treg e PD-1+ está ligada à maior agressividade e chance de recorrência ${ }^{63}$. Cunha et al. ${ }^{61}$ falharam em mostrar o impacto prognóstico do infiltrado por linfócitos Foxp3+, demonstrando, de forma contrária ao esperado, que o maior infiltrado por estes linfócitos associou-se a tumores menores e sem extensão extratireoidiana. Curiosamente, este estudo evidenciou papel prognóstico negativo deste marcador em núcleo de células tumorais de carcinoma papilífero, o que também foi reportado por outro grupo, que demonstrou maior presença de extensão extratireoidiana, iodorresistência e metástases em tumores FoxP3+, mas, que também falhou 
em relacionar o infiltrado por linfócitos FoxP3+ com qualquer fator de agressividade em carcinomas papilíferos $^{62}$. O mesmo grupo, utilizando TMA e marcadores imuno-histoquímicos, relatou associação inversa entre infiltração por linfócitos T CD8+ e extensão extratireoidiana, multifocalidade, resultando em maior sobrevida livre de recorrência. No mesmo estudo, linfócitos CD4+ e Foxp3 também mostraram relação inversa com extensão extratireoidiana, contrária ao esperado pelo papel que, geralmente, desempenham no microambiente ${ }^{57,96}$. Estudando a mesma casuística com IHQ e a extração de RNA, os autores ainda relataram que o aumento da expressão de PD-L1 nas células de carcinoma papilífero não apresenta papel prognóstico ou relação com agressividade, mas está associado a maior infiltrado por células CD4+, CD8+, CD20+ e FoxP3+, além de TAMs, o que pode oferecer uma nova perspectiva de tratamento sistêmico para pacientes com carcinoma tireoidiano ${ }^{60}$, noção compartilhada em um estudo de Bastman et al. $^{91}$, em que a maior parte de carcinomas papilíferos avançados e carcinomas anaplásicos apresentavam expressão de PD-L1 em células tumorais e TILs.

As controvérsias que percebemos ao confrontar as diferentes publicações sobre microambiente imune tumoral têm causa multifatorial. A metodologia aplicada nos estudos é bastante heterogênea e parece, na maioria das vezes, incapaz de abordar os variados aspectos desse complexo processo. Além disso, há muito a ser esclarecido, especialmente sobre os diferentes papéis que as células imunes podem assumir a depender de fatores regulatórios locais ainda não completamente 
elucidados. De maneira semelhante, a heterogeneidade encontrada na literatura médica sobre o microambiente imune no carcinoma papilífero, presente até na multiplicidade de metodologias utilizadas pelos diferentes autores, reflete o quanto ainda falta para compreensão precisa de toda a complexa interação entre a células neoplásicas e o sistema imunológico. Ainda assim, frutos já vêm sendo colhidos em outras doenças, onde este microambiente imune já foi melhor estudado, com o uso clínico de imunoterápicos, o que, com as inúmeras evidências já expostas, reforça a noção de que devemos insistir e aprofundar a análise do infiltrado imune e seu papel prognóstico e, possivelmente, terapêutico no carcinoma papilífero de tireoide.

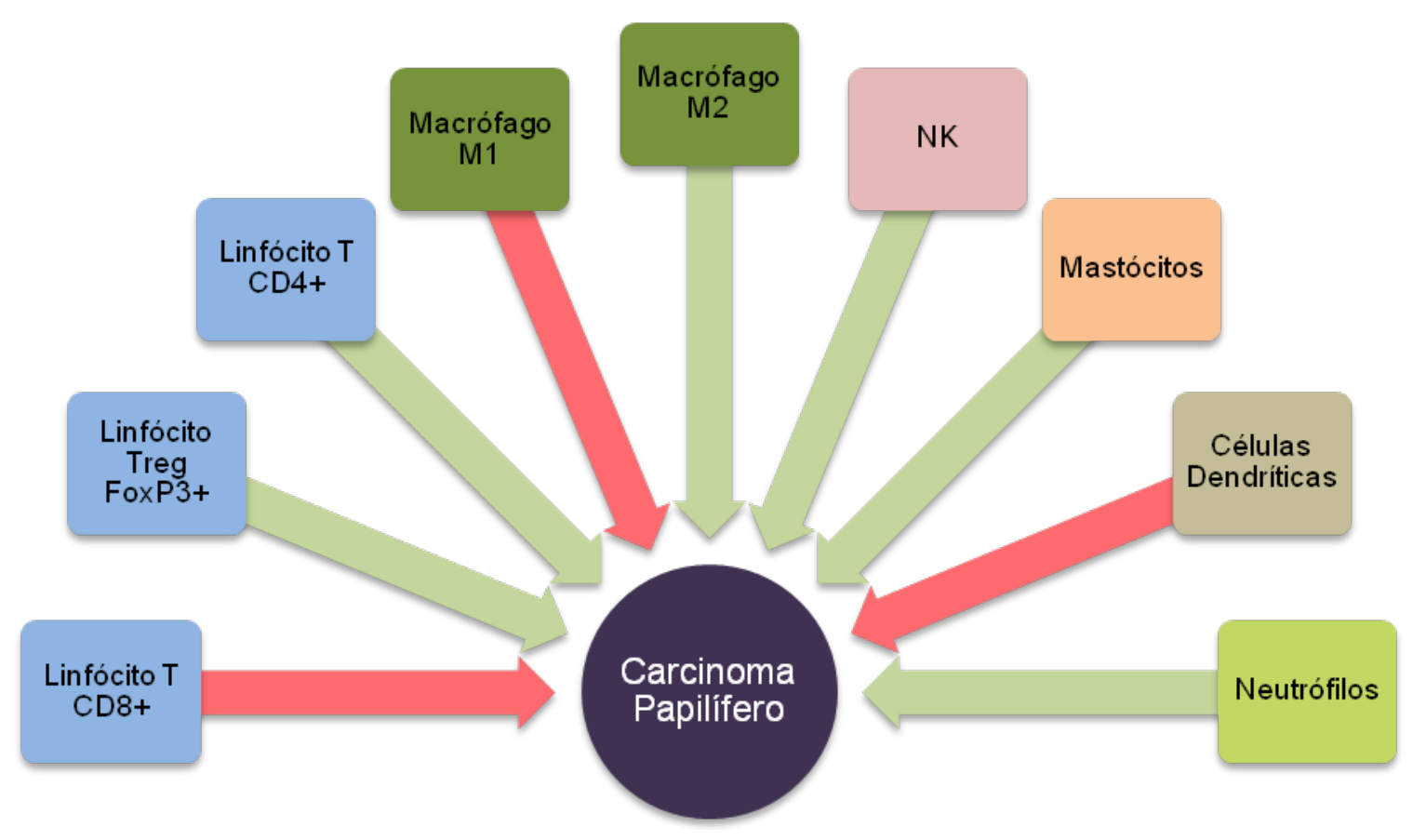

Figura 21 - Esquema do microambiente imune do carcinoma papilífero de tireoide com papel esperado das células. Setas verdes indicam efeito pró-tumoral e setas vermelhas, efeito antitumoral 


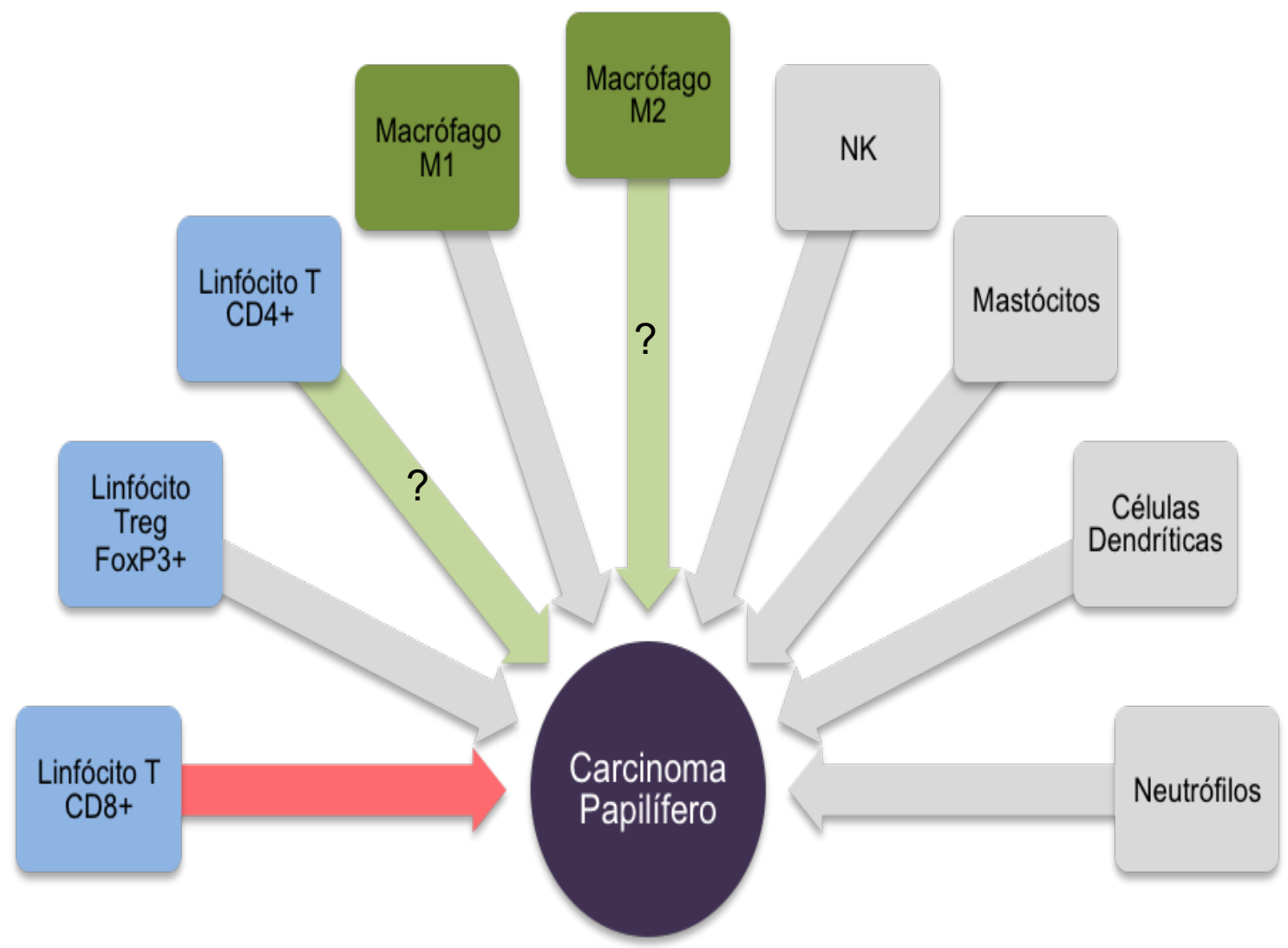

Figura 22 - Esquema do microambiente imune do carcinoma papilífero de tireoide com papel das células encontrado no estudo. Células representadas em cinza não foram estudadas. Setas verdes com interrogação indicam efeito pró-tumoral não conclusivo, setas vermelhas efeito antitumoral e setas cinza indicam que nenhum efeito foi encontrado 
6 Conclusões 


\section{$6 \quad$ CONCLUSÕES}

Neste estudo, analisamos o perfil de infiltrado de linfócitos e macrófagos em carcinomas papilíferos de tireoide sem tireoidite significativa, tentando melhor caracterizar o microambiente imune desses tumores.

Demonstramos que, em geral, a densidade de infiltrado inflamatório neste cenário é baixa, mas, que o perfil desse infiltrado parece, sim, interferir na agressividade do tumor. Casos com menor infiltração tumoral e tireoidiana por linfócitos T CD8+ apresentaram-se de forma clinicamente mais agressiva, com extensão extratireoidiana e metástases linfonodais, além de tendência a maiores taxas de recorrência.

Os resultados obtidos corroboram alguns dados recentemente reportados na literatura, expandindo o conhecimento e ajudando a dirimir controvérsias sobre o papel do infiltrado linfocitário no carcinoma papilífero de tireoide. 


\section{Anexos}




\subsection{Anexo 1 - Aprovação do Comitê de Ética em Pesquisa}



Centro de Tratamento, Ensino e Pesquisa em Câncer

\section{Comitê de Ética em Pesquisa - CEP}

São Paulo, 18 de julho de 2012.

Ao

Prof. Dr. Luiz Paulo Kowalski.

Ref.: Projeto de Pesquisa n. 1663/12

"Microambiente imune no carcinoma papilífero de tireóide e sua relação com fatores prognósticos clínico-patológicos e sobrevida".

Os membros do Comitê de Ética em Pesquisa em Seres Humanos da Fundação Antonio Prudente - Hospital do Câncer - A.C. Camargo/SP, em sua última reunião de 26/06/2012, após analisarem as respostas aos questionamentos realizados em reunião de 24/04/2012, aprovaram a realização do projeto do estudo em referência, versão 2011 e tomaram conhecimento dos seguintes documentos:

$>$ Folha de Rosto para Pesquisa Envolvendo Seres Humanos;

$>$ Termo de Compromisso do Pesquisador com as Resoluções do Conselho Nacional de Saúde;

> Declaração sobre os Dados Coletados, Publicação dos Dados e Propriedade das Informações Geradas;

$>\quad$ Termo de dispensa do Consentimento Livre e Esclarecido

$>$ Declaração Sobre o Uso e Destino do Material Biológico, Publicação dos Dados e Propriedade das Informações Geradas;

$>$ Declaração de Ciência e Comprometimento do Departamento de Anatomia Patológica do Hospital A. C. Camargo;

$>$ Declaração de Ciência e Comprometimento do Departamento de Cirurgia de Cabeça e Pescoço e Otorrinolaringologia do Hospital A. C. Camargo;

$>$ Declaração de Infraestrutura e Instalações do Departamento de Anatomia Patológica do Hospital A. C. Camargo;

$>$ Declaração de Infraestrutura e Instalações do Departamento de Cirurgia de Cabeça e Pescoço e Otorrinolaringologia do Hospital A. C. Camargo;

$>$ Orçamento Financeiro Detalhado.

Informações a respeito do andamento do referido projeto deverão ser encaminhadas à assistente do CEP dentro de 12 meses.

Atenciosamente

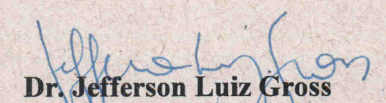

$1^{\circ}$ Vice-Coordenador do Comitê de Ética em Pesquisa 
Plataforma Brasil - Ministério da Saúde

Fundação Antônio Prudente-Hospital do Câncer A C Camargo

PROJETO DE PESQUISA

Título: MICROAMBIENTE IMUNE NO CARCINOMA PAPILÍFERO DE TIREOIDE E SUA RELAÇÃO COM FATORES PROGNÓSTICOS CLIINICO-PATOLÓGICOS E SOBREVIDA

Área Temática:

Pesquisador: Luiz Paulo Kowalski

Versão: 2

Instituição: Fundação Antônio Prudente-Hospital do Câncer -A C Camargo

CAAE: 02125912.8 .0000 .5432

\section{PARECER CONSUBSTANCIADO DO CEP}

Número do Parecer: 57828

Data da Relatoria: $\quad 12 / 06 / 2012$

\section{Apresentação do Projeto:}

Esse estudo de coorte retrospectivo incluirá pacientes com carcinomas bem-diferenciados de tireóide tratados cirurgicamente com finalidade curativa no período entre janeiro de 1990 e dezembro de 2010. Os dados referentes às variáveis demográficas, clínico-patológicas e terapêuticas serão coletados através da Ficha de Registro de Dados. Neste estudo estimamos que serão avaliados cerca de 2000 prontuários para a seleção dos casos elegiveis (aproximadamente 1000). Os prontuários serão revistos pelo autor.

\section{Objetivo da Pesquisa:}

O estudo se propõe a analisar o microambiente imune de uma amostra de carcinomas papiliferos de tireóide através da determinação do perfil de infiltração tumoral por linfócitos e macrófagos, assim como relacionar diferenças neste perfil com fatores clínico-patológicos prognósticos bem estabelecidos neste tipo de câncer, bem como sua influência nas taxas de sobrevida.

\section{Avaliação dos Riscos e Benefícios:}

Não há riscos ou beneficios para os pacientes participantes, já que se trata de um estudo retrospectivo que, independentemente de seu resultado não trará mudanças terapêuticas no grupo dos pacientes analisados.

\section{Comentários e Considerações sobre a Pesquisa:}

Estudo relevante que se propõe a analisar o microambiente imune de uma amostra de carcinomas papiliferos de tireóide através da determinação do perfil de infiltração tumoral por linfócitos e macrófagos. Do ponto de vista ético, não há impedimento para a realização desta pesquisa.

\section{Considerações sobre os Termos de apresentação obrigatória:}

Adequados.

Recomendações:

N/A.

\section{Conclusões ou Pendências e Lista de Inadequações:}

Em parecer anterior, datado de 15 de maio de 2012, foram descritas as pendências metodológicas, apontadas pela Comissão de Pesquisa (COPE). O pesquisador apresentou respostas à pendências desta Comissão, que as avaliou e considerou que foram respondidas a contento, tornando o projeto adequado do ponto de vista metodológico. 


\section{Situação do Parecer:}

Aprovado

Necessita Apreciação da CONEP:

Não

\section{Considerações Finais a critério do CEP}

O Comitê de Ética em Pesquisa, após análise das respostas às pendências apontadas com relação aos aspectos metodológicos, considera o projeto em questão como aprovado e sem impedimentos no que se refere aos aspectos éticos.

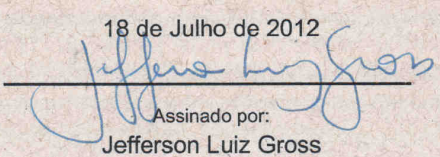




\subsection{Anexo 2 - Ficha de registro dos dados}

1-Número da ficha:

2- Nome do paciente:

3- $\mathrm{RGH}$ :

4- Sexo: 0 - feminino

1- masculino

5- Idade na época do tratamento:

6- Ultrassonografia de tireóide: 0 - não realizada

1 - bócio uninodular

2 - bócio multinodular

7- Tamanho do maior nódulo (índice):

8- Punção aspirativa com agulha fina pré-operatória:
0 - não realizada
1 - benigna
2 - padrão folicular
3 - maligna
4 - insatisfatória

9- Perfil hormonal tireoidiano

$$
0 \text { - eutiroidiano } 1 \text { - hipotireoidismo }
$$

2 - hipertireoidismo

10- Exposição prévia a radiação ionizante:

$$
1 \text { - não } 2 \text { - sim }
$$

11- Portador de outro câncer
0 - não
1 - mama
2 - outro

12- História familiar de câncer
0 - não
1 - tireóide
2 - outro

14- cT_N_M

15- Data da cirurgia 
16- Tipo de tireoidectomia

1 - tireoidectomia total

2 - parcial

3 - ampliada

4 - parcial seguida de totalização

5 - totalização

17- Esvaziamento cervical

0 - não

1 - central

2 - lateral

18- Local do tumor

1 - lobo direito

2 - lobo esquerdo

3 - multicêntrico

4 - istmo

19- Dimensão do maior nódulo:

20- Multifocalidade: 0-não, 1-sim

21- Extensão extratireoidiana: 0-não, 1-sim

22- pT_N

23- Linfonodos nível VI

Removidos: Comprometidos:

24- Linfonodos laterais

Removidos: Comprometidos:

25- Complicações:

$$
0 \text { - não } \quad 1 \text { - sim. Qual? }
$$

26- Hipotireoidismo pós-op (em caso de tireoidectomia parcial):

$$
0 \text { - não } 1-\operatorname{sim}
$$

27- lodoterapia adjuvante: 0 - não, 1 - sim

28- Dose do I131:

29- Tireoglobulina estimulada (valor):

30- Antitireoiglobulina: 0 - negativo, 1- positivo 
31- Recidiva:

0 - não

2 - nível VI

4 - à distância

32- Data do último controle

33- Status atual

0 - Vivo sem doença

1 - Vivo com doença

2 - Morte por câncer de tireóide

3 - Morte por outra causa

4 - Perdido de vista (não compareceu às duas últimas consultas de seguimento) 
8 Referências 


\section{REFERÊNCIAS}

1. Sipos JA, Mazzaferri EL. Thyroid cancer epidemiology and prognostic variables. Clin Oncol (R Coll Radiol). 2010;22:395-404.

2. Cramer JD, Fu P, Harth KC, Margevicius S, Wilhelm SM. Analysis of the rising incidence of thyroid cancer using the Surveillance, Epidemiology and End Results National Cancer Data Registry. Surgery. 2010;148:1147-53.

3. Estimativas para incidência de câncer no Brasil em 2012 - INCA. Disponível em: http://www.inca.gov.br/estimativa/2012/estimativa20122111.pdf. (Acesso: 8 Março 2012)

4. Coeli CM, Brito AS, Barbosa FS, Ribeiro MG, Sieiro AP, Vaisman M. Incidence and mortality from thyroid cancer in Brazil. Arq Bras Endocrinol Metabol. 2005;49(4):503-9.

5. Kent WD, Hall SF, Isotalo PA, Houlden RL, George RL, Groome PA. Increased incidence of differentiated thyroid carcinoma and detection of subclinical disease. CMAJ. 2007;177(11):1357-61.

6. Chen AY, Jemal A, Ward EM. Increasing incidence of differentiated thyroid cancer in the United States, 1988-2005. Cancer. 2009;115(16): 3801-7.

7. Enewold L, Zhu K, Ron E, Marrogi AJ, Stojadinovic A, Peoples GE, Devesa SS. Rising thyroid cancer incidence in the United States by demographic and tumor characteristics, 1980-2005. Cancer Epidemiol Biomarkers Prev. 2009;18(3):784-91. 
8. Aschebrook-Kilfoy B, Ward MH, Sabra MM, Devesa SS. Thyroid cancer incidence patterns in the United States by histologic type, 1992-2006. Thyroid. 2011;21(2):125-34.

9. Zhu C, Zheng T, Kilfoy BA, Han X, Ma S, Ba Y, Bai Y, Wang R, Zhu Y, Zhang $\mathrm{Y}$. A birth cohort analysis of the incidence of papillary thyroid cancer in the United States, 1973-2004. Thyroid. 2009;19(10):1061-6.

10. Liu S, Semenciw R, Ugnat AM, Mao Y. Increasing thyroid cancer incidence in Canada, 1970-1996: time trends and age-period-cohort effects. Br J Cancer. 2001;85(9):1335-9.

11. Lira RB, Carvalho GB, Gonçalves Filho J, Kowalski LP. Evolution in the profile of thyroid cancer cases treated in an oncology reference service: what changed in the last 20 years. Rev Col Bras Cir. 2014;41(5):320-4.

12. Lira RB, Carvalho GB, Gonçalves Filho J, Vartanian JG, Ikeda MK, Magrin J, Kowalski LP. Mudanças no perfil de atendimento do departamento de cirurgia de cabeça e pescoço em um hospital de referência pra câncer. Rev Bras Cir Cabeça Pescoço. 2012;41(1):1-4.

13. Lang BH, Lo CY, Chan WF, Lam KY, Wan KY. Staging systems for papillary thyroid carcinoma. Ann Surg. 2007;245(3):366-78.

14. Tuttle RM, Ball DW, Byrd D, Dilawari RA, Doherty GM, Duh QY, Ehya H, Farrar WB, Haddad RI, Kandeel F, Kloos RT, Kopp P, Lamonica DM, Loree TR, Lydiatt WM, McCaffrey JC, Olson JA Jr, Parks L, Ridge JA, Shah JP, Sherman SI, Sturgeon C, Waguespack SG, Wang TN, Wirth LJ; National Comprehensive Cancer Network. Thyroid carcinoma. J Natl Compr Canc Netw. 2010;8(11):1228-74. 
15. Podnos YD, Smith D, Wagman LD, Ellenhorn JDI. The implication of lymph node metastasis on survival in patients with well-differentiated thyroid cancer. Am Surg. 2005;71(9):731-4.

16. Mazzaferri EL, Jhiang SM. Long-term impact of initial surgical and medical therapy on papillary and follicular thyroid cancer. Am $J$ Med. 1994;97(5):418-28.

17. American Thyroid Association (ATA) Guidelines Taskforce on Thyroid Nodules and Differentiated Thyroid Cancer, Cooper DS, Doherty GM, Haugen BR, Kloos RT, Lee SL, Mandel SJ, Mazzaferri EL, Mclver B, Pacini F, Schlumberger M, Sherman SI, Steward DL, Tuttle RM. Revised American Thyroid Association management guidelines for patients with thyroid nodules and differentiated thyroid cancer. Thyroid. 2009;19(11):1167-214.

18. Simard EP, Ward EM, Siegel R, Jemal A. Cancers with increasing incidence trends in the United States: 1999 through 2008. CA Cancer J Clin. 2012;62(2):118-28.

19. Ywata de Carvalho A, Chulam TC, Kowalski LP. Long-term results of observation vs prophylactic selective level vi neck dissection for papillary thyroid carcinoma at a cancer center. JAMA Otolaryngol Head Neck Surg. 2015;141(7):599-606.

20. Pitoia F, Ward L, Wohllk N, Friguglietti C, Tomimori E, Gauna A, Camargo R, Vaisman M, Harach R, Munizaga F, Corigliano S, Pretell E, Niepomniszcze $\mathrm{H}$. Recommendations of the Latin American Thyroid Society on diagnosis and management of differentiated thyroid cancer. Arq Bras Endocrinol Metabol. 2009;53(7):884-7.

21. Guarino V, Castellone MD, Avilla E, Melillo RM. Thyroid cancer and inflammation. Mol Cell Endocrinol. 2010;321(1):94-102. 
22. Coussens LM, Werb Z. Inflammation and cancer. Nature. 2002; 420(6917):860-7.

23. Balkwill F, Mantovani A. Inflammation and cancer: back to Virchow? Lancet. 2001;357(9255):539-45.

24. Holm LE, Blomgren $\mathrm{H}$, Löwhagen $\mathrm{T}$. Cancer risks in patients with chronic lymphocytic thyroiditis. N Engl J Med. 1985;312(10):601-4.

25. Singh B, Shasha AR, Trivedi H, Carew JF, Poluri A, Shah JP. Coexistent Hashimoto's thyroiditis with papillary thyroid carcinoma: impact on presentation, management, and outcome. Surgery. 1999; 126(6):1070-6.

26. Kim SS, Lee BJ, Lee JC, Kim SJ, Jeon YK, Kim MR, Huh JE, Mok JY, Kim BH, Kim YK, Kim IJ. Coexistence of Hashimoto's thyroiditis with papillary thyroid carcinoma: The influence of lymph node metastasis. Head Neck. 2011;33(9):1272-7.

27. Del Rio P, Cataldo S, Sommaruga L, Concione L, Arcuri MF, Sianesi M. The association between papillary carcinoma and chronic lymphocytic thyroiditis: does it modify the prognosis of cancer? Minerva Endocrinol. 2008;33(1):1-5.

28. Jeong JS, Kim HK, Lee CR, Park S, Park JH, Kang SW, Jeong JJ, Nam $\mathrm{KH}$, Chung WY, Park CS. Coexistence of chronic lymphocytic thyroiditis with papillary thyroid carcinoma: clinical manifestation and prognostic outcome. J Korean Med Sci. 2012; 27(8):883-9.

29. Boon T, Coulie PG, Van den Eynde B. Tumor antigens recognized by $T$ cells. Immunol Today. 1997;18(6):267-8. 
30. Balkwill F. Cancer and the chemokine network. Nat Rev Cancer. 2004;4(7):540-50.

31. Allavena P, Sica A, Solinas G, Porta C, Mantovani A. The inflammatory micro-environment in tumor progression: the role of tumor-associated macrophages. Crit Rev Oncol Hematol. 2008;66(1):1-9.

32. Sica A, Allavena $P$, Mantovani A. Cancer related inflammation: the macrophage connection. Cancer Lett. 2008;267(2):204-15.

33. DeNardo DG, Brennan DJ, Rexhepaj E, Ruffell B, Shiao SL, Madden SF, Gallagher WM, Wadhwani N, Keil SD, Junaid SA, Rugo HS, Hwang ES, Jirström K, West BL, Coussens LM. Leukocyte complexity predicts breast cancer survival and functionally regulates response to chemotherapy. Cancer Discov. 2011;1(1):54-67.

34. Kim R, Emi M, Tanabe K. Cancer immunoediting from immune surveillance to immune escape. Immunology. 2007;121(1):1-14.

35. Solinas G, Germano G, Mantovani A, Allavena P. Tumor-associated macrophages (TAM) as major players of the cancer-related inflammation. J Leukoc Biol. 2009;86(5):1065-73.

36. Caillou B, Talbot M, Weyemi U, Pioche-Durieu C, Al Ghuzlan A, Bidart JM, Chouaib S, Schlumberger M, Dupuy C.. Tumor-associated macrophages (TAMs) form an interconnected cellular supportive network in anaplastic thyroid carcinoma. PLoS One. 2011;6(7):e22567. 
37. Buddingh EP, Kuijjer $M L$, Duim RA, Bürger $H$, Agelopoulos $K$, Myklebost O, Serra M, Mertens F, Hogendoorn PC, Lankester AC, Cleton-Jansen AM. Tumor-Infiltrating macrophages are associated with metastasis suppression in high-grade osteosarcoma: a rationale for treatment with macrophage activating agents. Clin Cancer Res. 2011;17(8):2110-9.

38. Ch'ng ES, Jaafar H, Sharif SET. Breast tumor angiogenesis and tumorassociated macrophages: histopathologist's perspective. Patholog Res Int. 2011;2011:572706.

39. Qian BZ, Li J, Zhang H, Kitamura T, Zhang J, Campion LR, Kaiser EA, Snyder LA, Pollard JW. CCL2 recruits inflammatory monocytes to facilitate breast-tumour metastasis. Nature. 2011;475(7355):222-5.

40. Lin EY, Nguyen AV, Russell RG, Pollard JW. Colony-stimulating factor 1 promotes progression of mammary tumors to malignancy. $J$ Exp Med. 2001;193(6):727-40.

41. DeNardo DG, Barreto JB, Andreu P, Vasquez L, Tawfik D, Kolhatkar N, Coussens LM. CD4+ $\mathrm{T}$ cells regulate pulmonary metastasis of mammary carcinomas by enhancing protumor properties of macrophages. Cancer Cell. 2009;16(2):91-102.

42. Gooden MJM, de Bock GH, Leffers N, Daemen T, Nijman HW. The prognostic influence of tumour-infiltrating lymphocytes in cancer: a systematic review with meta-analysis. Br J Cancer. 2011;105(1):93-103.

43. Levi I, Amsalem H, Nissan A, Darash-Yahana M, Peretz T, Mandelboim O, Rachmilewitz J. Characterization of tumor infiltrating natural killer cell subset. Oncotarget. 2015;6(15):13835-43. 
44. Palucka K, Banchereau J. Cancer immunotherapy via dendritic cells. Nat Rev Cancer. 2012;12(4):265-77.

45. Tran Janco JM, Lamichhane P, Karyampudi L, Knutson KL. Tumorinfiltrating dendritic cells in cancer pathogenesis. J Immunol. 2015; 194(7):2985-91.

46. Fridlender ZG, Albelda SM. Tumor-associated neutrophils: friend or foe? Carcinogenesis. 2012;33(5):949-55.

47. French JD. Revisiting immune-based therapies for aggressive follicular cell-derived thyroid cancers. Thyroid. 2013;23(5):529-42.

48. Ito $\mathrm{Y}$, Miyauchi $\mathrm{A}$, Inoue $\mathrm{H}$, Fukushima $\mathrm{M}$, Kihara $\mathrm{M}$, Higashiyama $\mathrm{T}$, Tomoda C, Takamura Y, Kobayashi K, Miya A. An observational trial for papillary thyroid microcarcinoma in Japanese patients. World $J$ Surg. 2010;34(1):28-35.

49. Imam S, Paparodis R, Sharma D, Jaume JC. Lymphocytic profiling in thyroid cancer provides clues for failure of tumor immunity. Endocr Relat Cancer. 2014;21(3):505-16.

50. Okayasu I. The relationship of lymphocytic thyroiditis to the development of thyroid carcinoma. Endocr Pathol. 1997;8(3):225-30.

51. Gupta S, Patel A, Folstad A, Fenton C, Dinauer CA, Tuttle RM, Conran $\mathrm{R}$, Francis GL. Infiltration of differentiated thyroid carcinoma by proliferating lymphocytes is associated with improved disease-free survival for children and young adults. $J$ Clin Endocrinol Metab. 2001;86(3):1346-54. 
52. Modi J, Patel A, Terrell R, Tuttle RM, Francis GL. Papillary thyroid carcinomas from young adults and children contain a mixture of lymphocytes. J Clin Endocrinol Metab. 2003;88(9):4418-25.

53. Fiumara A, Belfiore A, Russo G, Salomone E, Santonocito GM, Ippolito O, Vigneri R, Gangemi P. In situ evidence of neoplastic cell phagocytosis by macrophages in papillary thyroid cancer. $J$ Clin Endocrinol Metab. 1997;82(5):1615-20.

54. Ryder M, Ghossein RA, Ricarte-Filho J, Knauf JA, Fagin JA. Increased density of tumor-associated macrophages is associated with decreased survival in advanced thyroid cancer. Endocr Relat Cancer. 2008;15(4):1069-74.

55. Ryder M, Gild M, Hohl TM, Pamer E, Knauf J, Ghossein R, Joyce JA, Fagin JA. Genetic and pharmacological targeting of CSF-1/CSF-1R inhibits tumor-associated macrophages and impairs BRAF-Induced thyroid cancer progression. PLoS One. 2013;8(1):e54302.

56. $\quad$ Qing W, Fang WY, Ye L, Shen LY, Zhang XF, Fei XC, Chen X, Wang WQ, Li XY, Xiao JC, Ning G. Density of tumor-associated macrophages correlates with lymph node metastasis in papillary thyroid carcinoma. Thyroid. 2012;22(9):905-10.

57. Cunha LL, Morari EC, Guihen AC, Razolli D, Gerhard R, Nonogaki S, Soares FA, Vassallo J, Ward LS. Infiltration of a mixture of immune cells may be related to good prognosis in patients with differentiated thyroid carcinoma. Clin Endocrinol (Oxf). 2012;77(6):918-25.

58. Cunha LL, Marcello MA, Ward LS. The role of the inflammatory microenvironment in thyroid carcinogenesis. Endocr Relat Cancer. 2014;21(3):R85-R103. 
59. Zhang Q, Liu L, Gong CY, Shi HS, Zeng YH, Wang XZ, Zhao YW, Wei YQ. Prognostic significance of tumor-associated macrophages in solid tumor: a meta-analysis of the literature. PLoS One. 2012;7(12):e50946.

60. Cunha LL, Marcello MA, Morari EC, Nonogaki S, Conte FF, Gerhard R, Soares FA, Vassallo J, Ward LS. Differentiated thyroid carcinomas may elude the immune system by $\mathrm{B} 7 \mathrm{H} 1$ upregulation. Endocr Relat Cancer. 2013;20(1):103-10.

61. Cunha L, Morari EC, Nonogaki S, Soares FA, Vassallo J, Ward LS. Foxp3 expression is associated with aggressiveness in differentiated thyroid carcinomas. Clinics. 2012;67(5):483-8.

62. Ugolini C, Elisei R, Proietti A, Pelliccioni S, Lupi C, Borrelli N, Viola D, Leocata P, Vitti P, Miccoli P, Toniolo A, Basolo F. FoxP3 expression in papillary thyroid carcinoma: a possible resistance biomarker to iodine 131 treatment. Thyroid. 2014;24(2):339-46.

63. French JD, Kotnis GR, Said S, Raeburn CD, Mclntyre RC Jr, Klopper JP, Haugen BR. Programmed death-1+ T cells and regulatory $\mathrm{T}$ cells are enriched in tumor-involved lymph nodes and associated with aggressive features in papillary thyroid cancer. $J$ Clin Endocrinol Metab. 2012;97(6):E934-43.

64. French JD, Weber ZJ, Fretwell DL, Said S, Klopper JP, Haugen BR. Tumor-associated lymphocytes and increased FoxP3+ regulatory $\mathrm{T}$ cell frequency correlate with more aggressive papillary thyroid cancer. J Clin Endocrinol Metab. 2010;95(5):2325-33.

65. Huang FJ, Zhou XY, Ye L, Fei XC, Wang S, Wang W, Ning G. Follicular thyroid carcinoma but not adenoma recruits tumor-associated macrophages by releasing CCL15. BMC Cancer. 2016;16:98. 
66. Gogali F, Paterakis G, Rassidakis GZ, Liakou Cl, Liapi C. CD3 ${ }^{-}$CD16 ${ }^{-}$ CD56 bright Immunoregulatory NK cells are increased in the tumor microenvironment and inversely correlate with advanced stages in patients with papillary thyroid cancer. Thyroid. 2013;23(12):1561-8.

67. Melillo RM, Guarino V, Avilla E, Galdiero MR, Liotti F, Prevete N, Rossi FW, Basolo F, Ugolini C, de Paulis A, Santoro M, Marone G. Mast cells have a protumorigenic role in human thyroid cancer. Oncogene. 2010;29(47):6203-15.

68. Pufnock JS, Rothstein JL. Oncoprotein signaling mediates tumorspecific inflammation and enhances tumor progression. $J$ Immunol. 2009;182(9):5498-506.

69. Stassi G, Todaro M, Zerilli M, Ricci-Vitiani L, Di Liberto D, Patti M, Florena A, Di Gaudio F, Di Gesù G, De Maria R. Thyroid cancer resistance to chemotherapeutic drugs via autocrine production of interleukin-4 and interleukin-10. Cancer Res. 2003;63(20):6784-90.

70. Kirkwood JM, Butterfield LH, Tarhini AA, Zarour H, Kalinski P, Ferrone S. Immunotherapy of cancer in 2012. CA: Cancer J Clin. 2012; 62(5):309-35.

71. Amino N, Pysher T, Cohen EP, Degroot LJ. Immunologic aspects of human thyroid cancer. Humoral and cell-mediated immunity, and a trial of immunotherapy. Cancer. 1975;36(3):963-73.

72. Brose MS, Nutting CM, Jarzab B, Elisei R, Siena S, Bastholt L, de la Fouchardiere C, Pacini F, Paschke R, Shong YK, Sherman SI, Smit JW, Chung J, Kappeler C, Peña C, Molnár I, Schlumberger MJ; DECISION investigators. Sorafenib in radioactive iodine-refractory, locally advanced or metastatic differentiated thyroid cancer: a randomised, double-blind, phase 3 trial. Lancet. 2014;384(9940):319-28. 
73. Schlumberger M, Tahara M, Wirth LJ, Robinson B, Brose MS, Elisei R, Habra MA, Newbold K, Shah MH, Hoff AO, Gianoukakis AG, Kiyota N, Taylor MH, Kim SB, Krzyzanowska MK, Dutcus CE, de las Heras B, Zhu J, Sherman SI. Lenvatinib versus placebo in radioiodine-refractory thyroid cancer. N Engl J Med. 2015;372(7):621-30.

74. Nucera C. Targeting thyroid cancer microenvironment: basic research and clinical applications. Front Endocrinol (Lausanne). 2013;4:167.

75. Simard EP, Ward EM, Siegel R, Jemal A. Cancers with increasing incidence trends in the United States: 1999 through 2008. CA Cancer J Clin. 2012;62(2):118-28.

76. Bilimoria KY, Bentrem DJ, Linn JG, Freel A, Yeh JJ, Stewart AK, Winchester DP, Ko CY, Talamonti MS, Sturgeon C. Utilization of total thyroidectomy for papillary thyroid cancer in the United States. Surgery. 2007;142(6):906-13.

77. Cordioli MI, Canalli MH, Coral MH. Increase incidence of thyroid cancer in Florianopolis, Brazil: comparative study of diagnosed cases in 2000 and 2005. Arq Bras Endocrinol Metabol. 2009;53(4):453-60.

78. Davies L, Welch HG. Increasing incidence of thyroid cancer in the United States, 1973-2002. JAMA. 2006;295(18):2164-7.

79. Shah JP, Patel SG, Singh B. Head and neck: surgery and oncology. St. Louis: Elsevier, Mosby; 2012.

80. Shaha AR, Shah JP, Loree TR. Patterns of failure in differentiated carcinoma of the thyroid based on risk groups. Head Neck. 1998;20(1): 26-30. 
81. Nixon IJ, Ganly I, Patel SG, Palmer FL, Whitcher MM, Tuttle RM, Shaha A, Shah JP. Thyroid lobectomy for treatment of well differentiated intrathyroid malignancy. Surgery. 2012;151(4):571-9.

82. Haugen BR, Alexander EK, Bible KC, Doherty GM, Mandel SJ, Nikiforov YE, Pacini F, Randolph GW, Sawka AM, Schlumberger M, Schuff KG, Sherman SI, Sosa JA, Steward DL, Tuttle RM, Wartofsky L. 2015 American Thyroid Association Management Guidelines for Adult Patients with Thyroid Nodules and Differentiated Thyroid Cancer: The American Thyroid Association Guidelines Task Force on Thyroid Nodules and Differentiated Thyroid Cancer. Thyroid. 2016;26(1):1-133.

83. Kowalski LP, Filho JG. Results of the treatment of locally invasive thyroid carcinoma. Head Neck. 2002;24(4):340-4.

84. Ugolini, C. Basolo F, Proietti A, Vitti P, Elisei R, Miccoli P, Toniolo A. Lymphocyte and immature dendritic cell infiltrates in differentiated, poorly differentiated, and undifferentiated thyroid carcinoma. Thyroid. 2007;17(5):389-93.

85. DeNardo, D. G. Brennan DJ, Rexhepaj E, Ruffell B, Shiao SL, Madden SF, Gallagher WM, Wadhwani N, Keil SD, Junaid SA, Rugo HS, Hwang ES, Jirström K, West BL, Coussens LM. Leukocyte complexity predicts breast cancer survival and functionally regulates response to chemotherapy. Cancer Discov. 2011;1(1):54-67.

86. Luo Y, Zhou H, Krueger J, Kaplan C, Lee SH, Dolman C, Markowitz D, Wu W, Liu C, Reisfeld RA, Xiang R. Targeting tumor-associated macrophages as a novel strategy against breast cancer. J Clin Invest. 2006;116(8):2132-41. 
87. Chen JJ, Lin YC, Yao PL, Yuan A, Chen HY, Shun CT, Tsai MF, Chen $\mathrm{CH}$, Yang PC. Tumor-associated macrophages: the double-edged sword in cancer progression. J Clin Oncol. 2004;23(5):953-64.

88. Diederichsen AC, Hjelmborg Jv, Christensen PB, Zeuthen J, Fenger C. Prognostic value of the CD4+/CD8+ ratio of tumour infiltrating lymphocytes in colorectal cancer and HLA-DR expression on tumour cells. Cancer Immunol Immunother. 2003;52(7):423-8.

89. Salgado R, Denkert C, Demaria S, Sirtaine N, Klauschen F, Pruneri G, Wienert S, Van den Eynden G, Baehner FL, Penault-Llorca F, Perez EA, Thompson EA, Symmans WF, Richardson AL, Brock J, Criscitiello C, Bailey H, Ignatiadis M, Floris G, Sparano J, Kos Z, Nielsen T, Rimm DL, Allison KH, Reis-Filho JS, Loibl S, Sotiriou C, Viale G, Badve S, Adams S, Willard-Gallo K, Loi S; International TILs Working Group 2014. The evaluation of tumor-infiltrating lymphocytes (TILs) in breast cancer: recommendations by an International TILs Working Group 2014. Ann Oncol. 2015;26(2):259-71.

90. Cho SW, Kim YA, Sun HJ, Kim YA, Oh BC, Yi KH, Park do J, Park YJ. CXCL16 signaling mediated macrophage effects on tumor invasion of papillary thyroid carcinoma. Endocr Relat Cancer. 2016;23(2):113-24.

91. Bastman JJ, Serracino HS, Zhu Y, Koenig MR, Mateescu V, Sams SB, Davies KD, Raeburn CD, McIntyre RC Jr, Haugen BR, French JD. Tumor-infiltrating T cells and the PD-1 checkpoint pathway in advanced differentiated and anaplastic thyroid cancer. J Clin Endocrinol Metab. 2016;101(7):2863-73.

92. Weber F. Lymphocytes and thyroid cancer: more to it than meets the eye? Endocr Relat Cancer. 2014;21(3):C1-5. 
93. Ward LS. Immune response in thyroid cancer: widening the boundaries. Scientifica (Cairo). 2014;2014:125450.

94. Pusztaszeri MP, Faquin WC, Sadow PM. Tumor-associated inflammatory cells in thyroid carcinomas. Surg Pathol Clin. 2014;7(4): 501-14.

95. Moretti S, Menicali E, Voce P, Morelli S, Cantarelli S, Sponziello M, Colella R, Fallarino F, Orabona C, Alunno A, de Biase D, Bini V, Mameli MG, Filetti S, Gerli R, Macchiarulo A, Melillo RM, Tallini G, Santoro M, Puccetti P, Avenia N, Puxeddu E. Indoleamine 2,3-dioxygenase 1 (IDO1) is up-regulated in thyroid carcinoma and drives the development of an immunosuppressant tumor microenvironment. J Clin Endocrinol Metab. 2014;99(5):E832-40.

96. Martins MB, Marcello MA, Batista Fde A, Cunha LL, Morari EC, Soares FA, Vassallo J, Ward LS. CD8+ TIL recruitment may revert the association of MAGE A3 with aggressive features in thyroid tumors. $J$ Immunol Res. 2014;2014:921864.

97. Fang W, Ye L, Shen L, Cai J, Huang F, Wei Q, Fei X, Chen X, Guan H, Wang W, Li X, Ning G. Tumor-associated macrophages promote the metastatic potential of thyroid papillary cancer by releasing CXCL8. Carcinogenesis. 2014;35(8):1780-7.

98. Chang WC, Chen JY, Lee CH, Yang AH. Expression of decoy receptor 3 in diffuse sclerosing variant of papillary thyroid carcinoma: correlation with M2 macrophage differentiation and lymphatic invasion. Thyroid. 2013;23(6):720-6. 